\title{
School-Based Performance Award Programs, Teacher Motivation, and School Performance: Findings From a Study of Three Programs
}

Carol Kelley

University of Pennsylvania

Herbert G. Heneman III

Anthony Milanowski

Follow this and additional works at: https://repository.upenn.edu/cpre_researchreports

Part of the Educational Assessment, Evaluation, and Research Commons, Educational Methods Commons, and the Education Policy Commons

\section{Recommended Citation}

Kelley, Carol; Heneman III, Herbert G.; and Milanowski, Anthony. (2000). School-Based Performance Award Programs, Teacher Motivation, and School Performance: Findings From a Study of Three Programs. CPRE Research Reports.

Retrieved from https://repository.upenn.edu/cpre_researchreports/10

View on the CPRE website.

This paper is posted at ScholarlyCommons. https://repository.upenn.edu/cpre_researchreports/10

For more information, please contact repository@pobox.upenn.edu. 


\title{
School-Based Performance Award Programs, Teacher Motivation, and School Performance: Findings From a Study of Three Programs
}

\author{
Abstract \\ Building on a strong foundation of research and experience with educational reform across the nation, in \\ the 1990s educational policymakers undertook sophisticated comprehensive educational reform efforts. \\ The centerpiece of these reforms was the creation of state educational standards, assessments, and \\ goals, and the realignment of state and local resources to support the achievement of these goals. A \\ number of states and districts have embraced the idea of performance-based accountability (Fuhrman, \\ 1999), in which rewards and sometimes sanctions are used as incentives for measurable improvement in \\ student achievement. Some jurisdictions have modified their teacher compensation systems in order to \\ provide incentives that support improving student achievement. Learning from the relative failure of prior \\ efforts to realign teacher compensation via individual performance pay systems (Murnane and Cohen, \\ 1986), states and districts undertaking compensation reform in the 1990s have tended to focus on \\ innovations such as school-based performance awards (SBPAs) and pay based on knowledge and skills, \\ which are thought to be better ways of supporting collaborative cultures in schools (Odden and Kelley, \\ 1997). \\ This report provides an overview of the findings of a series of studies of SBPA programs conducted by the \\ Consortium for policy Research in Education between 1995 and 1998. The research reported here \\ focuses on two such programs, in Kentucky and Charlotte-Mecklenburg (North Carolina), that pay \\ teachers bonuses, and on one program, in Maryland, that provides the award to schools to use for \\ activities and improvements. \\ Disciplines \\ Educational Assessment, Evaluation, and Research | Educational Methods | Education Policy \\ Comments \\ View on the CPRE website.
}




\section{School-Based Performance Award Programs, Teacher Motivation, and School Performance:}

Findings from a Study of Three Programs

Carolyn Kelley, Herbert Heneman III, and Anthony Milanowski

CPRE Research Report Series

RR-44

April 2000

Consortium for Policy Research in Education

University of Pennsylvania

Graduate School of Education

(C) Copyright 2000 by the Consortium for Policy Research in Education 



\section{CONTENTS}

LIST OF TABLES

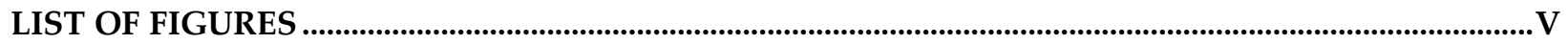

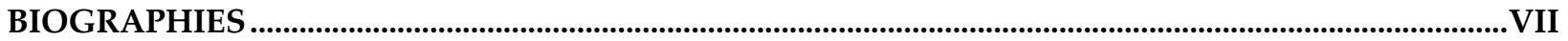

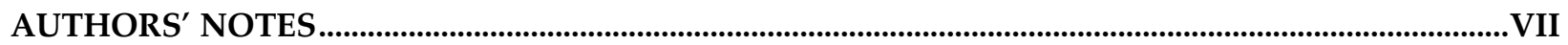

INTRODUCTION

WHAT ARE SCHOOL-BASED PERFORMANCE AWARD PROGRAMS?.................................................1

AN OVERVIEW OF THE PROGRAMS WE STUDIED ..........................................................................2

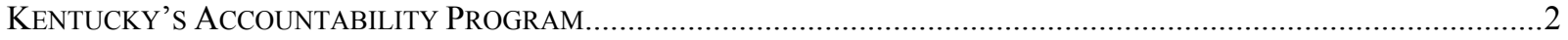

Charlotte-MEcklenburg's Benchmark Goals Program .....................................................................4

The MARYLAND SCHOOL PERformanCE PROGRAM ......................................................................................

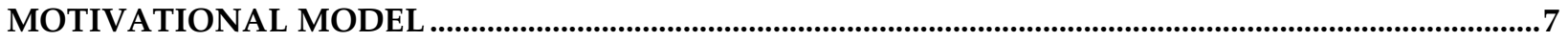

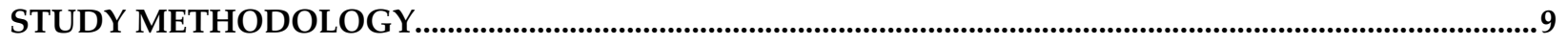

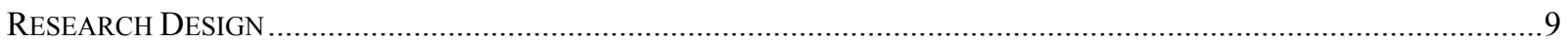

FINDINGS: MOTIVATIONAL RESPONSES OF TEACHERS ...........................................................11

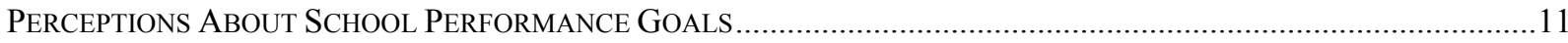

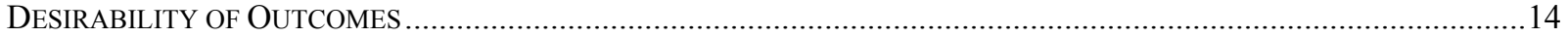

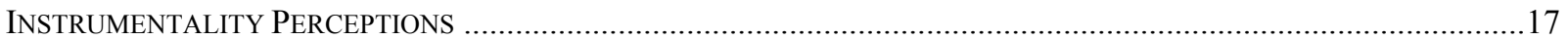

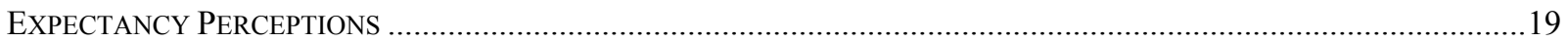

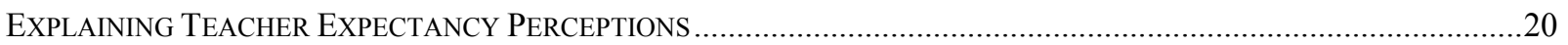

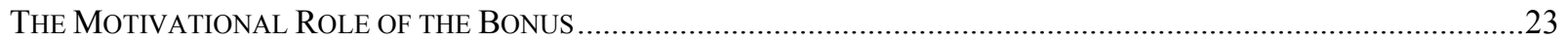

MotivationAL REACTIONS OF A SUBSAMPLE OF KENTUCKY TEACHERS .....................................................24

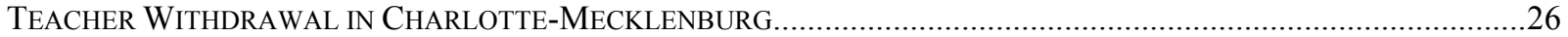

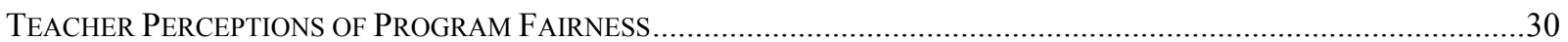

DOES TEACHER MOTIVATION AFFECT SCHOOL PERFORMANCE? ...............................................31

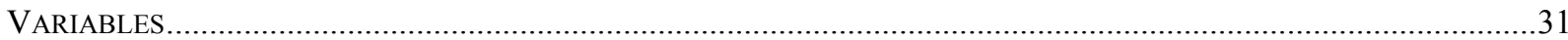

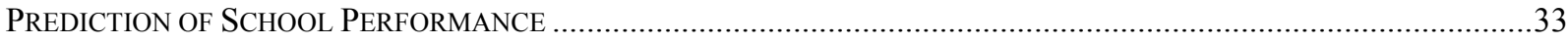

PRINCIPALS' REACTIONS TO SCHOOL-BASED PERFORMANCE AWARD PROGRAMS...............35

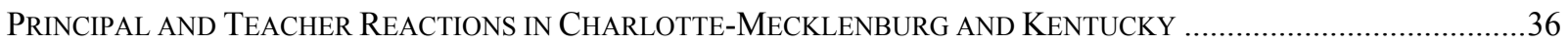

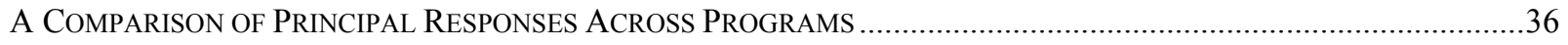

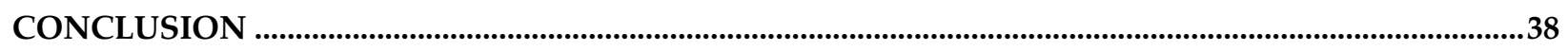

IMPLICATIONS FOR THE DESIGN OF SCHOOL-BASED PERFORMANCE AWARD ProgramS.....................................40

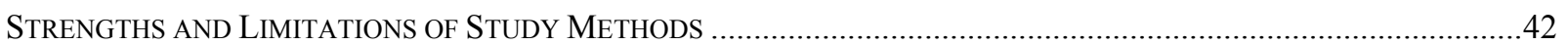

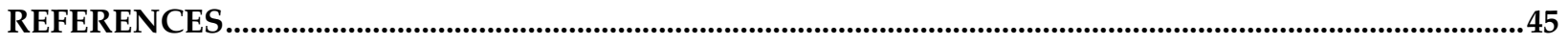

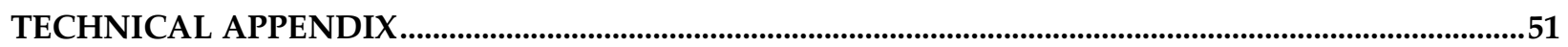




\section{LIST OF TABLES}

TABLE 1. MEANS AND STANDARD DEVIATIONS OF RESPONSES ON GOAL-RELATED SCALES

TABLE 2. PERCENT OF RESPONDENTS INDICATING THEY TRIED TO ACHIEVE VARIOUS PERFORMANCE OR GOAL LEVELS IN CHARLOTTE-MECKLENBURG AND KENTUCKY ..

TABLE 3. PERCENTAGES OF TEACHERS INDICATING GOALS WERE BECOMING HARDER TO ACHIEVE, BY SCHOOL'S AWARD STATUS IN PRIOR CYCLE.

TABLE 4. DESIRABILITY OF OUTCOMES ASSOCIATED WITH SCHOOL-BASED PERFORMANCE AWARD PROGRAMS

TABLE 5. GROUPING OF OUTCOME ITEMS BASED ON FACTOR ANALYSIS OF DESIRABILITY RATINGS

TABLE 6. AVERAGE PERCEIVED PROBABILITY OF OUTCOMES ASSOCIATED WITH SCHOOLBASED PERFORMANCE AWARD PROGRAMS IN CHARLOTTE-MECKLENBURG AND KENTUCKY

TABLE 7. AVERAGE INDIVIDUAL AND GROUP EXPECTANCY: KENTUCKY AND CHARLOTTEMECKLENBURG TEACHERS

TABLE 8. REGRESSION ESTIMATES (STANDARDIZED COEFFICIENTS) OF THE EFFECTS OF FACTORS AFFECTING INDIVIDUAL AND TEACHER GROUP EXPECTANCY PERCEPTIONS IN CHARLOTTE-MECKLENBURG'S SCHOOL-BASED PERFORMANCE AWARD PROGRAM . 21

TABLE 9. REGRESSION ESTIMATES (STANDARDIZED COEFFICIENTS) OF THE EFFECTS OF FACTORS AFFECTING INDIVIDUAL AND TEACHER GROUP EXPECTANCY PERCEPTIONS IN KENTUCKY'S SCHOOL-BASED PERFORMANCE AWARD PROGRAM.

TABLE 10. EFFECT OF KENTUCKY TEACHERS' BONUS ATTITUDES ON THEIR REPORTED MOTIVATION BY BONUS, SUPPORT FOR BONUS CONTINUATION, AND WITHDRAWAL INTENTIONS (STANDARDIZED REGRESSION COEFFICIENTS).

TABLE 11. EFFECT OF COMPENSATION VARIABLES ON TEACHER TURNOVER IN CHARLOTTE-MECKLENBURG

TABLE 12. TEACHERS' PERCEPTIONS ABOUT THE FAIRNESS OF THE SCHOOL-BASED PERFORMANCE AWARD PROGRAMS.

TABLE 13. THE EFFECT OF TEACHER EXPECTANCY AND EXPECTED OUTCOME VALUE ON SCHOOL PERFORMANCE

TABLE 14. MEAN RESPONSES OF CHARLOTTE-MECKLENBURG AND KENTUCKY PRINCIPALS AND TEACHERS TO GOAL-RELATED SCALES

TABLE 15. MEAN RESPONSES ${ }^{A}$ OF PRINCIPALS TO SELECTED REWARD ITEMS .37

TABLE 16. A COMPARISON OF MEAN PRINCIPAL RESPONSES ACROSS PERFORMANCE AWARD PROGRAMS IN CHARLOTTE-MECKLENBURG, KENTUCKY, AND MARYLAND.. 37 


\section{LIST OF FIGURES}

FIGURE 1. THEORETICAL FRAMEWORK: TEACHER MOTIVATION IN SCHOOL-BASED PERFORMANCE AWARD PROGRAMS.

FIGURE 2. OVERVIEW OF THE RESEARCH PROCESS IN CHARLOTTE-MECKLENBURG AND 


\section{BIOGRAPHIES}

Carolyn Kelley is an Assistant Professor of Educational Administration at the University of Wisconsin-Madison and a senior researcher at CPRE. Her expertise is in organizational theory, policy design and implementation, teacher compensation, and school-linked services.

Herbert Heneman is the Dickson-Bascom Professor in the Business: Management and Human Resources Department at the University of Wisconsin-Madison. He also serves as a participating faculty member in the Industrial Relations Research Institute, and as a Senior Research Associate in the Wisconsin Center for Education Research. His areas of expertise are reward systems, staffing, motivation, and performance management.

Anthony Milanowski is a researcher with CPRE's Teacher Compensation project at the University of Wisconsin-Madison. He has worked in human resource management for 16 years, primarily with the Wisconsin Department of Employment Relations, where his responsibilities included staffing, job evaluation, labor market analysis, contract costing, employee attitude surveys, and policy analysis. He also taught courses in compensation, staffing, and general human resource management at the University of Wisconsin-Madison's School of Business.

\section{AUTHORS' NOTES}

Versions of this report were presented at the American Education Finance Association conference held March 18-21, 1999 in Seattle, Washington, and the American Educational Research Association meeting held April 19-23, 1999 in Montreal, Canada. The research reported in this report was supported by grants from the National Institute on Educational Governance, Finance, Policymaking and Management, Office of Educational Research and Improvement, U.S. Department of Education (Grant No. OERI-R308A60003), and the Pew Charitable Trusts (Grant No. 97001184000) to CPRE. The views expressed in this publication are those of its authors and are not necessarily shared by the U.S. Department of Education, the Pew Charitable Trusts, the Wisconsin Center for Education Research, CPRE, or its institutional members. 


\section{INTRODUCTION}

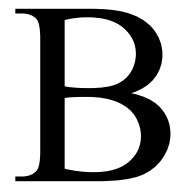
uilding on a strong foundation of research and experience with educational reform across the nation, in the 1990s educational policymakers undertook sophisticated comprehensive educational reform efforts. The centerpiece of these reforms was the creation of state educational standards, assessments, and goals, and the realignment of state and local resources to support the achievement of these goals. A number of states and districts have embraced the idea of performance-based accountability (Fuhrman, 1999), in which rewards and sometimes sanctions are used as incentives for measurable improvement in student achievement. Some jurisdictions have modified their teacher compensation systems in order to provide incentives that support improving student achievement. Learning from the relative failure of prior efforts to realign teacher compensation via individual performance pay systems (Murnane and Cohen, 1986), states and districts undertaking compensation reform in the 1990s have tended to focus on innovations such as school-based performance awards (SBPAs) and pay based on knowledge and skills, which are thought to be better ways of supporting collaborative cultures in schools (Odden and Kelley, 1997). This report provides an overview of the findings of a series of studies of SBPA programs conducted by the Consortium for Policy Research in Education between 1995 and 1998. The research reported here focuses on two such programs, in Kentucky and Charlotte-Mecklenburg (North Carolina), that pay teachers bonuses, and on one program, in Maryland, that provides the award to schools to use for activities and improvements.

\section{WHAT ARE SCHOOL-BASED PERFORMANCE AWARD PROGRAMS?}

School-based performance award programs provide teachers and often other school staff with pay bonuses when their school as a whole achieves specific educational objectives. These objectives typically involve improvement in student achievement as measured by some form of test. These programs differ from merit pay in that all teachers in a school receive the bonus based on meeting an objective, a predefined schoolwide goal, rather than based on individual teacher performance as rated by administrators.

In addition to pay bonuses, SBPA programs might also include money for school improvements, public recognition, and exemption from regulatory requirements. These award programs are meant to provide an incentive for teachers to work toward improved student performance, while avoiding the divisiveness and discomfort that can accompany merit pay. The group nature of the goal is intended to encourage teachers to work together, and the collective nature of the incentive may provide an important symbolic focus on key educational outcomes (Odden and Kelley, 1997). During the 1990s, the states of Kentucky and North Carolina, and the Dallas, Philadelphia, and Charlotte-Mecklenburg school districts had programs that paid bonuses to teachers. Programs that provided money to schools were implemented in Maryland, Pennsylvania, South Carolina, and in the districts of Boston and Minneapolis. To some extent, the interest in schoolbased performance award programs in the education sector parallels the rising use of group performance or incentive awards in the U.S. private sector. There, the reported results of group re- 
wards has generally been positive (Heneman and Judge, in press; McAdams and Hawk, 1994). The experience in the educational sector is still to be assessed, and the research reported here is intended as a contribution to that assessment.

Understanding the effects of school-based performance award programs on school and teacher performance is particularly important in light of past research on individual performance (or "merit") pay plans for teachers (Hatry, Greiner, and Ashford, 1994; Jacobson, 1987; Johnson, 1986; Murnane and Cohen, 1986). This literature has consistently shown that merit pay plans tend to be ineffective and short-lived. The programs create competition among teachers by identifying a small proportion of the "best" teachers, which is inconsistent with the findings of other research that suggests that the "best" schools require high levels of professional collaboration among teachers (for example, Rosenholtz, 1989). In addition, the definition of "best" is rarely specified, and teachers often perceive that recognition is unfairly distributed among teachers. Finally, there is inconsistent support for merit pay plans over time. The programs that remain in place tend to operate in districts with high pay for teachers, and they evolve to include more and more teachers, gradually linking the additional pay to additional job responsibilities (Murnane and Cohen, 1986; Odden and Kelley, 1997). The poor performance of merit pay plans in education is similar to the experience in the private sector, particularly in organizations where success requires collaboration and teamwork (Lawler, 1990).

This report concentrates on three main topics: teachers' motivational reactions to these programs, the degree to which teachers' motivational reactions are related to school performance (as defined by each program), and principals' assessments of the effects of the programs. It should be noted that our research does not tell us whether or not school-based performance award programs "cause" improvements in student achievement and, if so, by how much. This would require the use of an experimental or quasi-experimental research design, which was not possible given the need to study existing implementation sites and the absence of equivalent or nearly equivalent states or districts to serve as comparisons. Instead, we used a combination of on-site interviews and survey questionnaires to assess teacher and principal attitudinal responses to these programs and to determine whether the programs created conditions likely to motivate teachers to work toward improving student achievement. We also aggregated these responses to the school level in order to examine whether Kentucky and Charlotte-Mecklenburg schools, where teachers would be expected to be more motivated on the average, were more successful in improving student achievement.

\section{AN OVERVIEW OF THE PROGRAMS WE STUDIED}

\section{Kentucky's Accountability Program}

The Kentucky Accountability Program held schools accountable for improvement in school performance in seven academic subjects (reading, writing, math, science, social studies, arts/humanities, and vocational/practical living) and school-level indicators such as student attendance, retention, and dropout rates, and successful transition to adult life (see Kelley, 1998b; Kelley and Protsik, 1997). The school performance index was called KIRIS, for Kentucky In- 
structional Results Information System. Both the accountability program and the assessment instrument were created in 1990 as part of Kentucky's state education reforms. The assessment instrument, which consisted of portfolio entries, performance events, open-response, and multiple choice questions, was administered in grades four and five, seven and eight, and eleven and twelve. Student scores were placed in one of four categories on the assessment: novice, apprentice, proficient, and distinguished. The calculation of the academic portion of the KIRIS index was based on the proportion of the school's students who score in each category multiplied by a weight that gives more credit for students who performed at the higher levels.

Beginning in 1991-92, the state set a series of two-year goals for each school. Schools were expected to increase their KIRIS scores 10 percent of the distance between their school's baseline score (initially the 1991-92 score, then the score from the prior cycle) and a long-term target (equivalent to 100 percent of students scoring at the proficient level). If schools exceeded their goal, they were designated as "reward" schools and received a pool of award funds that could be used for any purpose, including salary bonuses, as decided by a vote of the school's certified staff. The amount awarded to each school was based on the degree to which the school exceeded its goals and the number of certified staff. Fifty-two award amount levels were established. State law set the maximum award amount at approximately 10 percent of the average teacher salary in the five Kentucky districts having the highest average salary ( $\$ 3,690$ for Cycle 1$)$. The minimum amount was set at 50 percent of this maximum. Certified staff at each winning school decided how to use the reward, including whether only teachers, or teachers and support staff, would be paid bonuses. In the first accountability cycle, 39 percent of schools exceeded their performance target and received performance awards, and teachers in over 98 percent of award schools voted to use all or part of the money for salary bonuses. In the second cycle, 40 percent of schools achieved reward status, and 88 percent of the schools voted to use all or part of the money for salary bonuses (Gong, 1997; Kentucky Department of Education, 1996; Reidy, 1995). The average bonus paid to teachers at the end of Cycle 2 (1995-96) was approximately $\$ 2,600$.

Schools that met their target were termed "successful" and received neither bonuses nor sanctions. Schools that improved over their baseline KIRIS score but failed to reach the target were called "improving." They had to submit a transformation plan to the state that described how they planned to meet their achievement goals in the future. Schools that dropped below baseline were designated "in decline" and were assigned a distinguished educator, received improvement funds, and had to submit a transformation plan. Distinguished educators were experienced teachers or administrators from the state of Kentucky, hired and trained by the state to provide technical assistance to schools to help them meet accountability goals. Schools that dropped more than five points below baseline were designated "in crisis." They were treated like schools in decline, with one notable exception. The distinguished educators assigned to crisis schools had broad powers to terminate teachers and override school site council decisions if they deemed it appropriate (Kentucky Department of Education, 1995). In the first biennium of the program, the crisis category was suspended due to concerns about the reliability of the assessment instrument. The crisis category was reinstituted for the second biennium, and nine schools were designated "in crisis” (Kentucky Department of Education, 1995; Kentucky Department of Education, 1996).

Our research, conducted from 1995 through 1998, concerns the program as described above. Due to a variety of factors, including difficulties with the assessment portion of the program 
(Blackford, 1997; Lawton, 1997; Strecklow, 1997), the state modified the program in 1998 to change the way school goals are set, to change the nature of the sanctions, and to eliminate the possibility of paying bonuses to individual staff members (Cody, 1998).

\section{Charlotte-Mecklenburg's Benchmark Goals Program}

Under the direction of a new superintendent, the Charlotte-Mecklenburg School District established its Benchmark Goals Program in 1991 in an attempt to reverse a record of low student achievement and limited success with minority students (see Heneman, 1998). At the time, the district had about 90,000 students (60 percent white and 40 percent African-American or other) and was growing at a rate of 3,500 students per year. This growth rate and racial composition continue to the present. Approximately 33 percent of the schools in the district are magnet schools. Teacher salaries in North Carolina were comparatively low, with an average of $\$ 30,564$ in 1995-96, ranking 42nd among the states. A statewide teacher salary schedule set minimums for all districts, though district supplements were permitted. The district provided a small supplement, placing its starting teachers at $\$ 23,600$, which was $\$ 2,300$ above the state minimum (Cenziper, 1997).

The Benchmark Goal Program became operational in 1992-93, with annual implementation and management plans extending through the 1996-97 school year. In 1996-97, the program entered a transitional period due to the hiring of a new superintendent and the beginning of a new statewide accountability program for school districts called the ABC's program, a quasi-acronym for accountability, emphasis on basics and high standards, and maximum local control. The district decided to harmonize the Benchmark Goal Program with the state program for the 1997-98 school year, but its major elements, described below, remained intact during the period of our study (the 1996-97 school year).

In the original Benchmark Goal Program, the district set improvement goals for student achievement in nine areas: primary grade readiness, absenteeism, social studies, end-of-grade reading, writing, pre-algebra, dropouts, higher level course enrollment, and end-of-course subject matter mastery. Depending on grade-level composition, schools had between 14 and 44 subgoals. Student achievement in cognitive areas was assessed by standardized multiple choice tests. In addition, goals were set for student absences, and for high schools, dropout rates and enrollment in higher-level courses. Initial performance baselines in the nine areas were established in 1991-92, with annual improvement goals set for each subsequent school year. Every year an overall district improvement goal was set in each area (for example, the percentage of students scoring below the competent range on the writing test will decrease by five percent compared to the previous year). The district then set improvement goals for each school based on the performance level of the previous year's students in each grade. Every school was given specific numerical improvement goals for each area. Maintenance goals also were established in areas in which the school was already performing at a high level, such as having 95 percent of its students prepared for pre-algebra. Maintenance goals were common for all students. There were separate improvement goals for white, African-American, and other students.

Schools received points for achieving goals in each separate area. The central administration divided 100 points evenly among the school's subgoals, so if a school had 25 subgoals, each subgoal was worth four points. A school received 100 percent of the assigned bonus points for a 
fully met subgoal, 75 percent of the bonus points for a partially met subgoal, and no bonus points for an unmet goal. Points earned on subgoals were summed to form a school's total score.

Schools that received 75 or more points were designated as "exemplary" and their certified staff received $\$ 1,000$ and support staff $\$ 400$. Schools that earned between 60 and 74 points were designated as "outstanding." Their certified staff received $\$ 750$ and support staff $\$ 300$. Schools that earned fewer than 60 points were given no special designation and staff did not receive a bonus.

There were no formal sanctions for schools that failed to achieve the accountability goals in any one year. However, schools with chronically low achievement could be placed in the Priority Schools program. In 1995-96, 14 schools were so designated. With district assistance, these schools prepared special improvement plans and identified resources needed to improve student achievement. In addition, each school received assistance in staff training from a university team.

The Benchmark Goals Program also contained a separate performance evaluation system for principals. The principal could earn up to 100 points annually, with 40 of those points based on school performance on the goals. Other evaluation factors included results of teacher, student and family surveys, facilities, and site-specific performance determined in consultation with the superintendent. Despite this separate evaluation system, principals were eligible to receive a bonus equivalent to the teacher amount if their schools were exemplary or outstanding.

\section{The Maryland School Performance Program}

The Maryland School Performance Program was adopted by the State Board of Education in 1990 and is administered by the Maryland State Department of Education. This program holds schools accountable for academic improvement, monitors progress toward state standards, recognizes school success with monetary awards, and assists or reconstitutes schools declining in performance. Rather than comparing schools and school systems, the performance of each school or district was measured in terms of its own growth toward the state's long-term goals (Maryland Department of Education, 1997). To measure school performance, the State Department of Education developed a School Performance Index. The School Performance Index is a weighted average of a school's relative distance from satisfactory standards for attendance and student performance on two test batteries: the Maryland School Performance Assessment Program and the Maryland Functional Test. The former is a statewide performance-based assessment used as the primary gauge of elementary and middle school performance. It was given in grades three, five, and eight. The Maryland School Performance Assessment Program was specifically designed to generate focused instructional change based on state learning outcomes (standards) as well as to monitor school performance. The performance target was for all schools to have 70 percent of students at or above satisfactory performance in all subjects covered by the Maryland School Performance Assessment Program by the year 2000. The Maryland Functional Tests are basic skills exams measuring competencies in reading, mathematics, writing, and citizenship and must be passed for high school graduation. The tests were given as early as grades seven and eight and are reported for grades nine and eleven. The long-term goal was that schools would achieve a 95 percent pass rate in reading, an 80 percent pass rate in mathematics, and a 90 percent pass rate in writing by 2000 . At the time of our study, a high school performance assessment was under construction and was scheduled to be tested in 1999. 
The School Performance Index was calculated by averaging scores across the performance measures. For an elementary school, the Index was the average of the student attendance score and grade three and five achievement scores, the latter based on the percentage of students achieving the proficient level on the Maryland School Performance Assessment Program. A school's ultimate goal was to reach 70 on the Index. The school recognition and rewards program was based on the improvement in performance over a two-year cycle. Change was measured by subtracting the current year's performance index from the average of the previous two years' indices. (Averaging was intended to reduce the impact of fluctuations in the index on the change measure.) A school's yearly goal was to make an improvement in the index that was judged by the Maryland Department of Education to be "sustained and significant." "Significant" refers to statistically significant, and "sustained" to a pattern of improvement continuing over a number of years.

Maryland elementary and middle schools that achieved a sustained and significant level of improvement were eligible for a monetary bonus that could be used for school improvements, but not for staff pay bonuses. The amount of the award depended upon the size of the state appropriation, the number of eligible schools, and the number of students in the reward schools. Between 1996 and 1998, awards ranged from about \$14,500 to \$64,600 per school (Maryland Department of Education, 1999). To date, Maryland has allocated $\$ 8.25$ million in monetary awards and has estimated that 10 percent of elementary and middle schools qualify for performance recognition awards each year. Funds go to improving schools, not necessarily to schools where scores are high but are not improving. Non-monetary recognition certificates were awarded to schools that showed one year of significant improvement. The public reporting of scores also provided incentives in the form of public recognition for schools that improved, and sanctions, in the form of public exposure, for those schools that did not. The State Department of Education released a report card each December on state and district progress toward meeting the standards. The school districts were then responsible for reporting on individual school performance to their communities through the newspapers or other media (Maryland Department of Education, 1997).

Schools that failed to improve faced a range of potential sanctions, from identification as being declared reconstitution-eligible to being identified as "at-risk of reconstitution," to some form of reconstitution. Reconstitution could involve replacing the school's administrative or teaching personnel and/or modifying the school's organization or instructional program. Once the Department of Education identified a school as reconstitution-eligible, the school district had to respond by completing a local school reconstitution proposal, which outlines a framework to address those areas of decline. If failure persisted, the Department's options included more drastic measures, such as contracting with a third party to run the school. At the time of our study (199798), this final action had not yet been pursued (Goertz, Massell, and Chun, 1997). To date, 97 schools have been listed as reconstitution-eligible, with the majority in Baltimore City (Maryland Department of Education, 1999). For additional information on the Maryland program, see Kelley, Conley, and Kimball (1999). 


\section{MOTIVATIONAL MODEL}

Our initial research on the motivational effects of school-based performance award programs on teachers in Kentucky (described in Kelley and Protsik, 1997), using a grounded theory approach (Strauss and Corbin, 1994), suggested that Expectancy Theory (Vroom, 1964) and Goal Setting Theory (Locke and Latham, 1990) would be useful in understanding how teachers responded to the programs. Figure 1 shows the model of motivation, derived from Expectancy Theory and adapted to the SBPA context, that we then used to structure further research. The model depicts the requirements a successful award program must meet in order for teachers to be motivated to work toward improving student achievement. The central elements of the model are teachers' perceptions of the degree to which the teacher's own effort will influence student achievement, as measured in the program (called the expectancy perception), the teacher's perception of the probability that meeting the student achievement goal will lead to the consequences (outcomes, such as receiving a bonus) associated with the program (called the instrumentality perception), and the positive and negative value (desirability) that they attribute to these outcomes or consequences.

In this model, teachers' motivation is a function of the expectancy, instrumentality, and desirability of outcomes. Starting with the expectancy link between effort and student achievement, the model shows that the overall effort expended by the teacher is derived from beliefs about how likely it is that effort (its intensity, focus, and persistence) will lead to the attainment of student achievement goals. The more a teacher perceives that working hard will pay off in meeting the goals, the greater the teacher's motivation to expend the effort to do so. Moreover, borrowing from goal-setting theory (Locke and Latham, 1990), student achievement goals that are clear and specific will focus teachers' efforts and foster stronger expectancy perceptions.

Figure 1. Theoretical Framework: Teacher Motivation in School-Based Performance Award Programs

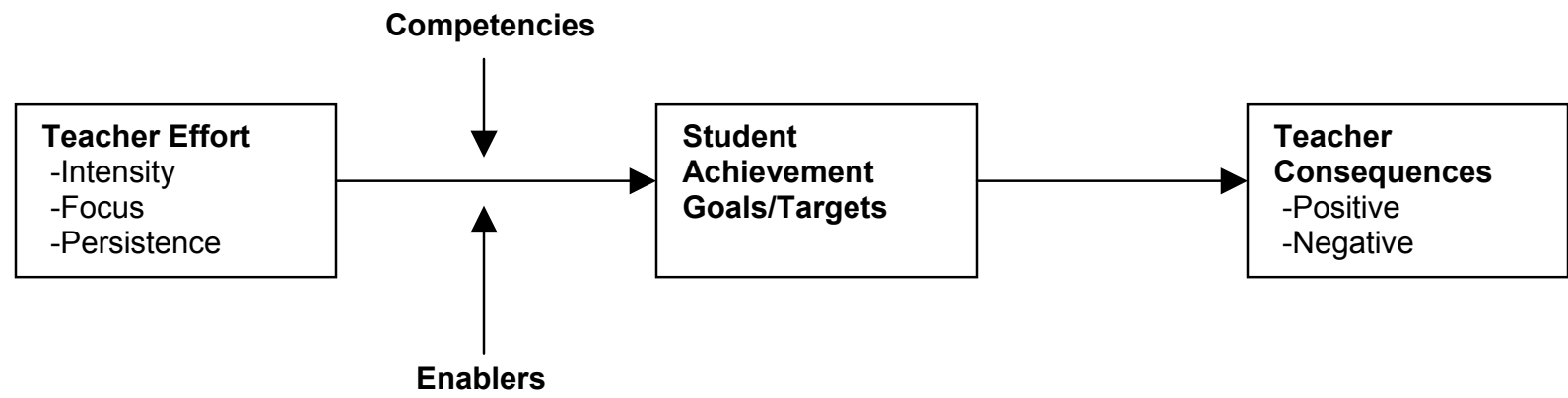

In this model, teachers' motivation is a function of the expectancy, instrumentality, and desirability of outcomes. Starting with the expectancy link (between effort and student achievement), the model shows that the overall effort expended by the teacher is derived from beliefs about how likely it is that effort (its intensity, focus, and persistence) will lead to the attainment of student achievement goals. The more a teacher perceives that working hard will pay off in meeting the 
goals, the greater the teacher's motivation to expend the effort to do so. Moreover, borrowing from goal-setting theory (Locke and Latham, 1990), student achievement goals that are clear and specific will focus teachers' efforts and foster stronger expectancy perceptions.

Teachers' beliefs about the effort-student achievement linkage are influenced by their beliefs about their competencies and the presence of enabling conditions. Competencies refer to teacher knowledge and skills relevant to helping students meet achievement goals. Enabling conditions are organizational conditions that facilitate the meeting of student achievement goals. Examples include curricular resources, principal support, professional development opportunities, and feedback about progress toward meeting the goals.

The instrumentality link (between meeting the goals and obtaining the outcomes) is also important in understanding the motivational impacts of school-based performance award programs. Instrumentality refers to teachers' beliefs about the probability that meeting (or not meeting) student achievement goals will lead to the consequences or outcomes associated with the program, such as receiving a pay bonus or experiencing public criticism for failing to meet improvement goals. To the extent that teachers believe that consequences they value have a high probability of occurrence as a result of meeting the goals, they will be motivated to expend effort to meet the goals. Similarly, to the extent they believe that if the goals are not achieved, consequences they value negatively will occur, they will be motivated to try to achieve the goals. The point is that outcomes will motivate to the extent that teachers see them as highly likely to occur.

The outcomes or consequences associated with the school-based performance award program must also have substantial negative or positive value to teachers in order to motivate them. Examples of positively valued (desirable) consequences of SBPA programs include receiving a bonus, public recognition for meeting student achievement goals, and a sense of accomplishment from having students reach the achievement goals. Negatively valued (undesirable) consequences include not receiving a bonus, heightened job stress, experiencing public criticism for not meeting student achievement goals, and threats to job security. It should be noted that teachers are likely to differ as to whether a given consequence is seen as desirable or undesirable as well as the degree to which a consequence is perceived as desirable or undesirable. For example, though some teachers may negatively value stress, others may view stress positively, as a stimulant. The desirability or undesirability of each consequence is defined by the individual teacher. The importance of the desirability or value of outcomes or consequences is also recognized in the Goal Setting theory: goals associated with highly desirable outcomes are likely to attract a higher degree of acceptance and commitment.

The theoretical framework illustrated in Figure 1 implies that attempts to motivate teachers to improve student achievement by an awards program is a complex undertaking. Program designers need to ensure that the outcomes associated with reaching accountability goals are highly valued by teachers and are perceived as highly likely to occur if the goals are reached. Program designers must also try to make sure that some likely consequences of trying to reach the goals (such as higher stress) are not so negatively valued as to counteract the likely positive consequences of reaching them. Teachers must also believe that if they expend effort to achieve the goals, their effort will bring results. This may require action aimed at improving teachers' capacities or competencies and providing enabling conditions to support their efforts. Schoolbased performance award programs are likely to motivate teachers when all of these 
performance award programs are likely to motivate teachers when all of these requirements are addressed. Teachers in states, districts, or schools where these requirements are better addressed should be more motivated by these programs.

We used this motivational model as the framework for our research to identify important variables to study and relationships to test. Our study sought to address two connected issues: what are the motivational responses of teachers to school-based performance award programs, and are teachers' motivational responses to these programs predictive of schools' success in meeting subsequent student achievement goals? The next section describes the way we explored these issues.

\section{STUDY METHODOLOGY}

\section{Research Design}

This study examined school-based performance award programs in three jurisdictions: the state of Kentucky, the Charlotte-Mecklenburg district in North Carolina, and the state of Maryland. All three jurisdictions had comprehensive standards-based reform strategies in place. Kentucky and Charlotte-Mecklenburg were selected for the study because they paid salary bonuses to all of the teachers in a school for improvements in student outcomes toward a specified goal. We wanted research sites in which an awards program had already been implemented so that teachers had accumulated experiences with it. Maryland was chosen as a contrasting site because it provided awards to schools as school improvement funds not directly to teachers in the form of salary bonuses.

Figure 2 provides an overview of our general research design, showing the basic steps we followed in Charlotte-Mecklenburg and Kentucky.

Figure 2. Overview of the Research Process in Charlotte-Mecklenburg and Kentucky

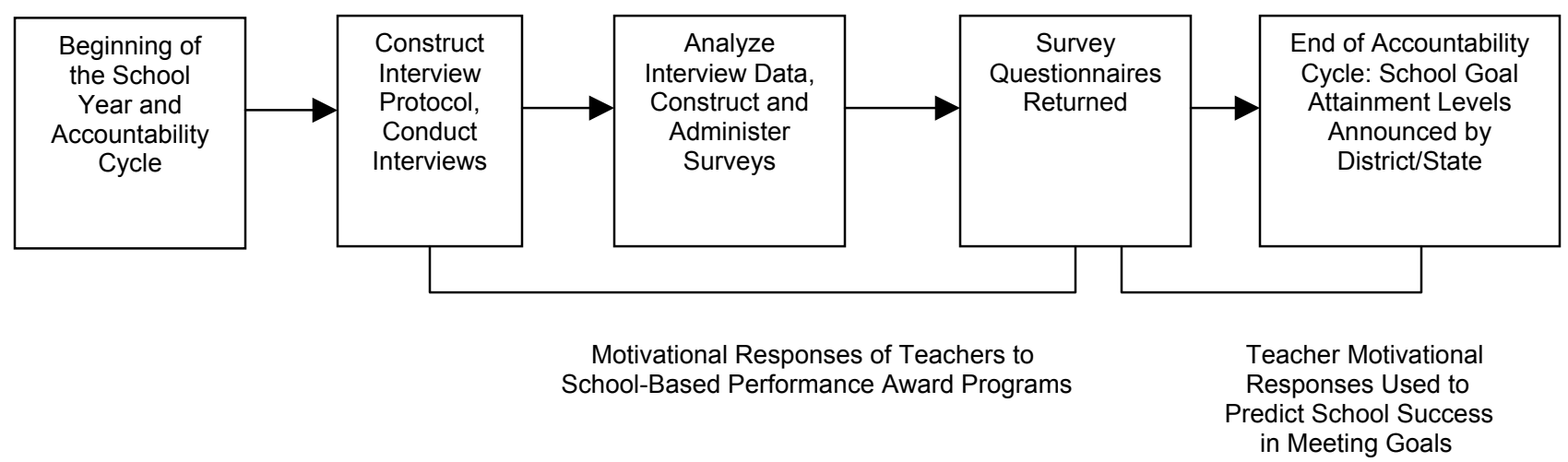

We conducted our research in each jurisdiction between the beginning and end of a single program cycle. This allowed us to frame our interviews and survey questions, particularly regarding schools' student achievement goals, in terms of that performance cycle. After determining our research sites and samples, we began by conducting interviews with teachers and principals from 
a wide range of schools, varying in student socioeconomic status, grade level, and previous success in meeting student achievement goals. We used a semi-structured interview protocol based on the teacher motivation model. We specifically asked questions about expectancy, instrumentality, desirability of consequences or outcomes, competencies, and enabling conditions. We recorded the interviews, transcribed them, and content analyzed the responses. Our content analysis of the responses was our first assessment of teachers' motivational responses to the schoolbased performance award programs.

Based upon what we learned from the interviews, we constructed surveys for administration to large, representative samples of teachers and principals in Charlotte-Mecklenburg and Kentucky, and of principals in Maryland. The primary content of the teacher survey focused on the five components of the teacher motivation model. From this survey we learned about the relative desirability of 17 outcomes (including the bonus) to teachers, the perceived probability of receiving these outcomes if a school met its goals, the perceived probability that teacher effort would result in a school meeting its goals, teacher perception of their competencies, and teacher perceptions of the presence of various enabling conditions in their schools. These responses allowed us to examine how well the awards program was functioning in generating positive motivational responses from teachers. These interpretations of the survey data formed our second assessment of teachers' motivational responses to school-based performance award programs.

We also wanted to know whether variations in motivational responses of teachers were related to school success in meeting its student achievement goals at the end of the performance cycle. In this analysis we aggregated teachers' motivational responses to the school level and used these aggregates to predict how well schools met their goals. In essence, we viewed the average level of motivation of teachers within each school as a predictor of whether or not their school met its goals. We expected that higher average levels of teacher motivation would lead to a greater likelihood of goal attainment. We also recognized that the strength of the relationship between teacher motivation and school achievement we were likely to find might be weakened by many factors, including unreliability in the motivation and achievement measures and the impact of many factors other than teacher motivation on student achievement. However, these results would be our best answer to the question of whether teacher motivation leads to school achievement success.

In summary, in each jurisdiction, data collection involved on-site interviews with principals and teachers in schools with varying degrees of success in meeting school performance goals, followed by mail surveys of teachers (in Charlotte-Mecklenburg and Kentucky) and principals (in all three jurisdictions) in a larger sample of schools. Table A1 in the Technical Appendix summarizes the nature and timing of the data collection effort. The Technical Appendix also includes a discussion of sampling designs, survey response rates, and other data collection issues. 


\section{FINDINGS: MOTIVATIONAL RESPONSES OF TEACHERS}

\section{Perceptions About School Performance Goals}

According to Goal Setting Theory (Locke and Latham, 1990), in order for teachers to be motivated to expend effort to meet student achievement goals, they need to understand the goals and be committed to them. We expected school-based performance award programs to have positive impacts on both the degree to which teachers understand the goals and on goal commitment. Our interviews with teachers and principals suggested that the Charlotte-Mecklenburg and Kentucky programs were reasonably successful in getting teachers to understand and be committed to achieving the goals. All of the teachers we interviewed in both jurisdictions were aware of and had a significant degree of understanding of program goals. This is in contrast to our findings in Maryland, where a number of teachers we interviewed were unaware of the incentive program or poorly informed about the details. In both Kentucky and Charlotte-Mecklenburg, many teachers indicated that the presence of the award program provided them with clear direction and focus. Accountability and focus on the goals was named by many principals and teachers alike as the major positive effect of the programs in both Charlotte-Mecklenburg and Kentucky. While teacher commitment to these goals varied across schools, grade levels, and subjects, all of the teachers we talked to indicated that they had made changes in teaching practice to align curriculum and instruction with program goals. This finding is consistent with other research in Kentucky. For example, Stecher and Barron (1999) found that teachers in assessed subjects and grade levels had greater alignment of curriculum to the standards compared to teachers in subjects or grade levels where there was no assessment. In the most successful schools, changes to teaching practice appear to have occurred schoolwide. Despite these substantial effects, some teachers expressed a degree of conflict between the program's and other goals. Competing goals mentioned were the need to emphasize basic skills, the importance of instilling a "love of learning," or pursuing a different program emphasis, such as at a fine arts magnet school (Heneman, 1998; Kelley, 1998b).

Our survey results were for the most part consistent with these interview findings. Teachers in both jurisdictions were asked about their commitment to achieving the goals, about how well they understood the goals, and whether these goals conflicted with other important educational goals. Teachers in Kentucky were also asked to agree or disagree with two statements about the focus or guidance provided by the goals. Table 1 shows the means and standard deviations on the scales we developed from these items. (Technical Appendix Table A2 provides for information on the items included in the scales and their reliabilities.)

Table 1. Means and Standard Deviations of Responses on Goal-Related Scales

\begin{tabular}{lcccc}
\hline & $\begin{array}{c}\text { Charlotte- } \\
\text { Mecklenburg } \\
\text { Mean }\end{array}$ & $\begin{array}{c}\text { Charlotte- } \\
\text { Mecklenburg } \\
\text { Std. Deviation }\end{array}$ & Kentucky Mean & $\begin{array}{c}\text { Kentucky Std. } \\
\text { Deviation }\end{array}$ \\
\hline Goal Commitment & 3.9 & 0.8 & 3.9 & 0.7 \\
Goal Clarity & 3.4 & 1.0 & 3.6 & 0.8 \\
Goal Focus & -- & -- & 3.3 & 0.9 \\
Goal Conflict & 2.8 & 1.0 & 3.2 & 1.1 \\
\hline
\end{tabular}

Scales are averages of responses to items with rating scales of $1=$ strongly disagree to $5=$ strongly agree. All of the differences between Charlotte-Mecklenburg and Kentucky means are statistically significant at the .05 level or beyond. 
On the average, teachers reported a high level of commitment to the goals. The averages for both Charlotte-Mecklenburg and Kentucky teachers on our commitment measure was 3.9 on a 1 to 5 scale. Teachers also reported a reasonably high level of understanding of the goals, though the Kentucky average of 3.6 (on a 1 to 5 scale) was slightly higher than the average of 3.4 for Charlotte-Mecklenburg teachers. There was less agreement by Kentucky teachers that the goals provided a focus for teaching efforts. On the average, the level of agreement with the statements making up this two item scale was, at only 3 above the neutral point, somewhat lower than was expected based on what we heard in interviews with Kentucky teachers. On average, teachers in both jurisdictions reported some degree of conflict between the program goals and other important educational goals, though the fact that the averages were close to the neutral point suggests that this was not, overall, a major problem. (All of the differences in means across jurisdictions are statistically significant at the .05 level or beyond. However, it should be borne in mind that small differences in means will be statistically significant given the relatively large samples we used. This holds true for most of the other mean differences shown in subsequent tables.)

Teachers in both jurisdictions also were asked about the level of performance they were aiming to achieve during the accountability cycle. There were asked specifically whether they were trying to achieve school performance levels that would lead to a reward, to avoid declines in student performance, or were they not particularly trying to meet the goals. Table 2 shows the percentages of respondents who indicated they were trying to attain the different levels of achievement established by each program.

Table 2. Percent of Respondents Indicating They Tried to Achieve Various Performance or Goal Levels in Charlotte-Mecklenburg and Kentucky

\begin{tabular}{|c|c|c|c|}
\hline $\begin{array}{l}\text { Charlotte-Mecklenburg } \\
\text { During this year, did you: }\end{array}$ & All Respondents & $\begin{array}{c}\text { Respondents in } \\
\text { Schools Rewarded in } \\
\text { Prior Year }\end{array}$ & $\begin{array}{c}\text { Respondents in } \\
\text { Schools Not Rewarded } \\
\text { in Prior Year }\end{array}$ \\
\hline not try to achieve goals & 5.6 & 3.5 & 7.5 \\
\hline $\begin{array}{l}\text { try to avoid decline in student } \\
\text { performance measures }\end{array}$ & 7.2 & 7.5 & 7.0 \\
\hline $\begin{array}{l}\text { try to achieve Outstanding status } \\
\text { (partial reward) }\end{array}$ & 13.4 & 9.3 & 17.1 \\
\hline $\begin{array}{l}\text { try to achieve Exemplary status } \\
\text { (full reward) }\end{array}$ & 73.8 & 79.6 & 68.4 \\
\hline $\begin{array}{l}\text { Kentucky } \\
\text { During this year, did you: }\end{array}$ & All Respondents & $\begin{array}{l}\text { Respondents in } \\
\text { Cycle } 2 \text { Reward } \\
\text { Schools } \\
\end{array}$ & $\begin{array}{l}\text { Respondents in Cycle } \\
2 \text { Nonreward Schools }\end{array}$ \\
\hline not try to achieve goals & 1.5 & 2.2 & 1.2 \\
\hline try to avoid decline in KIRIS scores & 10.0 & 7.3 & 11.6 \\
\hline try to achieve Improving Status & 10.8 & 6.3 & 13.6 \\
\hline try to achieve Successful Status & 24.4 & 12.0 & 32.2 \\
\hline try to achieve Reward Status & 53.4 & 72.2 & 41.4 \\
\hline
\end{tabular}

In both jurisdictions, the vast majority of teachers indicated they were trying to reach their school's student achievement goals. Over 87 percent were trying for Outstanding or Exemplary status in Charlotte-Mecklenburg, and over 77 percent for Successful or Reward status in Kentucky. Few teachers indicated that they were not trying or were trying only to avoid performance declines. Moreover, as one might expect, meeting school goals in the last accountability cycle had an effect on the goal level teachers reported that they were aimed to achieve in the current period, particularly for schools in the highest prior achievement (and bonus-winning) level. 
Teachers in Charlotte-Mecklenburg were more likely to report trying for Exemplary status if their school had earned a bonus the prior year (79.6 percent versus 68.4 percent in schools not earning a bonus last year). The effect of prior winning was even greater among Kentucky teachers, with Reward status being sought by more teachers in schools that had won (72.2 percent) than had not won (41.4 percent) a bonus for the previous cycle. Another point of interest is that relatively fewer Kentucky teachers indicated that they were not trying to achieve the goals compared to Charlotte-Mecklenburg teachers, perhaps because the Kentucky program had stronger sanctions.

The use of bonuses may help to increase teachers' understanding of and commitment to goals by calling attention to the goals and signaling their importance. To investigate this possibility, we multiplied the desirability rating of the bonus by its perceived probability of occurrence if goals are met (instrumentality) to create the expected value of the bonus. Goal commitment and goal clarity were then each regressed on this expected value and on several control variables for Charlotte-Mecklenburg and Kentucky survey respondents. We obtained significant positive coefficients for the effect of the expected value of the bonus on goal commitment in both jurisdictions and for goal clarity in the Charlotte-Mecklenburg sample. (The goal clarity coefficient in the Kentucky analysis just missed significance at the .10 level.) For Kentucky, we also assessed the impact of the expected value of the bonus on goal focus, and found a positive and significant coefficient. Appendix Table A3 shows the coefficients. These results confirm the positive role that bonuses can play in getting teachers to understand and accept the goals. A stronger test, however, would be to compare goal clarity and commitment between programs with and without a bonus component.

Because policy implementation research has repeatedly underscored how difficult it is for policy change to penetrate teaching practice (Fullan, 1991; Odden, 1991), these results are encouraging. In both jurisdictions with award programs that paid bonuses to teachers for goal attainment, there was definite penetration of the bonus-linked goals to the teachers in the form of goal commitment and understanding of the goals.

Though each program seems to have succeeded in communicating expectations and securing commitment toward improvements in student achievement, one threat to goal commitment over time in both programs is the increasing difficulty of meeting ever-rising goals for successful schools. Both the Charlotte-Mecklenburg and Kentucky programs measure school performance in terms of improvement in student achievement. For schools that do improve, the absolute level of student achievement that must be produced to meet future goals will be higher in each succeeding accountability cycle. For schools that do not improve in a cycle, the goal for the next cycle does not increase much, if at all, in terms of absolute student performance. We wondered if teachers in successful schools recognized that the goals were likely to get harder each year. In each jurisdiction, teachers were asked whether they thought the goals were harder this cycle than last, and would be harder yet next cycle. Table 3 shows the percentages of teachers who indicated that future goals would be more difficult, by the award status of their school in the last accountability cycle. In both jurisdictions, teachers in award schools were more likely to indicate that goals would get harder than teachers in non-award schools. 
Table 3. Percentages of Teachers Indicating Goals Were Becoming Harder to Achieve, by School's Award Status in Prior Cycle

\begin{tabular}{lcc}
\hline Percent of Charlotte-Mecklenburg respondents indicating that: & Award Prior Cycle & $\begin{array}{c}\text { No Award } \\
\text { Prior Cycle }\end{array}$ \\
\hline $\begin{array}{l}\text { This year's goals are much or somewhat harder } \\
\text { Next year's goals will be much or somewhat harder }\end{array}$ & 67.4 & 43.5 \\
\hline Percent of Kentucky respondents strongly agreeing or agreeing & 59.5 & 44.1 \\
\hline that: & & \\
\hline This cycle's goals will be harder to achieve & 73.5 & 63.5 \\
Next cycle's goals will be even harder to reach & 70.9 & 65.7 \\
\hline
\end{tabular}

\section{Desirability of Outcomes}

Teachers' interview responses provided several insights about what teachers perceived as outcomes associated with school-based performance award programs and their desirability (see Heneman, 1998; Kelley, 1998a; Kelley and Protsik, 1997). Teachers identified a number of outcomes, both extrinsic and intrinsic, that they experienced as a result of working under an award program. While many teachers indicated that bonuses for schoolwide improvement in student performance were appropriate, just as bonuses were appropriate for other types of professionals, many of the teachers said that they were not directly motivated by the promise of a bonus. In Charlotte-Mecklenburg, a number of teachers complained that the size of the bonus was too small ( $\$ 400$ to $\$ 600$ after taxes) given the additional work required to achieve the bonus. This was particularly problematic given the overall low salaries, which required many beginning teachers to moonlight in order to support themselves.

The interview data suggested that there were a variety of other important outcomes that teachers associated with participation in the school-based performance award program. Teachers identified things like public recognition and professional pride as outcomes that motivated them to achieve program goals. They also mentioned that the changes they had made to curriculum and instruction were important improvements in their teaching practice. As a result of working to achieve program goals, teachers said they had improved their own teaching skills in ways that would make them better teachers, whether or not the award program continued. Teachers indicated that the programs provided new and valued opportunities for professional development, for working with other teachers, and for seeing measured improvement in student performance over time.

Kentucky teachers were very aware of the sanctions component of the program and saw it as a real potential outcome for any school that did not improve performance. This was in sharp contrast to the responses of Maryland teachers who accurately assessed that most schools were not in danger of sanctions. (The Maryland program identified schools for sanctions based on a combination of performance level and changes in performance, so only the lowest-performing schools in the state, mostly in Baltimore city, were likely to be sanctioned.) As a result, the sanctions component was not generally viewed as an important or motivating outcome for most teachers. Kentucky teachers indicated that they were motivated by the sanctions component out of fear of losing professional autonomy (due to the assignment of a Distinguished Educator to schools with declining performance), losing professional pride, and for some, a potential loss of job security. 
Based on the teacher interview findings, we identified 17 potential outcomes directly relevant to experiences under the award programs, which we then included in the questionnaires sent to Charlotte-Mecklenburg and Kentucky teachers. Teachers rated the desirability of each outcome on a 1 to 5 scale. The average desirability ratings of the outcomes are shown in Table 4 (see also Heneman and Milanowski, 1999).

Receiving a bonus was rated quite high in desirability, as were outcomes pertaining to recognition, satisfaction in meeting goals, seeing students learn and improve performance, and working with other teachers. These results were consistent with our interview findings, confirming that under a school-based performance award program teachers find numerous outcomes desirable, and teachers find both extrinsic (such as receiving the bonus) and intrinsic (such as opportunities for professional development) outcomes desirable. Analysis of the ratings also showed that teachers who rated the bonus as more desirable did not rate as less desirable outcomes like personal satisfaction from achieving the goals, personal satisfaction from improved student achievement, and seeing students learn new skills.

Table 4 shows that teachers rated other outcomes quite low in desirability. These undesirable outcomes included public criticism for not meeting goals, loss of professional pride for not meeting goals, risk to job security, intervention, putting in more hours, less freedom to teach things unrelated to goals, and more pressure and job stress. In Kentucky, the intervention and risk to job security outcomes were rated about as undesirable as the positive outcomes associated with the program were rated desirable. This suggests the potential motivating strength of these sanctions. Avoiding these negative outcomes was not rated as desirable as the positive outcomes by Charlotte-Mecklenburg teachers, which is likely a reflection of the more powerful negative sanctions program in Kentucky. These results are also consistent with the interview findings.

To determine if there were any meaningful patterns or clusters of intercorrelations among the desirability ratings, we factor-analyzed (principal components, varimax rotation) the desirability ratings. Our interpretation of the factor loadings yielded the four groupings shown in Table 5. We labeled these "Goal Attainment Rewards," "Learning," "Sanctions," and "Stress." (One item relating to participation in meaningful education reform was discarded because of high crossloadings across the factors.) These factors provide an intuitively meaningful way to summarize the desirability of the outcomes and largely reflect the distinctions between positive rewards and negative sanctions contingent on school performance.

Outcome desirability ratings were not strongly related to teachers' age, years of experience, salary level, school level, percent of students receiving free and reduced price lunch, and whether a school had met its goals in the previous award cycle. There were very few statistically significant correlations between desirability ratings and these variables were obtained, and those that were significant were very small (i.e., $\mathrm{r}<.15$ ). Thus, these desirability ratings appear to be generalizable across teachers within each jurisdiction. 
Table 4. Desirability ${ }^{(a)}$ of Outcomes Associated with School-Based Performance Award Programs

\begin{tabular}{|c|c|c|c|c|}
\hline Outcome & $\begin{array}{c}\text { Charlotte- } \\
\text { Mecklenburg } \\
\text { Mean }\end{array}$ & $\begin{array}{c}\text { Charlotte- } \\
\text { Mecklenburg } \\
\text { Std. Deviation }\end{array}$ & $\begin{array}{l}\text { Kentucky } \\
\text { Mean }\end{array}$ & $\begin{array}{c}\text { Kentucky } \\
\text { Std. } \\
\text { Deviation }\end{array}$ \\
\hline Receiving a bonus ${ }^{(\mathrm{b})}$ & 4.5 & 0.7 & 4.1 & 1.1 \\
\hline Receiving funds for school improvements & 4.4 & 0.7 & 4.1 & 0.9 \\
\hline Public recognition for meeting goals & 4.1 & 0.9 & 4.0 & 0.9 \\
\hline Personal satisfaction of meeting goals & 4.3 & 0.8 & 4.2 & 0.8 \\
\hline $\begin{array}{l}\text { Personal satisfaction from improved student } \\
\text { Performance }\end{array}$ & 4.6 & 0.6 & 4.4 & 0.6 \\
\hline Participation in education reform program & 3.6 & 1.0 & 3.2 & 1.1 \\
\hline Having clear schoolwide goals & 4.4 & 0.7 & 4.3 & 0.7 \\
\hline $\begin{array}{l}\text { Working cooperatively with other teachers on } \\
\text { Curriculum and instruction }\end{array}$ & 4.3 & 0.7 & 4.0 & 0.8 \\
\hline Having your students learn new skills & 4.5 & 0.6 & 4.4 & 0.7 \\
\hline $\begin{array}{l}\text { Having additional opportunities for professional } \\
\text { Development }\end{array}$ & 4.3 & 0.7 & 3.9 & 0.8 \\
\hline $\begin{array}{l}\text { Public criticism or embarrassment due to not achiev- } \\
\text { ing goals }\end{array}$ & 4.4 & 1.2 & 1.6 & 0.8 \\
\hline $\begin{array}{l}\text { Loss of professional pride due to not achieving } \\
\text { goals }{ }^{(\mathrm{C})}\end{array}$ & 3.6 & 1.2 & 1.8 & 0.8 \\
\hline Risk to job security ${ }^{(c)}$ & 3.9 & 1.1 & 1.6 & 0.8 \\
\hline Intervention ${ }^{(c)(d)}$ & 3.7 & 1.3 & 1.8 & 0.8 \\
\hline Putting in more hours & 2.0 & 0.9 & 1.9 & 0.9 \\
\hline Less freedom to teach things unrelated to goals & 2.0 & 0.9 & 1.9 & 0.9 \\
\hline More pressure and job stress & 1.6 & 0.8 & 1.5 & 0.8 \\
\hline
\end{tabular}

(a) Scale: 1 = highly undesirable...5 = highly desirable.

(b) \$1,000 in Charlotte-Mecklenburg, \$2,000 in Kentucky

(c) Charlotte-Mecklenburg respondents were asked to rate the desirability of avoiding these outcomes; Kentucky respondents were asked to rate the desirability or undesirability of the outcomes themselves.

(d) Charlotte-Mecklenburg respondents were asked about having their school designated a Priority School; Kentucky respondents were asked about having a Distinguished Educator assigned to their school.

All differences between comparable Charlotte-Mecklenburg and Kentucky averages are statistically significant at the .05 level or beyond.

Table 5. Grouping of Outcome Items Based on Factor Analysis of Desirability Ratings

\section{Goal Attainment Rewards}

- public recognition for meeting goals

- personal satisfaction from meeting goals

- $\quad$ receiving a bonus for meeting goals

- $\quad$ receiving school improvement funds for meeting goals

\section{Learning}

- $\quad$ working cooperatively with other teachers

- working toward clear schoolwide goals

- $\quad$ having students learn new skills

- additional opportunities for professional development

- $\quad$ personal satisfaction from improved student performance

\section{Sanctions}

- $\quad$ public criticism and embarrassment for not meeting goals

- $\quad$ risk to job security

- $\quad$ loss of professional pride from not meeting goals

- intervention

Stress

- $\quad$ more pressure and job stress

- $\quad$ putting in more hours

- less freedom to teach things unrelated to the goals

Combining the interview and survey data, we clearly and convincingly found that a school-based performance award program is not just a bonus program; rather, it is one element in an interrelated system of rewards, opportunities, and demands that influences teachers' jobs and lives in a multitude of ways, leading them to experience (and form values about) a variety of both extrinsic 
and intrinsic outcomes. However, it is the bonus part of the program that is distinctive (and costly), so teachers' reaction to it are especially important. We found that most teachers viewed receiving a bonus per se as appropriate, desirable, and not in conflict with other outcomes traditional seen as motivating to teachers. We were surprised to find less desirability and motivation being reported for the bonus program as a whole. This inconsistency seemed to be a reflection of unfavorable attitudes about components of the school-based performance award programs, and how they are administered, rather than about the bonus per se. This is discussed further below.

We were also somewhat surprised by the number of relatively undesirable outcomes that teachers mentioned, and the intensity of some teachers' feelings about them. Increased work hours, pressure, and stress stood out in this regard. In addition, for many Kentucky teachers, the job security and intervention threats were perceived as intense. Some teachers, however, viewed the longer hours and "being under the gun" as necessary to improve student achievement and motivate the shifts in practice required. Also, some teachers who had experienced state intervention viewed it as professional growth experience that brought new resources and a sense of focus to the school.

\section{Instrumentality Perceptions}

In the interviews, we asked teachers about the likelihood of various outcomes occurring if their school met, or did not meet, its student achievement goals. We concentrated particularly on the bonus, risk to job security, and intervention. We also asked about the likelihood of outcomes occurring simply as a consequence of trying to reach the student achievement goals. We found some degree of skepticism that the bonus would be paid if a school met its goals. This skepticism was most pronounced in Kentucky and may have been a reflection of teachers' experience years earlier when the state promised, but then never paid, a $\$ 300$ bonus payment to all teachers. The Kentucky teachers also were skeptical about the long-term survival of the award program. The Charlotte-Mecklenburg teachers, although less skeptical, questioned whether there would be long-term funding for the bonus payments, as well as the longevity of the program itself. (Some level of skepticism was probably justified in both jurisdictions since both programs were changed significantly after our research was completed.) Compared to Charlotte-Mecklenburg teachers, the Kentucky teachers saw losing their jobs or having an intervention occur as much more likely, a reflection of the strong negative sanctions not only possible, but sometimes used, in Kentucky. Kentucky teachers also appeared to perceive that program participation was more likely to lead to increased pressure and stress. They cited loss of professional autonomy as a more likely outcome (Kelley, 1998a; Kelley and Protsik, 1997) than teachers in CharlotteMecklenburg or Maryland did. This may have been due to the more difficult goals with which many Kentucky teachers were confronted, as well as the more stringent sanctions that could be imposed for poor performance on the accountability index.

Our survey asked teachers about the likelihood of each of the 17 outcomes. For some outcomes (e.g., receiving a bonus), teachers were asked to indicate the probability of the outcome occurring if their school met its goals. For others (e.g., loss of job security), they were asked to indicate the likelihood of that outcome occurring if the school did not meet its goals. For outcomes such as increased work hours and more job stress, they were asked the probability of experiencing the outcome if trying to meet school goals. The probabilities were assessed on a 0 to 100 percent scale, in 10 percent increments. The means of the probabilities are shown in Table 6. 
Table 6. Average Perceived Probability(a) of Outcomes Associated with School-Based Performance Award Programs in Charlotte-Mecklenburg and Kentucky

\begin{tabular}{|c|c|c|c|c|c|c|}
\hline \multirow[t]{2}{*}{ Outcome } & \multicolumn{2}{|c|}{$\begin{array}{l}\text { Probability if School } \\
\text { Meets Goals }\end{array}$} & \multicolumn{2}{|c|}{$\begin{array}{c}\text { Probability if You Try to } \\
\text { Meet Goals }\end{array}$} & \multicolumn{2}{|c|}{$\begin{array}{l}\text { Probability if School } \\
\text { Does Not Meet Goals }\end{array}$} \\
\hline & Charlotte & Kentucky & Charlotte & Kentucky & Charlotte & Kentucky \\
\hline Receiving a bonus $^{(\mathrm{b})}$ & 72.8 & 54.8 & & & & \\
\hline $\begin{array}{l}\text { Personal satisfaction from } \\
\text { meeting goals }\end{array}$ & 79.4 & 73.9 & & & & \\
\hline $\begin{array}{l}\text { Personal satisfaction from } \\
\text { improved student }\end{array}$ & 78.9 & 73.6 & & & & \\
\hline Performance & & & & & & \\
\hline $\begin{array}{l}\text { Public recognition for meet- } \\
\text { ing goals }\end{array}$ & 67.6 & 62.1 & & & & \\
\hline $\begin{array}{l}\text { Receiving funds for school } \\
\text { improvements }\end{array}$ & 45.2 & 49.6 & & & & \\
\hline $\begin{array}{l}\text { Working cooperatively with } \\
\text { other teachers on curricu- } \\
\text { lum and instruction* }\end{array}$ & & & 72.9 & 71.5 & & \\
\hline $\begin{array}{l}\text { Feel you are working to- } \\
\text { ward clear schoolwide } \\
\text { goals }\end{array}$ & & & 73.6 & 63.3 & & \\
\hline $\begin{array}{l}\text { Having additional opportu- } \\
\text { nities for professional } \\
\text { development }\end{array}$ & & & 63.5 & 68.5 & & \\
\hline $\begin{array}{l}\text { Having your students learn } \\
\text { new skills }\end{array}$ & & & 54.6 & 59.9 & & \\
\hline $\begin{array}{l}\text { Feel you are participation in } \\
\text { education reform program }\end{array}$ & & & 58.0 & 56.4 & & \\
\hline $\begin{array}{l}\text { More pressure and job } \\
\text { stress }\end{array}$ & & & 73.6 & 84.4 & & \\
\hline Putting in more hours & & & 65.8 & 81.9 & & \\
\hline $\begin{array}{l}\text { Less freedom to teach } \\
\text { things unrelated to goals }\end{array}$ & & & 68.9 & 74.9 & & \\
\hline $\begin{array}{l}\text { Public criticism or } \\
\text { Embarrassment due to not } \\
\text { achieving goals }\end{array}$ & & & & & 53.8 & 68.6 \\
\hline Intervention & & & & & 46.5 & 75.9 \\
\hline $\begin{array}{l}\text { Loss of professional pride } \\
\text { due to not achieving goals }\end{array}$ & & & & & 44.9 & 61.0 \\
\hline Risk to job security & & & & & 31.8 & 50.2 \\
\hline
\end{tabular}

(a) Response scale ranged from 0 (Highly Unlikely) to 100 (Highly Likely) in 10 point steps. For standard deviations, see Technical Appendix Table A4.

(b) \$1,000 in Charlotte-Mecklenburg, \$2,000 in Kentucky.

All differences between comparable Charlotte-Mecklenburg and Kentucky averages are statistically significant at the .05 level or beyond except where indicated by an asterisk (*).

Except in the case of the bonus, there were only small differences between CharlotteMecklenburg and Kentucky teachers in the perceived probabilities of the other positive outcomes occurring if a school meets its goals. The perceived bonus probability was much higher (72.8 percent) in Charlotte-Mecklenburg than in Kentucky (54.8 percent). The perceived probability of most of the positive outcomes associated with trying to meet school goals appeared quite similar for Charlotte-Mecklenburg and Kentucky teachers, but the latter saw a higher probability of more pressure and stress and working more hours. Perceived probabilities of outcomes associated with failing to meet goals were substantially higher for all four outcomes for Kentucky 
teachers, probably due to the formal sanctions provided by the program. In comparison to the Kentucky teachers, the Charlotte-Mecklenburg teachers perceived a much greater probability of receiving a bonus if school goals were met, and they perceived a much lower probability of experiencing sanctions if the goals were not met.

In another set of analyses, we correlated probability perceptions with teachers' age, years of experience, salary, school level, school's percent of students receiving free and reduced-price lunch, and whether a school met its goals in the previous award cycle. Most of these correlations were not statistically significant, and those that were significant were small (for example, $r<15$ ). The one exception was a moderate and significant correlation between the probability of winning a bonus for meeting school goals and whether the school had met its goals (and teachers earned bonuses) in the previous award cycle $(\mathrm{r}=.23$ for Charlotte-Mecklenburg teachers, $\mathrm{r}=.30$ for Kentucky teachers, $\mathrm{p}<.05)$.

The interview and survey findings converge and complement one another. The most striking finding in both Charlotte-Mecklenburg and Kentucky was the relatively low perceived probability of receiving a bonus even if school goals had been met. Moreover, there was only a small correlation between perceived probability of receiving the bonus for achieving the goals and having received a bonus in the past award cycle. These findings suggest a possible lack of credibility of the bonus portion of the programs. Even reaching goals and winning bonuses in the previous cycle was not a very strong influence on believing that history would indeed repeat itself. A second striking finding was that Kentucky teachers, relative to Charlotte-Mecklenburg teachers, perceived much greater probabilities of occurrence of negative outcomes if they tried to meet the goals. Putting in more hours and more pressure and stress were seen as more likely than any of the positive outcomes. Kentucky teachers also saw a higher probability of sanctions for poor performance than Charlotte-Mecklenburg teachers, reflecting the stronger sanctions provided by the Kentucky program. Kentucky teachers appear to have gotten the message of the potential sanctions. Coupled with the low rated desirability of these outcomes, the perceived connection between not improving and sanctions confirms their potential motivating power in Kentucky.

\section{Expectancy Perceptions}

Interview data from Kentucky and Charlotte-Mecklenburg suggest that characteristics of individual teachers and schools have an important effect on the level of teacher expectancy (the belief that teacher effort will lead to meeting program goals) and school success. When present, these characteristics, which we call "enabling conditions," provide organizational contexts that can foster high levels of expectancy and high achievement gains. The interview data from Kentucky revealed that award schools differed from non-award schools in some important ways. Award schools shared the following perceived enabling conditions: high teacher and principal expectancy perceptions, principal and district support for the goals of the program, high quality professional development linked with the accountability program, meaningful collaboration among teachers, and connections to external professional communities. In non-award schools, teachers and principals tended to have lower expectancies about their efforts leading to success and multiple or conflicting goals that competed with the goals of the accountability program (Kelley, 1998a). 
The teacher surveys administered in Charlotte-Mecklenburg and Kentucky were designed to further illuminate important organizational conditions that contribute to teacher expectancy. We measured both individual teacher expectancy and teacher group expectancy. Individual teacher expectancy is the extent to which a teacher believes that her own effort will result in achievement of school accountability goals. Teacher group expectancy is the extent to which an individual teacher believes that she and her colleagues working together can achieve the school accountability goals. We measured these constructs by asking teachers to estimate the probability that if they (or they and their colleagues) worked hard, the school would achieve its goals to the extent needed to earn the performance award. The correlation between the two measures of expectancy was .88 in Charlotte-Mecklenburg and .69 in Kentucky. Table 7 shows the average expectancy scores for Charlotte-Mecklenburg and Kentucky teachers.

Table 7. Average Individual and Group Expectancy: Kentucky and Charlotte-Mecklenburg Teachers

\begin{tabular}{lcccc}
\hline & $\begin{array}{c}\text { Charlotte } \\
\text { Average* }^{*}\end{array}$ & $\begin{array}{c}\text { Charlotte } \\
\text { Std. } \\
\text { Deviation }\end{array}$ & $\begin{array}{c}\text { Kentucky } \\
\text { Average * }\end{array}$ & $\begin{array}{c}\text { Kentucky } \\
\text { Std. } \\
\text { Deviation }\end{array}$ \\
\hline Individual Expectancy-Achieve Award & 55.6 & 29.5 & 39.2 & 26.8 \\
Group Expectancy-Achieve Award & 62.0 & 29.1 & 52.7 & 27.3 \\
\hline
\end{tabular}

Response scale ranged from 0 (Highly Unlikely) to 100 (Highly Likely) in 10 point steps.

All differences between comparable Charlotte-Mecklenburg and Kentucky averages are statistically significant at the .05 level or beyond

Neither individual nor group expectancy levels were particularly high in either jurisdiction, but the averages were considerably lower in Kentucky. In Kentucky, teachers on the average did not see even a 50 percent probability that if as an individual they tried, their school would achieve a level of student performance necessary to achieve reward status. They were more positive, however, about the likelihood that if they and their colleagues worked hard together, their school would achieve reward status. Because sanctions were an important issue in Kentucky, we also asked our Kentucky respondents about their expectancy of achieving a performance level sufficient to avoid sanctions. The average probability that individual effort would lead to sufficient performance to avoid sanctions was 44.5 percent, and the average group expectancy probability was 60.9 percent. These averages were not all that much higher than those for reward-winning performance. Because avoiding sanctions required only maintaining last cycle's performance level, this suggests that many Kentucky teachers had serious doubts about the relationship between their efforts and student achievement.

\section{Explaining Teacher Expectancy Perceptions}

We found that the level of expectancy varies greatly across teachers. According to our motivational model, potential determinants of teacher expectancy include both teachers' assessments of their competencies and their assessments of whether important enablers were present. We used the survey responses to explore the degree to which these factors influenced teacher expectancy in Kentucky and Charlotte-Mecklenburg (see also Kelley, 1998a). Four kinds of factors were used to try to explain expectancy perceptions: school characteristics, organizational context, teacher attitudes, and teacher characteristics representing competencies. School variables were included to control for the effect of differences in school level and prior experience with the reward program (achieving award status or not), school size, and the percent of students receiving free or reduced-price lunch. 
Organizational context variables included feedback, alignment, professional community, teacher participation in decision-making, principal support, and goal conflict. All context variables represented equivalent constructs across jurisdictions, except that we added more professional community items to the Kentucky survey, and these were included in an alternative professional community variable for the Kentucky analysis. Teacher attitude variables included teacher perceptions of program fairness and goal clarity. Teacher competency variables included years of teaching experience and highest level of education completed. A description of the items included in the various scales used in the analysis is found in Technical Appendix Table A5.

Tables 8 and 9 present the results of the regression analyses for individual and group expectancy in Charlotte-Mecklenburg and Kentucky. (Means, standard deviations, and intercorrelations of the variables can be found in Technical Appendix Table A6.) Variables found to have a significant effect on expectancy in both jurisdictions include feedback, goal conflict, school management, leadership and culture, and the perceived fairness of the program. Professional community was measured in two ways in the Kentucky analysis. In Table 9, results of two alternative analyses are reported, each using a different version of the professional community variable. The variable labeled "Community (a)" was a single-item that was the same as used in the CharlotteMecklenburg analysis, while that labeled "Community (b)" was a multiple item measure drawn from the work of Newman and Associates (1996).

Table 8. Regression Estimates (Standardized Coefficients) of the Effects of Factors Affecting Individual and Teacher Group Expectancy Perceptions in Charlotte-Mecklenburg's School-Based Performance Award Program ( $\mathrm{N}=900)$

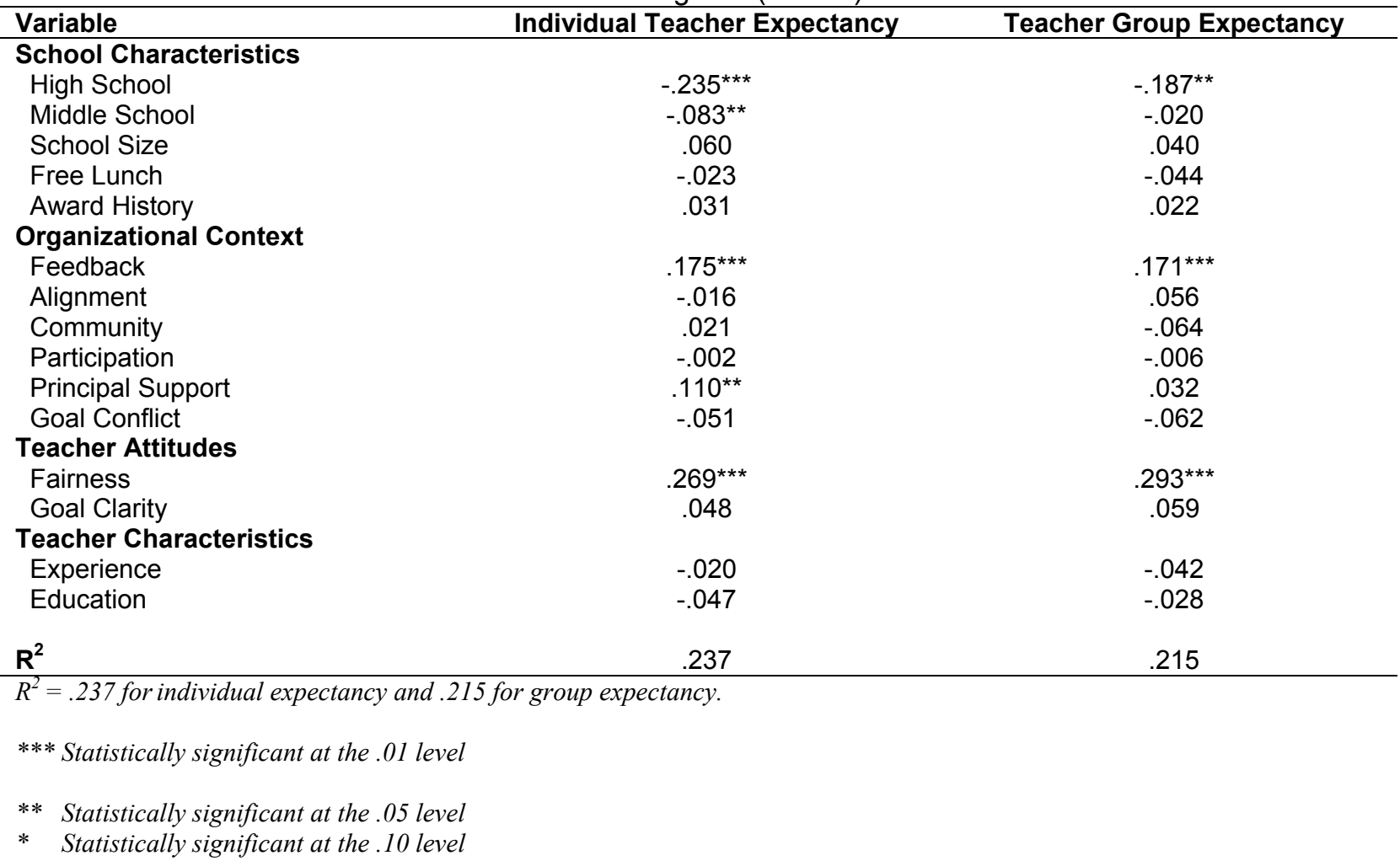


Among the organizational context variables, feedback had the strongest effect on individual teacher and teacher group expectancy. Feedback involves the receipt of the results of past assessments, and capacity to interpret and use this information to refine curriculum and instructional programs. Goal conflict had a consistently significant dampening effect on individual teacher and teacher group expectancies. Goal conflict is the presence of organizational goals that compete with the goals of the accountability program. Competing goals can have a variety of sources. During our interviews, we found that schools with academic programs ranging from very weak to very strong had other goals besides doing well in the accountability program. For example, teachers in magnet schools indicated that the presence of a strong magnet emphasis limited their ability to focus on the goals of the accountability program.

School management, leadership, and culture variables also had important effects on individual teacher, and teacher group expectancies. Principal support had a positive effect on expectancies in Charlotte-Mecklenburg, and professional community had a positive effect in Kentucky. Professional community may have a stronger impact in Kentucky because the accountability program had a slightly different focus. Some of the goals in Charlotte-Mecklenburg involved making structural changes, such as increasing course enrollments in higher level courses. High levels of professional community may not be required to successfully accomplish this type of goal.

Table 9. Regression Estimates (Standardized Coefficients) of the Effects of Factors Affecting Individual and Teacher Group Expectancy Perceptions in Kentucky's School-Based Performance Award Program

$(\mathrm{N}=1,384$ or 1,393$)$

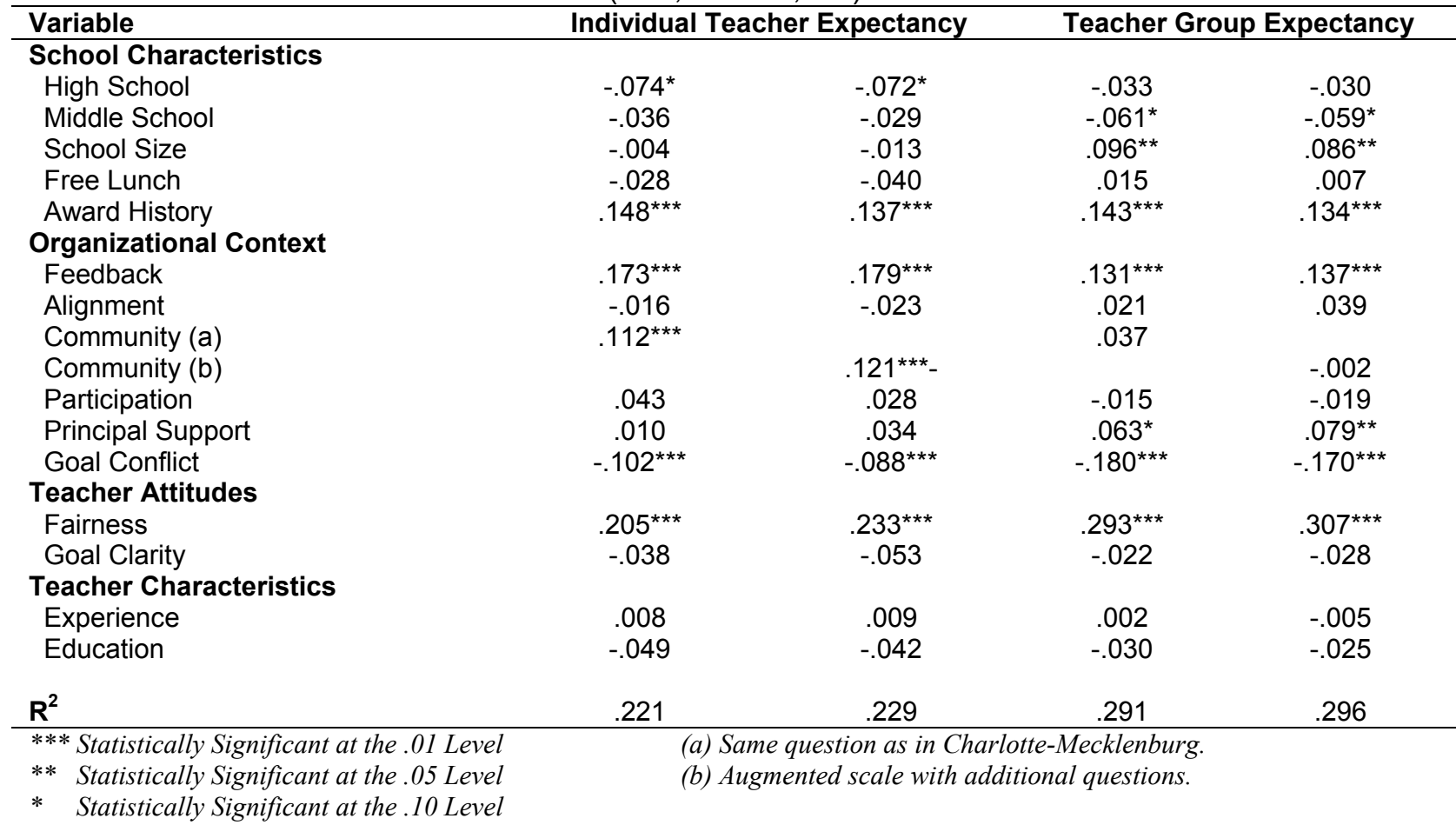

Among the teacher attitude variables, perceptions of program fairness was a strong predictor of expectancy. The fairness variable reflected the perception that the program was administered fairly and that each school had an equal chance of doing well in the program. Fairness responses may be important because they reflect teacher attitudes about the quality of the program and about how well the system as a whole can perform in meeting or exceeding accountability pro- 
gram goals. The importance of the fairness variable suggests that communication and teacher involvement may be key factors to consider in developing award programs to ensure that teachers understand and are comfortable with the rules of the game. Measures of goal clarity, alignment, and student socioeconomic status were not found to be significant predictors of teacher expectancies, nor were our measures of teacher competency, experience, and education level.

Student socioeconomic status may be less important as a predictor of expectancy in these programs because, by design, they define school goals in terms of improvement, so low socioeconomic status schools do not have to produce the same absolute student achievement as high socioeconomic status schools.

Further study is needed to better understand the importance of some of these variables. For example, goal clarity and alignment may be very important influences on teacher expectancy, but they may not have shown up strongly in these analyses for two reasons. First, alignment and clarity are correlated with each other and with many of the other enabling conditions making it hard to get a precise estimate of their effects. Second, a relatively high level of clarity and alignment may be present in most schools due to the communicative effect of school-based performance awards themselves (Kelley, 1998b), the efforts both jurisdictions made to communicate about the program, and the pressure placed on schools to align their programs to these goals. If most schools already have fairly high levels of alignment and clarity, then their effects would not show up strongly here, unlike a study that compared expectancies across accountability programs with and without an award component. There also is a need for better measures of teacher knowledge and skills, which theory suggests would influence expectancy perceptions. Years of experience and education credits and degrees, as used here, are probably weak proxies for actual skills (Odden and Kelley, 1997).

In sum, we found in both qualitative and quantitative data analyses that higher expectancy occurs when organizational incentives, resources, and values are aligned with the goals of the accountability program.

\section{The Motivational Role of the Bonus}

Because of the central role of bonuses in school-based performance award programs and the lack of evidence available about their motivational impact on teachers, we explored teachers' reactions to the bonuses in depth. From our interviews with teachers in the three jurisdictions, we learned that:

- Teachers felt it was appropriate for teachers and classified staff to receive bonuses and that receiving a bonus was deserved.

- Teachers had differing reactions to the size of the bonus. Some thought the bonus amounts were significant and meaningful, while others described them as inadequate after deductions for taxes (especially in Charlotte-Mecklenburg) or in relation to the amount of additional work required to earn the bonus (especially in Kentucky). 
- $\quad$ Teachers had varying views about how much the possibility of earning a bonus motivated them to improve student achievement or whether a larger bonus would motivate them more.

- $\quad$ Teachers were skeptical that earned bonuses would actually be paid due to past experiences with undelivered bonus payments. They had doubts about whether the funding for the bonuses would be continued and doubts about policymakers' continued commitment to the program.

- $\quad$ Teachers differed as to whether they wanted the bonus part of the program to continue.

- $\quad$ The meaning of the bonus varied. For some, it was a 'thank you,' or a formal recognition. For others, it was a reward that allowed for the purchase of desired goods, and for still others, it was simply irrelevant.

- $\quad$ Teachers in Kentucky said that having to decide how to allocate the award money among teachers and staff was a divisive process that created tension within and between schools. (See also Abelmann and Kenyon, 1996.)

- $\quad$ Awards paid as salary bonuses appeared to have more visibility than awards paid as school improvement funds. Of the three programs studied, teachers in Maryland were the least cognizant of the award program and least likely to report that they felt job pressure and stress as a result of the program.

These interview findings, in combination with the survey findings that teachers valued the potential bonuses while having doubts about receiving them even if school goals were met, suggested that teachers' reactions to the bonus per se and to the award program as they experienced it were complex. Moreover, there were clearly strong differences in reactions among teachers to all facets of the programs. To delve more deeply into the nature and causes of these reactions, and into possible teacher decisions to withdraw from being a part of a school-based performance award program, we conducted two additional sets of analyses. The first sought to predict teachers' overall responses to the bonus program in terms of their level of motivation, whether they felt the bonus part of the accountability program should continue, and their probability of withdrawing from the program in various ways. The independent variables pertained primarily to various elements of perceived fairness of the program. These analyses, described in more detail in Heneman and Milanowski (1999), were conducted using the survey responses of a subset of Kentucky teachers. We conducted a second set of analyses using Charlotte-Mecklenburg teachers to examine factors predictive of their withdrawal from the program by leaving the district or transferring to another school (see also Heneman and Milanowski, 1998). The independent variables were salary, satisfaction with salary, whether the teacher was working in an award-winning school, the perceived fairness of the bonus, and if the teachers had an intention to leave his or her current job.

\section{Motivational Reactions of a Subsample of Kentucky Teachers}

We randomly selected half of the Kentucky teacher sample to receive additional specific questions about their reactions to the bonus program. (These items are shown in Technical Appendix, 
Table A7.) The first three sets of items bonus motivation, desire to see the bonus continue, and withdrawal intentions constituted the three dependent variables. Bonus motivation and withdrawal intentions were measured on five-point rating scales $(1=$ strongly disagree to $5=$ strongly agree) and summed to form a single scale. Favorability toward bonus continuation was measured on a three point scale ( $1=$ should not continue, $2=$ neutral, $3=$ should continue). The means were 2.30 for bonus motivation, 3.09 for withdrawal intentions, and 2.03 for bonus continuation. The average level of the bonus motivation measure was more than .5 scale points below the 3.0 neutral point. Withdrawal intentions and the desire to see the program continue were slightly above the neutral point. (We also asked similar questions of the other half of the Kentucky teacher sample, and average response levels were similar.)

The independent variables were derived from the literature on distributive justice, procedural justice, and pay satisfaction (see Heneman and Judge, in press, for a review). Distributive justice refers to the fairness of the amount of reward that could be earned. Procedural justice refers to the fairness of the process used to administer the rewards. Pay satisfaction represents feelings about one's actual pay and its fairness. We hypothesized that the distributive justice scales (named "fair bonus," "expected bonus value," and "teachers divide" in Table 10) and procedural justice scales (fair chance, fair process, principal communication) would be positively related to bonus motivation and desire to see the bonus continue, and would be negatively related to withdrawal intentions. We hypothesized that the other procedural justice scale, unfair winners, would be negatively related to bonus motivation and bonus continuation, and positively related to withdrawal intentions. Pay satisfaction was measured by the pay level scale of the Pay Satisfaction Questionnaire (Heneman and Schwab, 1985). We hypothesized that pay satisfaction would be negatively related to bonus motivation and the desire to see the bonus continue and negatively

Table 10. Effect of Kentucky Teachers' Bonus Attitudes on Their Reported Motivation by Bonus, Support for Bonus Continuation, and Withdrawal Intentions (Standardized Regression Coefficients) $(\mathrm{N}=747$ to 754$)$

\begin{tabular}{|c|c|c|c|}
\hline Independent Variable & $\begin{array}{c}\text { Bonus } \\
\text { Motivation }\end{array}$ & $\begin{array}{l}\text { Bonus Should } \\
\text { Continue }^{a}\end{array}$ & $\begin{array}{c}\text { More Likely to } \\
\text { Withdraw }\end{array}$ \\
\hline Years Experience & $-.173^{* * *}$ & $-.102^{\star *}$ & -.000 \\
\hline Job Satisfaction & -.050 & .043 & $-.272^{* * *}$ \\
\hline Teach a KIRIS subject ( $1=$ yes) & -.026 & .013 & .041 \\
\hline Teach a KIRIS grade ( $1=$ yes) & -.013 & .013 & .066 \\
\hline High School & $.124^{* * *}$ & .054 & .027 \\
\hline Middle School & .031 & $.095^{*}$ & .051 \\
\hline MA Degree or above & $.092^{\star *}$ & -.028 & .020 \\
\hline Cycle 2 Bonus ( $1=y e s)$ & $.093^{* *}$ & .089 & .031 \\
\hline Pay Satisfaction & $-.188^{* * *}$ & $-.165^{\star \star *}$ & .001 \\
\hline Fair Bonus & $.266^{\star * \star}$ & $.621^{* * *}$ & .015 \\
\hline Expected Bonus Value & .050 & $.079^{*}$ & .033 \\
\hline Unfair Winners & .020 & -.062 & $130^{\star * *}$ \\
\hline Fair Chance & .014 & .077 & $-.091^{\star *}$ \\
\hline Fair Process & $.092^{*}$ & $.283^{\star \star *}$ & $-.237^{\star \star *}$ \\
\hline Teachers Divide & $.133^{* * *}$ & $.153^{\star * *}$ & -.006 \\
\hline Principal Communication & $-.138^{\star \star *}$ & -.067 & -.017 \\
\hline $\mathrm{R}^{2}$ & .220 & .275 & $.458^{\mathrm{b}}$ \\
\hline $\begin{array}{l}* \quad \text { significant at the } .10 \text { level } \\
* * \quad \text { significant at the } .05 \text { level }\end{array}$ & $\begin{array}{l}\text { gistic regre } \\
\text { based on t }\end{array}$ & $\begin{array}{l}\text { tially standardize } \\
\text { ood ratio }\end{array}$ & ients \\
\hline
\end{tabular}


related to withdrawal intentions. To help avoid the possibility of spurious correlations between the independent and dependent variables, we incorporated several control variables into the analysis. These variables included years of experience, overall job satisfaction, whether the respondent taught a KIRIS subject, taught a KIRIS grade, was a high school or middle school teacher, whether the respondent held a master's degree or above, and whether the school earned a bonus in last cycle. Means, standard deviations, and intercorrelation for the variables are shown in Technical Appendix Table A8. Regression results are presented in Table 10.

These analyses produced several significant results. The teachers most motivated by the bonus were those who were dissatisfied with their current salary, felt the bonus amount was fair, felt the bonus process was fair, felt teachers should divide the bonus money, and perceived less communication from the principal. Teachers in favor of seeing the bonus program continue also were more dissatisfied with their current salary, saw a high expected bonus value, felt that the bonus process was fair, felt that the bonus itself was fair, and felt that teachers should divide the bonus money. With the sole exception of the finding about principal communication, all of these results were as hypothesized. It should be noted, however, that no significant results were obtained for the unfair winners and fair chance variables.

Teachers were most likely to intend to withdraw (leave their school or leave teaching) if they perceived there were unfair winners, that the process was not fair, and that their school did not have a fair chance of winning. Surprisingly, pay satisfaction, did not significantly relate to withdrawal intentions.

To summarize, we found that the Kentucky teachers on average did not report being highly motivated by the bonus program, but were more neutral in their intentions to withdraw from the program and in their desire to see it continue. These data, however, were collected at a time of contention and uproar about the KIRIS program (Blackford, 1997; Lawton, 1997; Strecklow, 1997), and it is unknown whether more favorable attitudes would have been expressed had the data been collected earlier. There was considerable variability in teachers' overall attitudes about Kentucky's bonus program, and several hypothesized factors accounted for a significant portion of this variability. Teachers were more motivated by the program and wanted it to continue if they were dissatisfied with their current salary, felt that the use of bonuses and the process of awarding them were fair, and felt that teachers should decide how to divide up the bonus money. A different set of factors were related to teachers' withdrawal intentions. Teachers were more likely to want to withdraw from their current school because of perceived unfairness in how the bonus program was run, an unfair chance for their school to meet its goal, and the existence of unfair winners.

\section{Teacher Withdrawal in Charlotte-Mecklenburg}

In response to dissatisfaction with their compensation experiences, teachers may opt to withdraw from their current job by leaving the district altogether (turnover) or by transferring to another school within the district (transfer). Compensation experiences encompass both current base pay and the bonus earned under the award program. To evaluate the impacts of these compensation experiences on these two forms of withdrawal, we gathered turnover and school transfer data from the Charlotte-Mecklenburg personnel data base in September, 1997, roughly five months after the teacher surveys had been completed. We then used the survey data to predict whether 
teachers left the district $(1=$ yes $)$, or transferred schools $(1=$ yes $)$ using logistic regression analysis. We used five independent variables, four pertaining to compensation experiences and one pertaining to an overall intention to leave the current job and school for any reason, not just compensation experience. The first two variables were annual pay and an average of the three pay level items of the Pay Satisfaction Questionnaire (Heneman and Schwab, 1985). The second two variables were whether the teacher was working in a school that had earned an award in the previous year $(1=$ yes $)$ and a rating ( 1 to 5$)$ of the fairness of the bonus amount that could be received under the award program. The last variable was intent to leave, measured as the sum of the ratings ( 1 to 5 ) of the likelihood the teacher would leave because of the award program in order to pursue each of five alternatives (transfer to an award school, leave school for new teaching job, take an administrative job, leave for a job outside of teaching, retire). We controlled for several variables that might co-vary with withdrawal decisions: years in current job, age, gender, minority status, possession of an advanced degree, whether the teacher taught math or science, school level, and percentage of the school's students receiving free or reduced price lunch.

Means and standard deviations of the variables are shown in Technical Appendix Table A9. The total turnover rate was 19 percent with 11 percent due to school transfers and 8 percent due to leaving the district. The average pay level was $\$ 29,660$ and the average satisfaction with pay level was quite low (mean =1.61). On average, the teachers neither agreed nor disagreed that the amount of the bonus they could earn was fair $($ mean $=3.11)$, and 51 percent of the teachers worked in a school that had won an award the previous year. The average intent to leave one's current job within the next two years because of the award program (mean = 2.61) was slightly below the scale midpoint.

Logistic regression results are shown in Table 11 for each of the three dependent variables total turnover (leaving the district or transferring between schools), leaving the district, and transferring between schools.

Pay level was negatively related to all three types of turnover, though the coefficients in the analyses of leaving the district and transferring between schools just missed being significant. There was an unexpected positive, significant coefficient for pay level satisfaction on total turnover and leaving the district. Non-bonus schools had significantly more total turnover due to a greater number of teacher transfers out of those schools. Intent to leave within the next two years because of the award program had the strongest impact of all the variables on total turnover, leaving the district, and transferring schools.

It is important to note that the obtained relationships between withdrawal and the other variables are probably underestimates of their true magnitude for two reasons. First, there was decided restriction of range on the withdrawal measure that leads to a ceiling on the possible size of the correlations that may be obtained. Second, there was probably some sample selection bias because some unknown number of teachers who felt adversely affected by the Benchmark Goals Program in earlier time periods may have already left the district or had already transferred to a more satisfying school within the district. 
Table 11. Effect of Compensation Variables on Teacher Turnover in Charlotte-Mecklenburg $(\mathrm{N}=1,150)$

\begin{tabular}{|c|c|c|c|c|c|c|}
\hline \multirow[b]{2}{*}{ Variable } & \multicolumn{2}{|c|}{ Total Turnover } & \multicolumn{2}{|c|}{ Leave the District } & \multicolumn{2}{|c|}{$\begin{array}{c}\text { Transfer Between } \\
\text { Schools }\end{array}$} \\
\hline & $\begin{array}{c}\text { Standardized } \\
\text { Coefficient }\end{array}$ & $\begin{array}{l}\text { Odds } \\
\text { Ratio }^{(a)}\end{array}$ & $\begin{array}{c}\text { Standardized } \\
\text { Coefficient }\end{array}$ & $\begin{array}{l}\text { Odds } \\
\text { Ratio }^{(a)}\end{array}$ & $\begin{array}{c}\text { Standardized } \\
\text { Coefficient }\end{array}$ & $\begin{array}{l}\text { Odds } \\
\text { Ratio(a) }^{(a)}\end{array}$ \\
\hline Yrs in Current Job & $-0.13^{* *}$ & 0.785 & -0.05 & 0.914 & $-0.17^{\star *}$ & 0.738 \\
\hline MA \& MS or More $(0 / 1)$ & 0.00 & 1.004 & -0.05 & 0.824 & 0.04 & 1.159 \\
\hline Age & -0.01 & 0.999 & $-0.15^{\star}$ & 0.765 & 0.09 & 1.188 \\
\hline $\begin{array}{l}\text { Teach Science or Math } \\
(0 / 1)\end{array}$ & 0.07 & 1.567 & -0.04 & 0.769 & $0.11^{* * *}$ & 2.048 \\
\hline High School (0/1) & 0.06 & 1.463 & -0.07 & 0.619 & $0.13^{* *}$ & 2.257 \\
\hline Middle School (0/1) & 0.06 & 1.358 & 0.04 & 1.186 & 0.08 & 1.428 \\
\hline Gender $(0 / 1, F=1)$ & -0.01 & 0.957 & -0.03 & 0.823 & 0.01 & 1.087 \\
\hline Minority $(0 / 1)$ & 0.00 & 0.985 & 0.00 & 1.018 & 0.00 & 0.968 \\
\hline $\begin{array}{l}\text { Percent Free/ } \\
\text { Reduced Price Lunch }\end{array}$ & $0.12^{\star \star *}$ & 1.237 & 0.02 & 1.033 & $0.17^{* * *}$ & 1.354 \\
\hline Pay Level & $-0.12^{*}$ & 0.806 & -0.13 & 0.788 & -0.10 & 0.837 \\
\hline $\begin{array}{l}\text { Pay Level } \\
\text { Satisfaction }\end{array}$ & $0.09^{* *}$ & 1.171 & $0.13^{* *}$ & 1.266 & 0.03 & 1.058 \\
\hline $\begin{array}{l}\text { Teach in Bonus School } \\
(1=\text { Yes })\end{array}$ & $-0.08^{*}$ & 0.755 & 0.03 & 1.112 & $-0.14^{* * *}$ & 0.599 \\
\hline $\begin{array}{l}\text { Fair to Receive } \\
\text { Bonus }\end{array}$ & -0.03 & 0.951 & -0.01 & 1.002 & -0.05 & 0.911 \\
\hline Intent to Leave & $-0.24^{\star \star \star}$ & 1.804 & $0.29^{* * *}$ & 1.691 & $0.17^{* * *}$ & 1.350 \\
\hline Pseudo $\mathrm{R}^{2}$ & .100 & & .093 & & .082 & \\
\hline
\end{tabular}

(a) For 0/1 variables, the odds ratio is the change in the odds of leaving the district or transferring associated with the variable taking on a value of 1 . For the others, it is the change in odds associated with a one standard deviation increase in the value of the variable. An odds ratio greater than 1 indicates a increased chance of leaving the district or transferring. An odds ratio less than 1 indicates an decreased chance of leaving the district or transferring.

We offer the following interpretation of these results (also discussed in Heneman and Milanowski, 1998). Pay level appeared to influence both leaving the district and transferring between schools, whereas being in a bonus school influenced only transferring. This suggests that teacher withdrawal generally is more heavily influenced by base pay, which makes up 96 percent or more of their total pay, than by the bonus or other rewards associated with working in a bonus-winning school. Subjective reactions to pay level, as well as objective pay level, is important to account for teachers' withdrawal responses, since satisfaction with pay level was also significantly related to leaving the district. However, the relationship was unexpectedly positive, so that even after controlling for the numerous factors that might covary with either variable, teachers more satisfied with their pay level were more likely to leave the district. This puzzling result might be due to a subgroup of teachers who used a noncompensatory model to evaluate and respond to the totality of their terms and conditions of employment. That is, these teachers may have been satisfied with their base pay, but not other attributes of their job, and the pay could not or did not compensate for these other attributes, so they left the district.

Support for this interpretation comes from responses of Charlotte-Mecklenburg teachers in the interviews previously described. In response to questions about the Benchmark Goals Program and their possible bonus, many teachers spoke in very harsh terms about these matters (Heneman, 1998). While teachers generally valued the focus and challenge of the student achievement goals, many felt extreme pressure to achieve the goals and reported that they were working more 
hours (during the day or on weekends) in order to change what and how they taught in order to reach the goals. These teachers frequently mentioned increased stress when asked to describe how their jobs had changed for the worse under the Benchmark Goals Program. In short, these teachers did not view the new effort/pay level 'bargain' as a 'good deal,' regardless of whether or not they were working in an award winning school, and thus they may have chosen to leave the district.

This interpretation is consistent with the unfolding model of turnover proposed by Lee and Mitchell (1994). They hypothesize that some turnover is due to the employee experiencing a shock (such as the Benchmark Goals Program), which leads to one of four distinct quitting processes or paths. The paths differ in large part according to whether the employees quit with external job alternatives known (a pull process) or without job alternatives known (a push process). Based in part on the unfavorable comments about the Benchmark Goals Program made by some teachers in the interviews, we speculate that the teachers who left the district and were relatively satisfied with their base pay were likely on a push path. Additionally, leaving the district to teach in another district would require finding a job outside of the county in a smaller district with fewer job alternatives, accepting base pay likely to be the same or less than current base pay, and being willing to relocate to take the job. These factors mitigate against a strong external pull explanation. Finally, the teachers most likely to be marketable and pulled away from teaching altogether are those with advanced degrees and teaching math or science subjects, but the coefficients for these control variables were not significant, again suggesting little labor market pull on teachers to leave the district.

Teaching in a school that had received bonuses did not influence a decision to leave the district, but it did reduce the probability of transfer, implying that teachers tend to transfer out of nonaward schools (presumably to an award-winning schools, though we could not determine that from the data base). This finding would be explained by a lack of external job alternatives, a desire to remain in teaching, and wanting to work in the more positive work environment more likely to be found in award-winning schools. Such a positive work environment is probably made up of a constellation of both extrinsically rewarding job attributes (for example, receiving the bonus, pride in achieving goals, and public recognition) and intrinsically rewarding attributes (such as autonomy and coworker supportiveness). At least for some teachers, escaping nonaward-winning schools was important, though it is not possible to say how much of this was due to not receiving the bonus or other positive outcomes and how much was due to other working conditions that might be associated with not achieving award status. To control such withdrawal, it would be advisable for a district using school-based performance awards to take steps to improve schools' chances of being award winners.

The perceived fairness of the amount of the bonus that could be won had no impact on withdrawal. Perhaps this reflects the relatively small size of the bonus, so that the bonus was not a "noticeable difference" to teachers relative to other job attributes and thus was not a reward that by itself would cause withdrawal, regardless of how fair it was perceived to be. It is possible that perceived bonus fairness would have had a larger impact on withdrawal decisions had the bonus been larger. 
The most important predictor of both leaving the district and transferring to other schools in our models was intent to leave in reaction to experiences with the Benchmark Goals Program. The multiple outcomes (besides bonus) associated with the Benchmark Goals Program, and teachers' previously noted reactions to these outcomes, undoubtedly carried over into the formation of withdrawal intentions. In short, pay level satisfaction, being in a school that did not win an award, and intent to leave because of experiences with the awards program all played a role in teachers' decisions to leave the district or transfer between schools within the district.

\section{Teacher Perceptions of Program Fairness}

In the interviews, teachers often identified program design and context factors that they felt made the awards program less fair (see Heneman, 1998; Kelley, 1998a; Kelley and Protsik, 1997). Teachers and principals in some schools said that it was unfair to put so much pressure on the teachers in the assessment subjects and grade levels, although this became less of an issue in Kentucky when the state split the assessment across six instead of three grade levels. Teachers in some Kentucky schools did not clearly understand how school goals were set, and some lacked confidence in the validity and reliability of the assessment instrument. In CharlotteMecklenburg, teachers in a magnet school expressed concern that the goals of the school-based performance award program differed from the goals of the magnet program. Although teachers generally agreed that it was fair to hold them accountable for student performance (Heneman, 1998), some felt that differences across schools made it harder or easier to improve performance. Teachers said that high student mobility, high at-risk student populations (due to learning disabilities or low socioeconomic status of students) made it difficult for them to improve student performance (Kelley and Protsik, 1997). Teachers in the higher grade levels sometimes expressed concern about low student motivation to perform well on the assessment. Teachers in the most successful schools were somewhat less likely to mention fairness as a problem. Teachers and principals in these schools acknowledged issues such as mobility and student motivation, but they tended to mention actions taken to address these issues, rather than to dwell on them as insurmountable barriers to meeting their schools' goals. Principal leadership seemed to be critical in shaping and addressing teacher concerns about fairness (Kelley, 1998a).

By including in our survey a set of items dealing with the fairness of various aspects of schoolbased performance award programs, we were able to follow up on the fairness issues raised in the interviews. Table 12 presents the means and standard deviations for the teacher responses to these items. (Appendix Table A10 shows the items combined to form scales and the internal consistency reliabilities.)

While Charlotte-Mecklenburg teachers, on the average, expressed weak agreement that it is fair to hold teachers accountable for student achievement and fair for teachers who increase student achievement to receive a bonus, Kentucky teachers on the average disagreed with both ideas. Teachers in both jurisdictions were just below the neutral point as to whether they felt their school had a fair chance of winning the award. Teachers in both jurisdictions disagreed, on average, that the program was run in a fair way. As might be expected, teachers in schools that had consistently won awards had more positive perceptions of fairness than teachers in schools that had never won or had won only once, like in Charlotte-Mecklenburg. However, the differences in means were only about .2 to .4 scale points, and even for teachers in schools that had been consistent winners, the averages for the program fairness scale were still below the neutral point 
in both jurisdictions. This suggests that many teachers had reservations about the fairness of the way the programs were run. Since we found evidence, discussed earlier, that perceptions of fairness are important determinants of teacher expectancy, these perceptions of unfairness may have limited the motivational impact of the programs we studied.

Table 12. Teachers' Perceptions About the Fairness of the School-Based Performance Award Programs

\begin{tabular}{lcccc}
\hline Item & $\begin{array}{c}\text { Charlotte } \\
\text { Mean }^{\mathbf{a}}\end{array}$ & $\begin{array}{c}\text { Charlotte } \\
\text { Standard } \\
\text { Deviation }\end{array}$ & $\begin{array}{c}\text { Kentucky } \\
\text { Mean }^{\mathbf{a}}\end{array}$ & $\begin{array}{c}\text { Kentucky } \\
\text { Standard } \\
\text { Deviation }\end{array}$ \\
\hline $\begin{array}{l}\text { Fair to hold teachers accountable for } \\
\text { student achievement. }\end{array}$ & 3.3 & 1.1 & 2.5 & 1.2 \\
$\begin{array}{l}\text { Fair for teachers who increase student } \\
\text { achievement to get a bonus. }\end{array}$ & 3.6 & 1.1 & 2.8 & 1.2 \\
$\begin{array}{l}\text { School has a fair chance to win award } \\
(2 \text { item scale). }\end{array}$ & 2.8 & 1.2 & 2.9 & 1.1 \\
$\begin{array}{l}\text { Program is procedurally fair } \\
(3 \text { item scale). }\end{array}$ & 2.6 & 0.9 & 2.4 & 0.9 \\
\hline $\begin{array}{l}\text { (a) Response scale was } 1=\text { Strongly Disagree...5=Strongly Agree. } \\
\text { All differences between comparable Charlotte-Mecklenburg and Kentucky averages are statistically significant at the .05 level or } \\
\text { beyond. }\end{array}$ &
\end{tabular}

\section{DOES TEACHER MOTIVATION AFFECT SCHOOL PERFORMANCE?}

In addition to looking at how school-based performance award programs affect individual teacher's motivation, it is important to explore whether teachers' motivation affects subsequent school performance, as defined by the particular award program. To investigate this, we averaged the teachers' motivational responses assessed during the accountability cycle within each school, then used these school averages to predict subsequent school performance on the accountability indices at the end of the cycle. Based on our motivational model, we expected that the greater the average teacher motivation, the greater the school's success in improving student achievement levels.

\section{Variables}

We calculated school-level averages of teachers' individual expectancy perceptions and the expected value of outcomes (desirability times probability of occurrence) in order to represent the average level of teacher motivation at each school. The expected value of the bonus alone was calculated, along with a summed expected value for each of the four outcome groupings presented in Table 5 on page 16: goal attainment, learning, sanctions, and stress. Individual scores were then averaged across teachers within each school.

Whenever individual-level data are aggregated to form a score representing a higher-level entity such as a school, we need to be concerned about the degree of agreement in the individual responses that are averaged. When using the within-school averages of teachers' ratings of their motivational responses to represent the average level of motivation within each school, within- 
school variability in individual teachers' responses leads to sampling error in the estimate of each school average. This is a form of unreliability that is likely to have attenuated the relationships between the school-level averages of the motivational constructs and the measures of school performance. The issue of within-school variability is discussed further in the Technical Appendix.

We defined school performance using the same measures each program used to provide rewards and sanctions to teachers and schools. For Charlotte-Mecklenburg schools, performance was defined by the number of Benchmark Goals points each school achieved in the 1996-97 school year, as reported by the district. For Kentucky, the indicator was the change in the KIRIS index between the baseline (essentially the KIRIS index from Cycle 2) and the index for Cycle 3 (consisting of the average of the 1997 and 1998 indices). We obtained these data from the Kentucky Department of Education.

It should be noted that in neither jurisdiction was the school performance measure a simple improvement in test scores. These performance measures were indices that summarize performance on several dimensions and represented the particular jurisdictions' definition of school performance, rather than being a standardized measure of student achievement. Charlotte-Mecklenburg schools earned Benchmark Goals points not only by improving average scores on a wide variety of state and district assessments but also by maintaining desired levels already achieved. For a typical elementary school, approximately 62 percent of the maximum possible points could be earned by improving test scores, 36 percent by improving primary grade readiness assessments, and 2 percent by reducing absenteeism. For a typical high school, 60 percent of the points were related to improvement in test scores, 29 percent to enrollment in higher level classes, and 11 percent to reduction of absenteeism and dropout rates. Similarly, Kentucky's KIRIS index was based on test scores in several subjects (actually on the percentage of students scoring within certain proficiency ranges on tests) and on indicators like dropout and retention rates. In calculating the KIRIS index, improvements in student academic proficiency were given approximately 84 percent of the weight while the other indicators were given approximately 16 percent. The state administered rewards and sanctions based on changes in the KIRIS index. Because of the unique features and complex construction of each index, each represents a more complex concept of school performance than, for example, scores on the National Assessment of Educational Progress tests do. In our research, we have accepted each jurisdiction's definition of school performance. The school performance measures are best thought of as indicating the degree to which schools attained the goals the award programs set for them.

In the following analyses, we controlled for certain school characteristics that might affect how well schools did on the accountability indices. These included school size (represented by the natural $\log$ of enrollment), and the percentage of students receiving free and reduced-price lunch. For the Kentucky analysis, we included the value of the Cycle 2 KIRIS index because it might have been easier for schools with relatively low levels on the Cycle 2 index to improve enough to be a reward school than it was for schools with higher levels on the index. In CharlotteMecklenburg, many of the improvement goals underlying the Benchmark Goals points were adjusted for this possibility, so previous school performance was not used as a control variable. Data for these control variables were provided by the Charlotte-Mecklenburg district and the Kentucky Department of Education. 


\section{Prediction of School Performance}

We used regression analyses to estimate the effect of teacher motivation (as represented by expectancy and the expected value of outcomes) on school performance, controlling for the school characteristics mentioned above. The results are presented in Table 13. (Means, standard deviations, and intercorrelations of the variables are shown in Technical Appendix Table A12.) We estimated six regression models, along with a controls-only model, to reflect the six different treatments of expected value of outcomes (bonus only, goal attainment only, learning outcomes only, sanctions only, stress only, and all types together). These separate analyses allowed us to probe for potentially different effects of each type of outcome. Table 13 presents only results of additive models, since adding multiplicative terms (expectancy times expected value) did not significantly increase variance explained.

Table 13. The Effect of Teacher Expectancy and Expected Outcome Value on School Performance ( $N=114$ Charlotte-Mecklenburg Schools and 204 Kentucky Schools)

\begin{tabular}{|c|c|c|c|c|c|c|c|}
\hline Charlotte-Mecklenburg & $\begin{array}{l}\text { Con- } \\
\text { trols } \\
\text { Only }\end{array}$ & $\begin{array}{c}\text { Value of } \\
\text { Bonus }\end{array}$ & $\begin{array}{c}\text { Goal } \\
\text { Attain- } \\
\text { ment }\end{array}$ & Learning & Sanctions & Stress & $\begin{array}{c}\text { All } 4 \\
\text { Types of } \\
\text { Outcomes }\end{array}$ \\
\hline Log Enrollment & $-.310^{* * *}$ & $-.260^{\star \star \star}$ & $-.252^{\star * *}$ & $-.264^{* * *}$ & $-.276^{\star * *}$ & $-.273^{* * *}$ & $-.293^{* * *}$ \\
\hline $\begin{array}{l}\text { Percent Free/Reduced } \\
\text { Lunch }\end{array}$ & $-.542^{\star \star \star}$ & $-.527^{\star * *}$ & $-.520^{\star * *}$ & $-.487^{* * *}$ & $-.512^{* * *}$ & $-.536^{* * *}$ & $-.486^{\star * *}$ \\
\hline $\begin{array}{l}\text { Expectancy } \\
\text { Expected Value of Bonus }\end{array}$ & & $\begin{array}{l}.239^{* * *} \\
.049\end{array}$ & $.288^{\star * *}$ & $.343^{* * *}$ & $.269^{\star * \star}$ & $.274^{\star \star \star}$ & $.343^{\star * *}$ \\
\hline Goal Attainment Outcomes & & & -.050 & & & & .048 \\
\hline Learning Outcomes & & & & $-.170^{*}$ & & & -.179 \\
\hline Sanctions & & & & & 122 & & .122 \\
\hline Stress Outcomes & & & & & & $-.142^{*}$ & $-.154^{*}$ \\
\hline $\mathrm{R}^{2}$ & .216 & .284 & .284 & .302 & .296 & .302 & .337 \\
\hline Kentucky & $\begin{array}{l}\text { Con- } \\
\text { trols } \\
\text { Only }\end{array}$ & $\begin{array}{c}\text { Value of } \\
\text { Bonus }\end{array}$ & $\begin{array}{c}\text { Goal } \\
\text { Attain- } \\
\text { ment }\end{array}$ & Learning & Sanctions & Stress & $\begin{array}{c}\text { All } 4 \\
\text { Types of } \\
\text { Outcomes }\end{array}$ \\
\hline Log Enrollment & $-.143^{* *}$ & $-.129^{\star \star}$ & $-.142^{* *}$ & $-.145^{\star *}$ & $-.134^{* * *}$ & $-.145^{\star \star}$ & $-.129^{*}$ \\
\hline $\begin{array}{l}\text { Percent Free/Reduced } \\
\text { Lunch }\end{array}$ & $-.484^{\star \star \star}$ & $-.496^{\star * *}$ & $-.512^{\star \star \star}$ & $-.523^{\star \star *}$ & $-.517^{* * *}$ & $-.519^{\star \star *}$ & $-.514^{\star \star \star}$ \\
\hline $\begin{array}{l}\text { Cycle } 2 \text { KIRIS Index } \\
\text { Expectancy-Reward Status }\end{array}$ & $-.601^{* * *}$ & $\begin{array}{l}-.710^{\star * *} \\
.290^{\star * *}\end{array}$ & $\begin{array}{l}-.732^{\star \star \star} \\
.283^{* \star \star}\end{array}$ & $\begin{array}{l}-.740^{* * *} \\
.251^{* * *}\end{array}$ & & $\begin{array}{l}-.728^{* \star *} \\
.266^{* \star *}\end{array}$ & $\begin{array}{l}-.727^{\star * *} \\
.298^{\star * *}\end{array}$ \\
\hline Expectancy-Avoid Decline & & & & & $.222^{\star \star \star}$ & & \\
\hline Expected Value of Bonus & & $-.137^{\star \star}$ & & & & & \\
\hline Goal Attainment Outcomes & & & -.087 & & & & -.140 \\
\hline Learning Outcomes & & & & -.015 & & & .098 \\
\hline Sanctions & & & & & -.068 & & -.082 \\
\hline Stress Outcomes & & & & & & -.088 & -.040 \\
\hline $\mathrm{R}^{2}$ & .283 & .342 & .333 & .328 & .326 & .334 & .345 \\
\hline
\end{tabular}

*** Statistically significant at the .01 level

** Statistically significant at the .05 level

* Statistically significant at the .10 level

While the controls-only model accounted for significant variance in school performance, adding the variables representing teacher motivation significantly increased the proportion of variance explained, indicating that teacher motivation helps predict school performance. In all models, average expectancy had a positive coefficient of substantial magnitude and was significant at the .01 level. Thus, the higher the average teacher expectancy, the more Benchmark Goals points a Charlotte-Mecklenburg school achieved or the greater the increase in the KIRIS index a Ken- 
tucky school achieved. In the Charlotte-Mecklenburg analyses, a one standard deviation increase in average teacher expectancy (where one standard deviation equals 12.88 percentage points on the 0 to 100 percent likelihood scale) was associated with an increase in Benchmark Goal points of .239 to .343 standard deviations, depending on which outcome expected values were also included in the analysis. Since the standard deviation of the Benchmark Goal points was 15.73, the expected effect of a one standard deviation increase in average teacher expectancy was a 3.8 to 5.4 point increase in Benchmark Goal points. In the Kentucky analyses, a one standard deviation increase in average teacher expectancy of achieving reward status (where a standard deviation equals 14.35 percentage points on the 0 to 100 percent likelihood scale) was associated with an increase of .251 to .298 standard deviations on the KIRIS index. Since one standard deviation of the KIRIS index improvements equals 4.70 points, the expected effect of a one standard deviation increase in teacher expectancy was between 1.2 and 1.4 points of improvement on the KIRIS index. A one standard deviation increase in average teacher expectancy of avoiding a decline in the KIRIS index, which could lead to sanctions (where a standard deviation equals 12.20 percentage points on the 0 to 100 percent likelihood scale) is associated with an increase of .222 standard deviations on the KIRIS index. The effect of a one standard deviation increase in teacher expectancy of avoiding declines in the KIRIS index is a one point improvement on the KIRIS index.

While teacher expectancy had the expected positive effect on school performance, the expected value of outcome variables have relatively small coefficients, and some have unexpected signs. We anticipated that schools at which teachers had on the average higher expected values for the bonus, goal attainment, and learning outcomes would perform better, controlling for expectancy, because they would be more highly motivated by the chance to receive these positive outcomes. Our expectations were not realized. The expected values for these outcomes had either insignificant or significant but negative coefficients. These analyses therefore do not provide any evidence that schools at which the positive outcomes were more highly valued, and seen as more likely to be received if goals are met, did better on the school performance measure.

The coefficients for the sanctions outcomes were small and not statistically significant. This result does not support the expectation that schools will perform better in which teachers, on the average, value these outcomes more negatively and expect them to occur if the school fails to perform, implying that these sanctions do not have a strong motivational value. Finally, with respect to the stress outcomes, the coefficients are again small, and only statistically significant for the Charlotte-Mecklenburg schools. The negative signs are consistent with the expectation that schools in which teachers negatively valued these experiences and saw them as a more likely consequence of trying to meet the goals would not perform as well.

Similar analyses using only elementary schools ( $\mathrm{n}=81$ for Charlotte-Mecklenburg, $\mathrm{n}=83$ for Kentucky) did not show any substantially different results from those reported above.

Overall, these analyses strongly suggest that between-school differences in expectancy were related to the success of schools in improving student performance as defined by the school-based performance award programs in these two sites. However, between-school differences in the degree to which teachers valued and expected to receive the various outcomes, including bonuses, associated with the goal achievement appear to be mostly unrelated to differences in school goal 
achievement. These latter results were contrary to our theoretical expectations. As explained later, these results may be due to problems of unreliability in measurement.

\section{PRINCIPALS' REACTIONS TO SCHOOL- BASED PERFORMANCE AWARD PROGRAMS}

In this section, we examine the perceptions of principals based on surveys administered in Charlotte-Mecklenburg, Kentucky, and Maryland. Principals in the three jurisdictions were asked similar questions on surveys administered to them by mail in 1997 (Charlotte-Mecklenburg and Kentucky) and 1998 (Maryland). We first compared the reactions of principals to the reactions of teachers in Charlotte-Mecklenburg and Kentucky and then compared principal responses across the three jurisdictions. These data provided us with some clues about how variations in program design and program context produce different perceptions at the school level. We use the data to hypothesize ways in which different design features might produce different results.

Research evidence and common sense suggest that program design and program context are important determinants of program effects (Bennett, 1992; Bullock and Tubbs, 1991; Odden and Kelley, 1997). These three performance award programs provided interesting contrasts in level and focus of award, in presence or absence and focus of sanctions, and in differences of context. Some potentially important distinctions in program design and program context among the three programs are as follows. Both the Charlotte-Mecklenburg and Kentucky programs provided salary bonuses to teachers, while the Maryland program paid awards to schools in the form of school improvement funds. The Charlotte-Mecklenburg program provided lower awards more frequently (\$750 to $\$ 1,000$ per year), while the Kentucky program paid larger awards (roughly twice the Charlotte-Mecklenburg award) at the end of a two-year award cycle. In CharlotteMecklenburg, teacher salaries were relatively low compared to other states, while Kentucky infused additional resources into the education system to raise teacher salaries. Maryland made awards to a smaller proportion of schools than in Charlotte-Mecklenburg or Kentucky (10 percent versus 40 percent). The Charlotte-Mecklenburg program had no formal sanctions component, although the district placed significant pressure on principals to improve school performance toward the accountability goals. The Kentucky program also had a strong sanctions component that put all schools at risk of sanctions if their performance declined, regardless of absolute level of performance. Therefore, Kentucky's sanctions could affect the highest as well as the lowest performing schools in the state. The Maryland program includes sanctions, but they have not been widely used and were seen as applying only to Baltimore city schools.

The Charlotte-Mecklenburg program was created in part to address concerns about disparities in achievement between white and African-American students. The district's accountability goals attempted to raise the performance of all students, with a particular emphasis on improving the performance of the lowest-performing students and minority students. The Kentucky program was part of a massive court-ordered overhaul of the state's entire education system, including a reduction in local community control, a direct state-to-school reform effort, and comprehensive initiatives including mandatory site-based management, ungraded primary schools, and significant investment in technology, professional development, tutoring, and family services. Ken- 
tucky's accountability goals attempted to motivate significantly higher levels of performance and a shift to new models of instruction that emphasized performance, relationships to real-world problems and higher-order thinking skills. Maryland has been a leader in standards-based reform, and added the performance award for elementary and middle schools after the assessment was in place. Because Maryland has only 24 districts, the Department of Education can work closely with districts to implement the accountability program.

\section{Principal and Teacher Reactions in Charlotte-Mecklenburg and Kentucky}

Table 14 summarizes the mean responses of principals in Charlotte-Mecklenburg and Kentucky to questions about goal clarity, goal conflict, and goal commitment, and it compares principal with teacher means. Principals exceeded teachers in all three areas. From an accountability standpoint, Charlotte-Mecklenburg principals provided the most desirable responses. Of the four groups, they were highest on clarity and commitment and lowest on goal conflict. This is perhaps not surprising, because the district had in place a strategy of hiring principals who were committed to the accountability goals and of replacing those whose schools failed to meet accountability expectations.

Table 14. Mean Responses of Charlotte-Mecklenburg and Kentucky Principals and Teachers to Goal-

\begin{tabular}{lcccc}
\multicolumn{5}{c}{ Related Scales } \\
Scale & $\begin{array}{c}\text { Charlotte- } \\
\text { Mecklenburg } \\
\text { Principals }\end{array}$ & $\begin{array}{c}\text { Charlotte- } \\
\text { Mecklenburg } \\
\text { Teachers }\end{array}$ & $\begin{array}{c}\text { Kentucky } \\
\text { Principals }\end{array}$ & $\begin{array}{c}\text { Kentucky } \\
\text { Teachers }\end{array}$ \\
\hline Goal Clarity & 4.2 & 3.4 & 4.1 & 3.6 \\
Goal Conflict & 2.6 & 2.8 & 2.9 & 3.2 \\
Goal Commitment & 4.0 & 3.9 & 3.7 & 3.9 \\
\hline Differences between principal and teacher averages within each jurisdiction are statistically significant at the .05 level or be- \\
yond; differences in principal and teacher averages across jurisdictions are not statistically significant.
\end{tabular}

\section{A Comparison of Principal Responses Across Programs}

Table 15 presents the mean responses of principals to questions about the rewards provided by the programs. Again, Charlotte-Mecklenburg principals, on average, had the most positive perceptions of rewards as motivators, followed by Maryland principals. Kentucky principals were least enthusiastic about the rewards.

It is interesting that both Maryland and Charlotte-Mecklenburg principals were more optimistic about the motivational potential of rewards than were Kentucky principals. Charlotte-

Mecklenburg and Kentucky rewarded with pay bonuses while Maryland used school improvement funds, so apparently, the form of the reward does not account for these differences in principals' evaluation of motivational impact. Kentucky principals may have been relatively negative about performance rewards because on average, they did not view the accountability system as a fair way to measure student performance. Another possible explanation is that Kentucky principals on average estimated a lesser likelihood of achieving reward-level performance (if the principal and staff worked together as hard as they could): 58 percent for Kentucky; 70 percent for Maryland; and 71 percent for Charlotte-Mecklenburg.

Table 15. Mean Responses ${ }^{a}$ of Principals to Selected Reward Items

\begin{tabular}{lccc}
\hline Item & Charlotte & Kentucky & Maryland \\
& Principals & Principals & Principals
\end{tabular}




\begin{tabular}{|c|c|c|c|}
\hline $\begin{array}{l}\text { 1. Fair for teachers/schools that improve student achievement } \\
\text { to receive reward }\end{array}$ & 4.4 & 2.9 & 3.7 \\
\hline 2. Reward helps me motivate teachers & 3.4 & 2.3 & 3.0 \\
\hline 3. Reward provides shared goals & 3.7 & 2.4 & 3.2 \\
\hline 4. Tripling size of reward would improve teacher motivation & 4.2 & 2.3 & 2.9 \\
\hline $\begin{array}{l}\text { 5. Accountability system is a fair way to measure school } \\
\text { performance }\end{array}$ & - & 2.5 & 3.0 \\
\hline 6. Award part of accountability program should be continued & - & 2.3 & 3.5 \\
\hline $\begin{array}{l}\text { 7. Paying bonus directly to teachers would more } \\
\text { effectively motivate them }\end{array}$ & - & - & 3.5 \\
\hline
\end{tabular}

To summarize the entire set of principal responses and allow a more parsimonious comparison across programs, we factor analyzed common survey items from the Kentucky and Maryland questionnaires. (The Charlotte-Mecklenburg questionnaire did not include as many common items.) The survey items used one of two five-point rating scales, in which (depending on the question) $1=$ not at all or strongly disagree; $3=$ to a moderate extent or neither agree nor disagree, and $5=$ to a very great extent or strongly agree. We identified seven factors: the importance of financial incentives in motivating teacher performance; district support for program goals principal understanding and commitment of program goals; the allocation of resources to support the goals of the program; principal skills in helping teachers align and improve teaching practice; and teacher teamwork and learning in support of goal achievement (Kelley, Conley and Kimball, 1999). Technical Appendix Tables A13, A14, and A15 provide a breakdown of the items comprising each factor, reliabilities, and factor loadings. We created scale scores by averaging the Kentucky and Maryland items that loaded most strongly on each factor. We created Charlotte-Mecklenburg scale scores by averaging the corresponding items. Table 16 compares responses from Charlotte-Mecklenburg, Kentucky, and Maryland for each of the seven factors.

Table 16. A Comparison of Mean Principal Responses Across Performance Award Programs in Charlotte-Mecklenburg, Kentucky, and Maryland

\begin{tabular}{lccc}
\hline Scale & $\begin{array}{c}\text { Charlotte-Mecklenburg } \\
\text { (Salary Bonus, } \\
\text { Principal Sanctions) }\end{array}$ & $\begin{array}{c}\text { Kentucky } \\
\text { (Salary Bonus, } \\
\text { Sanctions) }\end{array}$ & $\begin{array}{c}\text { Maryland } \\
\text { (Award to School, } \\
\text { Limited Sanctions) }\end{array}$ \\
\hline Financial Incentive & -- & 2.36 & $3.10^{\wedge}$ \\
Improvement of Teaching & 3.73 & $3.82^{\wedge}$ & 3.67 \\
Principal Understanding & $4.28^{\wedge}$ & 4.13 & 3.82 \\
District Support & 2.92 & $3.69^{\wedge}$ & 3.61 \\
Resource Allocation & 3.49 & $3.51^{\wedge}$ & 3.15 \\
Principal Skill & $3.93^{\wedge}$ & 3.69 & 3.80 \\
Teacher Teamwork and & $3.90^{\wedge}$ & 3.80 & 3.87 \\
Learning & & & \\
\hline Indicates highest mean in the triad. & &
\end{tabular}

Because the Charlotte-Mecklenburg survey did not include a sufficient number of similar items related to financial incentives, no Charlotte-Mecklenburg factor score was calculated for the financial incentives group. For the other factors, Charlotte-Mecklenburg was highest of the three programs on principal understanding, principal skill, and teacher teamwork and learning. Principal understanding and principal skill may have been highest in Charlotte-Mecklenburg because 
the program included easily assessed structural changes (such as increased enrollment in higherlevel courses) and improvement in achievement that did not generally require wholesale modifications of curriculum and instruction (as did the Kentucky and Maryland programs). The teacher teamwork and learning factor was highest in Charlotte-Mecklenburg, although the differences across the three programs were not substantively significant. Examination of the individual items comprising this factor shows that Kentucky is highest on opportunities for professional development related to the assessment and on opportunities to learn best practices from other schools. Differences in these items probably reflect Kentucky's initiatives in these areas. This factor also included two other items related to structural changes that provided common planning time to teachers to work together on improving teaching practice. Both Charlotte-Mecklenburg and Maryland were high on these items, which may reflect efforts in both jurisdictions to evaluate principals based on the accountability goals.

Improvements in teaching and learning may be the most desirable outcome of a school-based performance award program. Table 16 shows that Kentucky's program, with salary bonuses and sanctions operating in the context of a broad-scale education reform effort, was highest on the improvement of teaching, district support, and resource allocation. This suggests that, of the three program types, award programs with sanctions in the context of a larger reform effort have the greatest impact on improvement of teaching, district support, and resource alignment. Principals in the two programs with salary bonuses rated improvement in teaching, principal understanding, and resource allocation significantly higher than did principals in Maryland's program, which made awards in the form of school improvement funds.

These data are not conclusive, and implications regarding program design should be considered in the larger cultural, educational, and reform context. Still, one interpretation of these findings is that a school-based performance award program with sanctions provides the most powerful effect, enhancing principal understanding and resource allocation, and motivating the greatest level of effort to modify teaching practice to achieve accountability goals. This type of program appears to provide the most powerful jump-start for the system, but also creates the greatest negative reaction from principals and teachers. Based on principals' reported perceptions, all three programs promoted some changes in teaching practice, teacher teamwork and learning, and at least some modest reallocation of resources to support reform. Policymakers will need to assess the need for change and weigh the trade-offs.

\section{CONCLUSION}

Our study of school-based performance award programs suggests that they are a potentially useful tool for policymakers and administrators interested in focusing teachers, principals, and educational systems on improving student performance. Their full potential may be difficult to reach, however, due to the complexity of designing and implementing such programs. We found that the programs we studied had mixed success in fulfilling the conditions that our motivational model suggests are important. Teachers in the programs we studied reported that they understood the program goals and were committed to them. The programs appeared to have a focusing effect on teaching practice, collaboration and teamwork, and resource alignment. Teachers who perceived the bonus and other positive outcomes associated with achieving the goals as having a higher expected value reported more understanding of and commitment to the goals. Though 
most teachers reported trying to reach the goals, many were skeptical about continuing to reach ever-rising goals. This skepticism was higher in schools that had previously met their goals.

Teachers perceived that both desirable and undesirable outcomes were associated with the award programs. The most desirable outcomes included personal satisfaction, seeing students learn new skills, having clear goals, and receiving a bonus. Least desirable outcomes included public criticism or embarrassment, additional pressure and job stress, and risk to job security. The outcomes may be grouped into four clusters: goal attainment (bonus, funds for school improvement, personal satisfaction from meeting the goals, public recognition); learning (having clear goals, professional development opportunities, working cooperatively with other teachers, having students learn new skills, satisfaction that student performance increased); stress (more pressure and job stress, working more hours, less freedom to teach things unrelated to the goals); and sanctions (loss of pride, public criticism, loss of job security, intervention). Outcomes in the first two clusters received high desirability ratings and outcomes in the last two clusters received low desirability ratings. Outcomes such as personal satisfaction from achieving the goals were as important to teachers as the formal rewards of the programs such as receiving a bonus, and teachers who rated goals like having students learn new skills as highly desirable did not rate receiving a bonus as highly undesirable. Bonuses per se do not seem to be seen by these teachers as antithetical to the intrinsic motivators of teaching.

While the desirability of receiving a bonus was rated relatively high, teachers were less than certain that achieving the goals would lead to receiving the bonus. (The average probability perceived by Charlotte-Mecklenburg teachers was 72.8 percent; by Kentucky teachers, 54.8 percent.) Teachers in both jurisdictions perceived a greater likelihood of experiencing personal satisfaction, but also of experiencing more stress, and in Kentucky, of longer hours and less freedom to teach. This suggests that, at least in Kentucky, the attraction of receiving a bonus may have been outweighed by the negative aspects of trying to meet the goals, thus weakening the potential motivating power of the bonus and other positive outcomes.

Teachers' expectancy perceptions (beliefs that their efforts would result in their school's meeting its goals) were weaker than expected. The individual expectancy was, on the average, quite low (39.2 percent in Kentucky and 55.6 percent in Charlotte-Mecklenburg). The average group expectancy perceptions were somewhat higher. Teachers reported higher levels of individual and group expectancy in schools in which teachers perceived stronger assessment data feedback mechanisms, principal support or professional community, lack of goal conflict, and higher levels of program fairness. Past performance in the program was important as well: teachers in schools with a history of success with the program reported higher levels of expectancy.

Kentucky teachers found the bonus per se desirable but they were not, on the average, highly in favor of having the bonus program continue, nor did they report that they were highly motivated by the bonus. Teachers who said they were more motivated by the bonus and wanted to see it continue were more dissatisfied with their current salary, felt that the use of bonuses and the bonus process were fair, and felt that teachers should decide how to divide up the award money. Teachers who reported a greater desire to withdraw from the bonus program were those who saw the program as less fair. 
We found that schools with higher average levels of teacher expectancy were more likely to show improvements in student achievement. This is consistent with the part of our motivational model that suggests that success is more likely to call forth higher levels of effort. These higher levels of effort in turn lead to higher levels of performance. This is consistent with results of research associating expectancy beliefs with performance. (See Van Eerde and Thierry, 1996, for a meta-analysis, and Tschannen-Moran, Hoy, and Hoy, 1998, for a discussion of research on a related construct, teacher efficacy.) The similarity of the magnitude and direction of the effect of average teacher expectancy on school performance across the two jurisdictions is notable, even though the actual measures of school performance (that is, the way student achievement was measured and combined with other indicators) and other program design features were quite different. This cross-jurisdiction similarity provides some evidence of the generalizability of the teacher expectancy-school performance relationship.

We had expected that greater value placed on the outcomes coupled with greater certainty that performance would lead to positive outcomes would lead to more effort, which would lead in turn to higher performance. But contrary to our expectations, the schools for which the average expected value of the positive outcomes (the bonus by itself or the goal attainment outcomes as a group) was higher were not more likely to show greater improvements in school performance. Nor were schools for which the average expected negative value of sanctions was greater more likely to show greater improvements. This finding that higher expected values of outcomes was not associated with higher performance is inconsistent with a substantial body of previous research (see Van Eerde and Thierry, 1996). We do not interpret these results to mean that teachers' valuation and beliefs about the likelihood of program rewards and sanctions do not influence teacher motivation. Rather, we attribute the results to a combination of measurement error, limitations in our research design (see the Strengths and Limitations of Study Methods section below) and, in the case of the bonus, the relatively weak nature of the intervention.

Comparing the perceptions of principals in Charlotte-Mecklenburg and Kentucky (both salary bonus programs) with the perceptions of principals in Maryland (a program that provided school improvement funds), we found that program design and program context appear to be important factors affecting motivation. Among the three programs, principals in Kentucky reported the greatest change in teaching practice. The Kentucky program had the largest salary bonus and the strongest sanctions component. In addition, principal understanding of, and resource allocation toward, the goals of the program were higher in the salary bonus programs. Both survey and interview responses from Kentucky principals suggested that the bonus is not a strong motivator. One interpretation of these findings is that salary bonus programs with sanctions focus teachers and educational systems on the improvement goals, but also produce pressure and stress, resulting in negative attitudes about the program and its effectiveness. Changes to teaching practice appear to come at a price.

\section{Implications for the Design of School-Based Performance Award Programs}

That the motivational effects of these school-based performance award programs were not as strong as might be expected reinforces the idea that a successful award program involves more than promising school staff a bonus for meeting performance goals. As our motivation model implies, making a group reward program work is a complex undertaking, and difficulties establishing any link weaken the potential motivational impact even when the other links are made. 
Because of this complexity, school-based performance award programs are not likely to be successful unless considerable attention is paid to their design and management. It is important to note that the level of success of group reward programs in the private sector also varies. A sizable minority of group incentive programs implemented in the private sector are judged unsuccessful (Abosch, 1998) or are discontinued (Bullock and Tubbs, 1990; Graham-Moore and Ross, 1990). The detailed prescriptions given for private sector group reward programs also illustrate the complexity of designing them (for example, Orens and Elliott, 1997; Graham-Moore and Ross, 1990; Wilson and Phalen, 1996). This literature has typically outlined a set of conditions under which group rewards are more likely to work and has tended to be cautious in recommending adoption where they are not present. Based on our research, and on research on private sector group reward programs, we recommend that designers of school-based performance awards attend to the following issues in order to improve motivational impact.

1. Teacher Expectancy. Our results show that schools with higher average teacher expectancy improve student achievement more, but also that many teachers perceived that the probability that their efforts would lead to their school's meeting its improvement goals was not very high. Award program designers should therefore be concerned with ways to build expectancy. The motivation model highlights the importance of teachers' perceptions of their competencies and the presence of enabling conditions. Though our measures of teacher competence did not predict expectancy, both the private sector research literature (for example, Hatcher et al., 1991; Welbourne and Gomez-Mejia, 1995) and the prescriptive literature (for example, O'Neill and Lough, 1994) on group reward programs have emphasized the importance of showing workers how their efforts can influence the performance measures. Reformers such as Cohen (1996) and the National Commission on Teaching and America's Future (1996) have argued that many teachers lack the skills to teach to high standards. Professional development focused on understanding the performance measures and the behaviors needed to influence them, as well as on providing the knowledge and skills needed to carry out the behaviors, may therefore help teachers believe that their efforts can lead to improved school performance. Pay incentives for acquiring the needed knowledge and skills may be a promising way to encourage teachers to develop the skills they need to believe they can succeed, and therefore might complement school-based performance award programs. The other influence on expectancy in the model is the presence of enabling conditions such as principal leadership, professional community, and assessment feedback. Our research suggests that these are likely places to begin positively influencing teachers' expectancy perceptions.

2. The Connection Between Goal Achievement and Receiving the Bonus. Our results show that many teachers were not very certain that if their school met its performance goals, the bonus would be paid out. Ways of strengthening teachers' perceptions of the link between achievement and the bonus include institutionalizing a consistent source of funding and a commitment to paying the bonus when it is earned. For example, when North Carolina's school-based performance award program was implemented in 1997, about $\$ 80$ million was budgeted for the awards. Because more schools than expected met their improvement targets, full funding required $\$ 120$ million. Rather than scaling back the level of the awards, the legislature increased the budget to pay all teachers in improving schools the awards that had been promised (Johnson et al. 1998). 
3. The Size of the Bonus. Our interviews, particularly with Charlotte-Mecklenburg teachers, suggested that many teachers did not find the amount of the bonus large enough to be motivating. In order to reach a meaningful threshold for most teachers, bonuses in the $\$ 1,500$ 3,000 range may be needed. Larger amounts may help to offset some of the undesirable outcomes such as increased stress and longer hours. However, other reports (Hall and Caffarella, 1997; Kelley, 1996; Kellor and Odden, 1998) suggest that teachers in some situations do see a $\$ 1,000$ bonus as significant. The difference may be that in these cases, hours of work and stress levels may have been lower or perceptions of fairness higher.

4. Active Support from Principals. Private sector literature has recognized the importance of the active commitment of site managers to the success of group reward programs (Bennett, 1998; Graham-Moore and Ross, 1990; Ross, Hatcher, and Collins, 1992). Managers in successful private sector programs make the program central to their management efforts. They generate continuous interest and enthusiasm for the program. In both the CharlotteMecklenburg and Kentucky programs, this important role fell to principals, who may have had little or no guidance from the district or state as to how to carry it out. Based on our interviews, there appeared to be a high level of variability in the extent to which CharlotteMecklenburg and Kentucky principals promoted the program. While some principals were very proactive, others seemed to be genuinely at a loss as to how to rally their staff around the goals.

5. Fairness Perceptions. The private sector research is clear about the importance of perceptions of fairness on the motivational impact of reward programs (Cooper, Dyck, and Frohlich, 1992; Gross and Barcher, 1993; Hatcher, Ross, and Collins, 1991; Lawler, 1988; Welbourne and Gomez-Mejia, 1995). We also found that perceptions of fairness were important to teachers and influenced their motivational reactions. Perceived fairness was related to teacher expectancy, reported level of motivation by the bonus, desire to see the bonus program continue, and withdrawal intentions. To influence fairness perceptions, it may be necessary to expend considerable effort explaining the rationale behind the performance measures, the level of the improvement goals, and the mechanics of the program. Reliability and face validity of student achievement assessments and other measures of school performance also are likely to be crucial.

6. Teacher Participation in Award Program Design. Involving affected staff in the design of award programs might be a promising way to improve fairness perceptions, to ensure that improvement goals are not set too high as to seem unattainable, and to promote understanding and buy-in to the program. Again, private sector research (Abosch, 1998; Bullock and Tubbs, 1990; White, 1979) and prescription (O’Neill and Lough, 1994; Wilson and Phalen, 1996) emphasizes the importance of participation in design and implementation. Kellor and Odden (1999) described a participative process used to design a school-based performance award program for the Cincinnati school district.

\section{Strengths and Limitations of Study Methods}

The results of our research and recommendations about program design should be interpreted within the context of the strengths and limitations of our methodology. Among the strengths is 
the use of a teacher motivation model based on accepted motivational theory to serve as a guiding framework to study design and measurement, the use of a predictive design to assess the relationship between teacher motivation and student achievement, the use of large samples from multiple research sites, and the use of qualitative and quantitative data collection and analysis. Analysis was also conducted at both the individual and school level to fully explore individual motivational reactions and the relation of motivation to performance. Because of these characteristics, we are confident that this research makes a substantive contribution to understanding how teachers function within, and respond to, a school-based performance award program in terms of their motivation to improve student achievement.

Certain limitations of our study should be kept in mind. A first limitation pertains to measurement. Our measures for most of the independent variables were ad hoc in nature, a common characteristic of expectancy and goal-setting theory studies. As a result, very little is known about their construct validity. Additionally, operationalizing expectancy theory requires the use of multiplicative combinations of variables, which in turn exacerbates the unreliability of measurement. We suspect that such unreliability is the major cause of the weak relationship between the expected value of outcome measures and other variables. This is a particular problem in the analyses that used school-level averages of the expected value of outcomes to predict schools' subsequent success in meeting their student achievement goals. That schools in which teachers valued the rewards associated with the award program do not appear to have higher levels of performance may be due to poor measurement rather than the lack of a substantive relationship.

Our measures of school performance may also be subject to measurement error. We relied upon existing achievement measures used by the Charlotte-Mecklenburg and Kentucky programs. We had no reliability or validity data for the Charlotte-Mecklenburg measures. The information available on Kentucky's KIRIS gain scores (Kentucky Department of Education, 1997) suggests that while they were fairly reliable, the scores were subject to a non-negligible degree of measurement error. This may have attenuated the predictive relationships between teacher motivation and subsequent school success. (See Milanowski, 1999 for a discussion of how the reported level of reliability affects the categorization of schools as eligible for receiving performance awards.)

A second major limitation is our lack of control or comparison groups. Ideally, we would have studied the school-based performance award programs alongside identical programs without such key features as the bonus. By studying only sites that had award programs, we had to rely on naturally occurring variation within these programs (such as differences in teacher expectancy, perceived probability of receiving a bonus after meeting goals, and bonus desirability) to infer how effectively the programs motivated teachers and to estimate the impact of teacher motivation on subsequent school success in meeting improvement goals. The availability of comparison or control groups would have allowed us to better measure the true magnitude of the impact of award programs on teacher motivation and the impact of teacher motivation on school success. A definitive assessment of motivational value of an outcome such as the pay bonus may require an experimental design comparing the performance of two groups of schools operating under an identical accountability program, but with and without the pay bonus.

A third limitation of our study pertains to the generalizability of our findings. The data were gathered midstream during the operation of the award programs, and it is uncertain whether our data and the relationships we found in them would have been the same at either earlier or later 
points in time. For example, the Charlotte-Mecklenburg data were gathered as the Benchmark Goal Program was beginning to be integrated with a state-wide accountability plan. Now that the integration has been completed, we are uncertain as to how well our results generalize to this new circumstance. In Kentucky, we gathered our data at the time of substantial controversy over the state's KIRIS testing process; had we gathered our data a year earlier, prior to the controversy, teachers' responses might have been very different. Another constraint on generalizability is that we studied just three particular school-based performance award programs. Though we sampled carefully within our jurisdictions, thus enhancing generalizability to our jurisdiction populations, we have no way of knowing how well our results might generalize to award programs in other jurisdictions. 


\section{REFERENCES}

Abelmann, C. H., and Kenyon, S. B. (1996, April). Distractions from teaching and learning: Lessons from Kentucky's use of rewards. Paper presented at the annual meeting of the American Educational Research Association, New York, NY.

Abosch, K. (1998, July/August). Variable pay: Do we have the basics in place? Compensation and Benefits Review, 12-22.

Bennett, L. (1992, July/August). Research from the trenches making group incentives work. Compensation and Benefits Review, 37-39.

Blackford, L. B. (1997). Plan would shift KERA rewards. Lexington Herald-Leader [online]. Available: http://www.kentuckyconnect/news/103197.

Bullock, R. J., and Tubbs, M. E. (1991). A case meta-analysis of gainsharing plans or organizational development interventions. Journal of Applied Behavioral Science, 26(3), 383404.

Cenziper, D. (1997, February 6). Paying to keep teachers. Charlotte-Mecklenburg Observer, $1 \mathrm{~A}$.

Cody, W. S. (1998, April 3). Memorandum to all Kentucky teachers. Available: http://www.kde.state.ky.us/coe/ocpg/dpi.

Cohen, D. K. (1996). Rewarding teachers for student performance. In S. H. Fuhrman and J. A. O'Day (Eds.), Rewards and reform: Creating educational incentives that work. San Francisco, CA: Jossey-Bass.

Cooper, C. L., Dyck, B., and Frohlich, N. (1992). Improving the effectiveness of gainsharing: The role of fairness and participation. Administrative Science Quarterly, 37, 471-490.

Fuhrman, S. H. (1999). The new accountability. (CPRE Policy Brief RB-27). Philadelphia, PA: Consortium for Policy Research in Education, Graduate School of Education, University of Pennsylvania.

Fullan, M. G. (1991). The new meaning of educational change ( $2^{\text {nd }}$ ed.). New York, NY: Teachers College Press.

Goertz, M. E., Massell, D. and Chun, T. (1997). Education reform policy: From Congress to the classroom. Maryland case study, 1996-1997. Philadelphia, PA: Consortium for Policy Research in Education, Graduate School of Education, University of Pennsylvania.

Gong, B. (personal communication, August 1, 1997). 
Graham-Moore, B., and Ross, T. L. (1990). Gainsharing: Plans for improving performance. Washington, D.C.: Bureau of National Affairs, Inc.

Gross, S. E., and Barcher, J. P. (1993, January/February). The new variable pay programs: How some succeed, why some don't. Compensation and Benefits Review, 51-56.

Hall, G. E., and Caffarella, E. P. (1997). Third year implementation assessment of the Douglas County, Colorado school district performance pay plan for teachers. No city: Authors.

Hatcher, L., Ross, T. L., and Collins, D. (1991). Attributions for participation and nonparticipation in gainsharing-plan involvement systems. Group and Organizational Studies, 16, 2543.

Hatry, H. P., Greiner, J. M., and Ashford, B. G. (1994). Issues and case studies in teacher incentive plans $\left(2^{\text {nd }}\right.$ ed). Washington, D.C.: Urban Institute Press.

Heneman, H. G., III. (1998). Assessment of the motivational reactions of teachers to a schoolbased performance award program. Journal of Personnel Evaluation in Education, 12(1), 43-59.

Heneman , H. G. III, and Judge, T. A. (in press). Compensation attitudes: A review and recommendations for further research. In S. L. Rynes and B. Gerhart (Eds.), Compensation in organizations: Progress and prospects. San Francisco, CA: New Lexington Press.

Heneman, H. G. III, and Milanowski, A. (1998, November). Employees' withdrawal responses to their individual base pay and group bonus pay systems. Paper presented at the Southern Management Association annual conference, New Orleans, LA. Unpublished manuscript, University of Wisconsin-Madison.

Heneman, H. G. III, and Milanowski, A. (1999). Teacher attitudes about teacher bonuses under school-based performance award programs. Journal for Personnel Evaluation in Education, 12(4), 327-342.

Heneman, H. G., III, and Schwab, D. P. (1985). Pay satisfaction: Its multidimensional nature and measurement. International Journal of Psychology, 20, 129-141.

Heneman, R. L., Ledford, Jr., G. E., and Gresham, M. T. (in press). The effects of changes in the nature of work on compensation. In S. L. Rynes and B. Gerhart (Eds.), Compensation in organizations: Progress and prospects. San Francisco, CA: New Lexington Press.

Jacobson, S.L. (1987). Merit pay and teaching as a career. In K. Alexander and D.H. Monk (Eds.), Attracting and compensating America's teachers (pp. 161-177). Eighth annual yearbook of the American Educational Finance Association, Cambridge, MA: Ballinger.

Johnson, S.M. (1986). Incentives for teachers: What motivates, what matters? Educational Administration Quarterly, 22(3), 54-79. 
Johnson, H., Leak, E., Williamson, G., Kellor, E. M., Odden, A. R., and Hanna, J. (1998) A case study of the state of North Carolina's school-based performance award program. Unpublished manuscript, University of Wisconsin-Madison.

Jones, A. P., Johnson, L. A., Butler, M. C., and Main, D. S. (1983). Apples and oranges: An empirical comparison of commonly used indices of interrater agreement. Academy of Management Journal, 26(3), 807-819.

Kelley, C. (1996). Implementing teacher compensation reform in public schools: Lessons from the field. The Journal of School Business Management, 8(1), 37-54.

Kelley, C. (1997). Teacher compensation and organization. Educational Evaluation and Policy Analysis, 19(1), 15-28.

Kelley, C. (1998a, April). Schools that succeed: The role of enabling conditions in facilitating student achievement in school-based performance award programs. Paper presented at the American Educational Research Association annual conference, San Diego, CA. Unpublished manuscript, University of Wisconsin-Madison.

Kelley, C. (1998b). The Kentucky school-based performance award program: Schoollevel effects. Educational Policy, 12(3), 305-324.

Kelley, C., Conley, S., and Kimball, S. (1999). Incentives, professional norms, and local realities: Evidence from Kentucky and Maryland. Paper prepared for the American Education Finance Association annual conference, Seattle, WA. Unpublished manuscript, University of Wisconsin-Madison.

Kelley, C., and Protsik, J. (1997). Risk and reward: Perspectives on the implementation of Kentucky's school-based performance award program. Educational Administration Quarterly, 33(4), 474-505.

Kellor, E. M., and Odden, A. R. (1999). Cincinnati: A case study of the design of a schoolbased performance award program. Paper prepared for the American Education Finance Association annual conference, Seattle, WA. Unpublished manuscript, University of Wisconsin-Madison.

Kellor, E. M., and Odden, A. R. (1998). Vaughn learning center: A case study. Available at the Consortium for Policy Research in Education, University of Wisconsin-Madison.

Kentucky Department of Education. (1995, February). Kentucky teacher. Frankfort, KY: Author.

Kentucky Department of Education. (1996, May). Kentucky teacher. Frankfort, KY: Author.

Kentucky Department of Education. (1997). KIRIS accountability cycle 2 technical manual (Chapter 11). Frankfort, KY: Author. 
Lawler, E. E. III (1988). Gainsharing theory and research: Findings and future directions. Research in Organizational Change and Development, 2, 323-344.

Lawler, E. E. III. (1990). Strategic pay: Aligning organizational strategies and pay systems. San Francisco, CA: Jossey-Bass.

Lawton, M. (1997, July 9). Kentucky fires firm that ran innovative testing program. Education Week.

Lee, T. W., and Mitchell, T. R. (1994). An alternative approach: The unfolding model of voluntary employee turnover. Academy of Management Review, 19, 51-89.

Locke, E. A., and Latham, G. P. (1990). A theory of goal setting and task performance. Englewood Cliffs, NJ: Prentice Hall.

Maryland Department of Education. (1997). Maryland school performance report, 1997: State and school systems. Annapolis, MD: Author.

Maryland Department of Education. (1999). Maryland school 'report card' shows solid gains; schools continue making progress on state test. Maryland State Department of Education Press Release. Annapolis, MD: Author.

McAdams, J. C., and Hawk, E. J. (1994). Organizational performance and rewards: 663 experiences in making the link. Scottsdale, AZ: American Compensation Association.

Milanowski, A. (1999). Measurement error or meaningful change? The consistency of school achievement in two school-based performance award programs. Journal of Personnel Evaluation in Education, 12(4), 343-363.

Murnane, R. J., and Cohen, D. K. (1986). Merit pay and the evaluation problem: Why most merit pay plans fail and a few survive. Harvard Education Review, 56, 1-17.

National Commission on Teaching and America's Future. (1996). What matters most: Teaching for America's future. Report of the National Commission on Teaching and America's Future. New York, NY: Author.

Newman, F. M., and Associates, (1996). Authentic achievement: Restructuring schools for intellectual quality. San Francisco, CA: Jossey-Bass.

Odden, A. R. (Ed.). (1991). Educational policy implementation. Albany, NY: State University of New York Press.

Odden, A. R., and Kelley, C. (1997). Paying teachers for what they know and do: New and smarter compensation strategies to improve schools. Thousand Oaks, CA: Corwin Press. 
O’Neill, D., and Lough, D. A. (1994). Team incentives and TQM: Building organizational excellence at National Semiconductor. American Compensation Association Journal, 3, 54-67.

Orens, R. M., and Elliott, V. J. (1997). Variable pay programs: Pay for results. In P. T. Chingos, (Ed.), Paying for performance: A guide to compensation management. New York, NY: Wiley.

Reidy, E. (1995, September). The Kentucky Education Reform Act and school-based performance awards. Paper presented at the CPRE Conference Series on Teacher Compensation, Washington, D.C.

Rosenholtz, S.J. (1989). Teachers' workplace: The social organization of schools. White Plains, NY: Longman.

Ross, T. L., Hatcher, L., and Collins, D. (1992). Why employees support (and oppose) gainsharing plans. Compensation and Benefits Management, 8, 17-27.

Stecher, B. M., and Barron, S. (1999). Test-based accountability: The perverse consequences of milepost testing. Paper presented at the annual meeting of the American Educational Research Association, Montreal, Canada.

Strauss, A., and Corbin, J. (1994). Grounded theory methodology: An overview. In N. K. Denzin and Y.S. Lincoln (Eds.), Handbook of qualitative research (pp. 273-285). Thousand Oaks, CA: Sage Publications.

Strecklow, S. A. (1997, September 2). Kentucky's teachers get bonuses, but some are caught cheating. Wall Street Journal, A1.

Tschannen-Moran, M., Hoy, A. W., and Hoy, W. K. (1998). Teacher efficacy: Its meaning and measure. Review of Education Research, 68(2), 202-248.

Van Eerde, W., and Thierry, H. (1996). Vroom's expectancy models and work-related criteria: A meta-analysis. Journal of Applied Psychology, 81(5), 575-586.

Vroom, V. H. (1964). Work and motivation. New York, NY: Wiley.

Welbourne. T. M. and Gomez-Mejia, L. R. (1995). Gainsharing: A critical review and a future research agenda. Journal of Management, 21, 559-609.

White, J. K. (1979). The Scanlon plan: Causes and correlates of success. Academy of Management Journal, 22, 293-312.

Wilson, T. B., and Phalen, C. P. (1996). Rewarding group performance: An approach to designing and implementing incentive pay programs. Scottsdale, AZ: American Compensation Association. 


\section{TECHNICAL APPENDIX}

\section{Further Description of Data Collection Activities}

In each jurisdiction, data collection involved on-site interviews with principals and teachers in schools with varying degrees of success in meeting school performance goals, followed by mail surveys of teachers (in Kentucky and Charlotte-Mecklenburg) and principals (in all three jurisdictions) in a larger sample of schools. Table A1 summarizes the nature and timing of the data collection effort.

Table A1. Summary of Data Collection Activities: Studies of School-Based Performance Awards

\begin{tabular}{|c|c|c|c|c|}
\hline SBPA Program & Timeframe & Method & Sample & Study Focus \\
\hline \multirow[t]{4}{*}{$\begin{array}{l}\text { Kentucky } \\
\text { Accountability } \\
\text { Program }\end{array}$} & 1995 & $\begin{array}{l}\text { Interviews (1/2 day } \\
\text { at each school) }\end{array}$ & $\begin{array}{l}\text { Teachers, principals in } 6 \\
\text { reward elementary and } \\
\text { middle schools; state } \\
\text { dept. of ed., state stake- } \\
\text { holders }\end{array}$ & $\begin{array}{l}\text { Motivation model; } \\
\text { program effects }\end{array}$ \\
\hline & 1996 & $\begin{array}{l}\text { Interviews (1/2 day } \\
\text { at each school) }\end{array}$ & $\begin{array}{l}\text { Teachers, principals in } \\
16 \text { elementary, middle } \\
\text { and high schools with } \\
\text { varying levels of success } \\
\text { in the program }\end{array}$ & $\begin{array}{l}\text { Motivation model; } \\
\text { program effects }\end{array}$ \\
\hline & 1997 & $\begin{array}{l}\text { Teachers sur- } \\
\text { veyed by mail }\end{array}$ & $\begin{array}{l}\text { Up to } 25 \text { teachers in } 262 \\
\text { elementary, middle, and } \\
\text { high schools; } 5654 \text { sent } \\
\text { questionnaires, } 1750 \\
\text { responded, for a } 30.9 \% \\
\text { response rate }\end{array}$ & $\begin{array}{l}\text { Motivation model; explana- } \\
\text { tion for differences in } \\
\text { achievement outcomes } \\
\text { across schools; program } \\
\text { effects }\end{array}$ \\
\hline & 1997 & $\begin{array}{l}\text { Principals sur- } \\
\text { veyed by mail }\end{array}$ & $\begin{array}{l}393 \text { principals sent ques- } \\
\text { tionnaires, } 204 \text { re- } \\
\text { sponded, for a } 51.9 \% \\
\text { response rate }\end{array}$ & $\begin{array}{l}\text { Explanation for differences } \\
\text { in achievement across } \\
\text { schools; program effects }\end{array}$ \\
\hline \multirow[t]{3}{*}{$\begin{array}{l}\text { Charlotte- } \\
\text { Mecklenburg } \\
\text { Benchmark Goals } \\
\text { Program }\end{array}$} & 1997 & $\begin{array}{l}\text { Interviews (1/2 day } \\
\text { at each school) }\end{array}$ & $\begin{array}{l}\text { Teachers and principals } \\
\text { in } 11 \text { elem., middle and } \\
\text { high schools with varying } \\
\text { levels of success in the } \\
\text { program; district level } \\
\text { staff }\end{array}$ & $\begin{array}{l}\text { Motivation model; } \\
\text { program effects }\end{array}$ \\
\hline & 1997 & $\begin{array}{l}\text { Teachers sur- } \\
\text { veyed by mail }\end{array}$ & $\begin{array}{l}\text { Up to } 25 \text { teachers in } 120 \\
\text { elementary, middle, and } \\
\text { high schools; } 2951 \\
\text { teachers sent question- } \\
\text { naires, } 1150 \text { responded, } \\
\text { for a } 39.0 \% \text { response } \\
\text { rate }\end{array}$ & $\begin{array}{l}\text { Motivation model; explana- } \\
\text { tion for differences in } \\
\text { achievement outcomes } \\
\text { across schools; program } \\
\text { effects }\end{array}$ \\
\hline & 1997 & $\begin{array}{l}\text { Principals sur- } \\
\text { veyed by mail }\end{array}$ & $\begin{array}{l}120 \text { principals sent ques- } \\
\text { tionnaires, } 74 \text { responded } \\
\text { for a } 61.6 \% \text { response } \\
\text { rate }\end{array}$ & $\begin{array}{l}\text { Explanation for differences } \\
\text { in achievement across } \\
\text { schools; program effects }\end{array}$ \\
\hline
\end{tabular}




\begin{tabular}{|l|l|l|l|l|}
\hline SBPA Program & Timeframe & Method & Sample & Study Focus \\
\hline $\begin{array}{l}\text { Maryland Reward } \\
\text { for Success }\end{array}$ & 1997 & $\begin{array}{l}\text { Interviews (1/2 day } \\
\text { at each school); } \\
\text { review of docu- } \\
\text { ments }\end{array}$ & $\begin{array}{l}\text { Teachers and principals } \\
\text { in 11 elem. and middle } \\
\text { schools with varying lev- } \\
\text { els of success in the pro- } \\
\text { gram; state and district- } \\
\text { level administrators }\end{array}$ & $\begin{array}{l}\text { Motivation model; program } \\
\text { effects as compared to } \\
\text { Charlotte-Mecklenburg and } \\
\text { Kentucky }\end{array}$ \\
\hline & 1997 & $\begin{array}{l}\text { Principals sur- } \\
\text { veyed by mail }\end{array}$ & $\begin{array}{l}\text { 430 principals sent ques- } \\
\text { tionnaires, 236 re- } \\
\text { sponded for a 54.9\% } \\
\text { response rate }\end{array}$ & $\begin{array}{l}\text { Explanation for differences } \\
\text { in achievement across } \\
\text { schools; program effects }\end{array}$ \\
\hline
\end{tabular}

\section{On-site Interviews}

An initial round of interviews was conducted in a purposive sample of six Kentucky reward schools in 1995, followed by a larger sample of 16 schools in Kentucky in 1996. Interviews in Charlotte-Mecklenburg were conducted in 12 schools in 1997 and in 11 schools in Maryland in 1998. The schools in the 1996, 1997, and 1998 studies were chosen to include those with a variety of rates of success with the two reward programs. The 1996 Kentucky sample was selected to include schools from each level (elementary, middle, and high schools) and all possible combinations across the first two accountability cycles of winning monetary awards (reward), winning neither awards nor receiving sanctions (nonreward), and receiving sanctions (sanction). Assignment of schools into three categories rather than the five categories used by the Kentucky Department of Education was based on our interest in understanding the effects of monetary awards and sanctions on teacher motivation and on our 1995 research in Kentucky, which suggested that teachers viewed the "real" reward as exceeding the goal and receiving the monetary award and the "real" sanction as occurring in the decline and crisis categories. This created six different patterns of award histories in Kentucky: reward/reward, nonreward/reward, sanction/reward, reward/nonreward, nonreward/nonreward, and reward/sanction. There were no schools in the sanction/sanction category, so this category was not included in our sample.

In Charlotte-Mecklenburg, the purposive sample included schools that received rewards in both 1994-95 and 1995-96 (at the 100 percent or 75 percent level), schools that were bonus winners in only 1994-95, and schools that did not receive bonus awards in either time period.

In Maryland, 11 elementary and middle schools from two districts were selected for study. High schools were not included because at the time of the study, they did not participate in the award program. The sample of schools included both elementary and middle schools in each district that had made improvements for two consecutive years (reward), those that made one year of improvement (certificate), and those that had declined in performance or failed to improve enough to be in an award category.

In all three jurisdictions, schools were selected for diversity with regard to socioeconomic status, geographic location, and in Charlotte-Mecklenburg, racial composition and magnet/nonmagnet status. Researchers spent a half-day in each school interviewing the principal and a sample of teachers, particularly those who taught in the accountability subject/grades. Typical interviews 
lasted 45 to 60 minutes. The total number of teachers interviewed was approximately 105 in Kentucky, 60 in Charlotte-Mecklenburg, and 60 in Maryland. In general, interviews with teachers were done in a group setting, with between 3 and 10 teachers participating. In all three sites, official program documents were examined. In Kentucky and Maryland, information was gathered from state-level personnel to better understand program context, design, and implementation. In Maryland and Charlotte-Mecklenburg, interviews also were conducted with districtlevel personnel. (District-level personnel were not typically interviewed in Kentucky, since the Kentucky program was largely designed to bypass districts and operate directly at the school level.)

Interview protocols were used to guide the interviews and provide consistency across research teams. Typically, two researchers worked together at each research site to provide greater flexibility in data collection and to help interpret findings. Over all, four researchers collected data at each research site. Immediately following each school visit, researchers recorded initial perceptions on a summary sheet. Findings from the early data collection and analysis efforts helped to inform later data collection efforts, both within and across research sites. Interviews with teachers and principals were taped, and the tapes were transcribed. Transcripts were content-analyzed to identify the major themes of each interview. A coding scheme was developed by having four different researchers who were involved in the data collection code one set of transcripts and together develop a coding scheme that was then used by 2 researchers to code the remaining data. Coding schemes were developed for Kentucky, Charlotte-Mecklenburg, and Maryland. The codes were allowed to emerge from the data, but coding schemes in Charlotte-Mecklenburg and Maryland were informed by the earlier work. Transcripts were analyzed for patterns across school levels, schools with different levels of success with the award program, and magnet versus non-magnet schools.

\section{Survey Research}

Findings from the qualitative phase of the research, along with research literature on highperformance organizations, effective schools, and teacher/employee motivation were used to develop the survey instruments. Separate instruments were developed for teachers and principals. Where possible, scale items were adapted from pre-existing survey instruments. Common questions were included across instruments, although the questions were tailored to be descriptive of the programs operating in each research site.

The teacher questionnaire used in both Charlotte-Mecklenburg and Kentucky contained a series of questions designed to measure the constructs of the motivation model (goal commitment, clarity, and conflict, expectancy perceptions, probability and valence of outcomes associated with the program, teaching skills and attitudes, organizational supports for achievement of program goals). Also, perceptions of program fairness, satisfaction with pay, effect of the program on intent to leave the school, and demographic items. In addition, teachers were given an opportunity to provide comments at the end of the questionnaire. The principal questionnaire was a shorter document, focusing on organizational supports for achievement of program goals, but also including questions on goal commitment, clarity, conflict, expectancy perceptions, and attitudes toward the accountability program. 
The questionnaires were administered to Charlotte-Mecklenburg teachers and principals in the spring of 1997. The teacher questionnaire was administered to 25 teachers selected randomly from 120 schools. (Ten small schools serving specialized populations were excluded.) If a school had 25 or fewer teachers, all of the teachers were selected. The initial sample included 2,951 teachers. Using district-supplied home address mailing labels, the survey questionnaires were sent out in mid-April of 1997. Two follow-up mailings were made. All questionnaires were returned in addressed, postage-paid envelopes to the Wisconsin Survey Research Laboratory at the University of Wisconsin-Madison. By the July 15 cutoff date, 1150 teachers had responded, for a 39 percent response rate. The responders matched the Charlotte-Mecklenburg teacher population relatively well by gender, race, and teaching service, but elementary teachers were somewhat over-represented and high school teachers under-represented. The principal questionnaire was sent to each of the 120 Charlotte-Mecklenburg principals, who were requested to return them to the CPRE Wisconsin office. By the July 15 cut-off, and after two rounds of follow-ups by phone, 76 principals had provided usable responses, for a response rate of 63 percent. Slightly more elementary schools were represented, at the expense of middle schools, and principals in reward schools were slightly more likely to respond than principals in nonreward schools.

In Kentucky, teachers and principals were sent questionnaires in the fall of 1997. Respondents were selected by means of a multi-stage sampling process based on a list of schools provided by the Kentucky Department of Education. First, schools were selected within strata based on five patterns of prior accountability status (e.g., reward both cycles, nonreward both cycles) and school level (high, middle or junior high, and elementary). There were a total of 15 strata. Within each strata, a random sample of 40 schools was chosen (or all the schools were chosen if there were 40 or fewer schools in the stratum). The total number of schools selected at this stage was 392. Because no single list of teacher names was available, districts or schools were contacted and asked to provide names of teachers. At this stage, districts or schools agreed to provide teacher names for 262 schools. Within these schools, a random sample of 25 teachers was taken. If there were 25 or fewer teachers in a school, all teachers were included. The 5,654 teachers in the sample were sent questionnaires by mail in late October of 1997. Two follow-up mailings were sent to teachers who did not respond to the initial questionnaire. All questionnaires were returned to the Wisconsin Survey Research Laboratory at the University of Wisconsin-Madison. The total number of useable responses received was 1,750, for a response rate, relative to the number of questionnaires sent, of 30.9 percent. At least one response was received from 261 of the 262 schools. (The estimated number of teachers who would have been sent questionnaires had all schools in the first stage sample provided names was 8,136.) At the school level, responses were obtained from 67 percent of the schools in the original sample. The percentage of the strata from which teacher responses were obtained ranged from 53 to $100 \%$. Only a very limited amount of information was available upon which to base a comparison of respondent demographic characteristics to characteristics of the overall Kentucky teacher population. The distribution of respondents in high schools versus elementary and middle schools was close to the distribution reported in the Common Core of Data (National Center for Education Statistics, 1996) for the 1994 school year. According to data obtained from the Kentucky Department of Education, the average annual teacher salary was $\$ 32,807$ in 1997 . The median pay level in our sample was in the $\$ 30,000$ to $\$ 34,999$ category. Because the sample was intended to over-represent some types of schools (e.g. Decline/Reward) relative to others (Nonreward both cycles), it likely contains more teachers from schools that achieved reward status in Cycle 2. 
The principals of each of the Kentucky schools selected in the first stage of the sampling process described above also were sent questionnaires in the fall of 1997. Questionnaires were mailed from the CPRE Wisconsin office and were returned there. After two sets of reminder mailings, of the 392 principals contacted, 204 returned useable questionnaires, for a response rate of 52 percent. Coverage within-strata ranged from 31 to 71 percent.

In Maryland, principals were sent questionnaires in the spring of 1998. A sample size of 500 was allocated equally between middle and elementary schools. A simple random sample of 250 schools was taken within each strata, based on mailing lists provided by the Maryland Department of Education. After the initial mailing, the district of Prince Georges County asked that their principals not be contacted. Responses received from this district were deleted from subsequent analysis and destroyed. Eight of the schools on the mailing list did not participate in the program, so they were removed from the sample. Usable responses were received from 252 principals, for a response rate of 51 percent ( 252 divided by 500 minus 8 ).

Additional data on schools were collected from documents and data files provided by the jurisdictions. The Charlotte-Mecklenburg district supplied information on the following variables: enrollment, percent of students receiving free and reduced priced lunch, and Benchmark Goals point totals and reward status for each of the years of program operation. Data files allowing identification of which teachers transferred schools or left the district also were provided. The Kentucky Department of Education supplied data on school enrollment and percent of students receiving free and reduced priced lunch. The KIRIS scores and prior accountability status of schools were obtained from the Kentucky Department of Education.

In most of the analyses reported, it was necessary to take into account the fact that simple random sampling was not used. At the individual teacher level, the probability of selection was not equal for individual respondents. In Charlotte, selection probabilities varied by school size. For Kentucky, selection probabilities for schools (the primary sampling unit) differed by strata, and selection probabilities for teachers within schools differed by school size. To reflect these differences, most of the statistical analyses were conducted using case weights proportional to the inverse of the selection probability. Additionally, since the sampling technique selects first schools, then teachers within schools, teachers in the sample were not independent picks from the populations. Standard errors and significance tests for analyses at the individual teacher level need to take this into account, and so most individual-level analyses were done using regression routines that adjusted standard errors to reflect this clustering. 
Table A2. Items Combined to Produce Goal Commitment, Goal Clarity, Goal Focus, and Goal Conflict Scales and the Internal Consistency Reliability of the Scales

\section{Goal Commitment}

\section{Charlotte-Mecklenburg}

It's hard to take the Benchmark Goals seriously. (scale reversed)

I am strongly committed to pursuing my school's Benchmark Goals.

Quite frankly, I don't care if my school achieves its Benchmark Goals or not.

(scale reversed)

Kentucky

It's hard to take the accountability goals seriously. (scale reversed)

I am strongly committed to pursuing my school's accountability goals.

Quite frankly, I don't care if my school achieves its accountability goals or not. (scale reversed)

\section{Goal Clarity}

\section{Charlotte-Mecklenburg}

I have a clear understanding of what my school's Benchmark Goals are.

I know how much each aspect of student achievement needs to improve in order to reach the

Benchmark Goals for this year.

I have a good understanding of how student achievement related to the Benchmark Goals is measured in the subject(s) I teach.

I could explain my school's Benchmark Goals to others if asked.

\section{Kentucky}

I have a clear understanding of what my school's accountability goals are.

I know how much each aspect of student achievement needs to improve in order to reach the accountability goals for this cycle.

I have a good understanding of how student achievement is measured by KIRIS in the subject(s) I teach.

I could explain my school's accountability goals to others if asked.

\section{Goal Focus}

\section{Kentucky}

The accountability goals provide a focus for my teaching efforts.

The accountability goals tell us what is most important for the school to accomplish.

\section{Goal Conflict}

\section{Charlotte-Mecklenburg}

This year's Benchmark Goals conflict with other important goals of our school.

Working toward our school's Benchmark Goals prevents me from working toward other important educational goals.

\section{Kentucky}

The accountability goals conflict with other important goals of our school.

Working toward our school's accountability goals prevents me from working toward other important educational goals. 
Table A3. Relationship of Expected Value of Positive Outcomes of School-Based Performance Award Programs to Goal Clarity, Commitment, and Choice of Goal Level

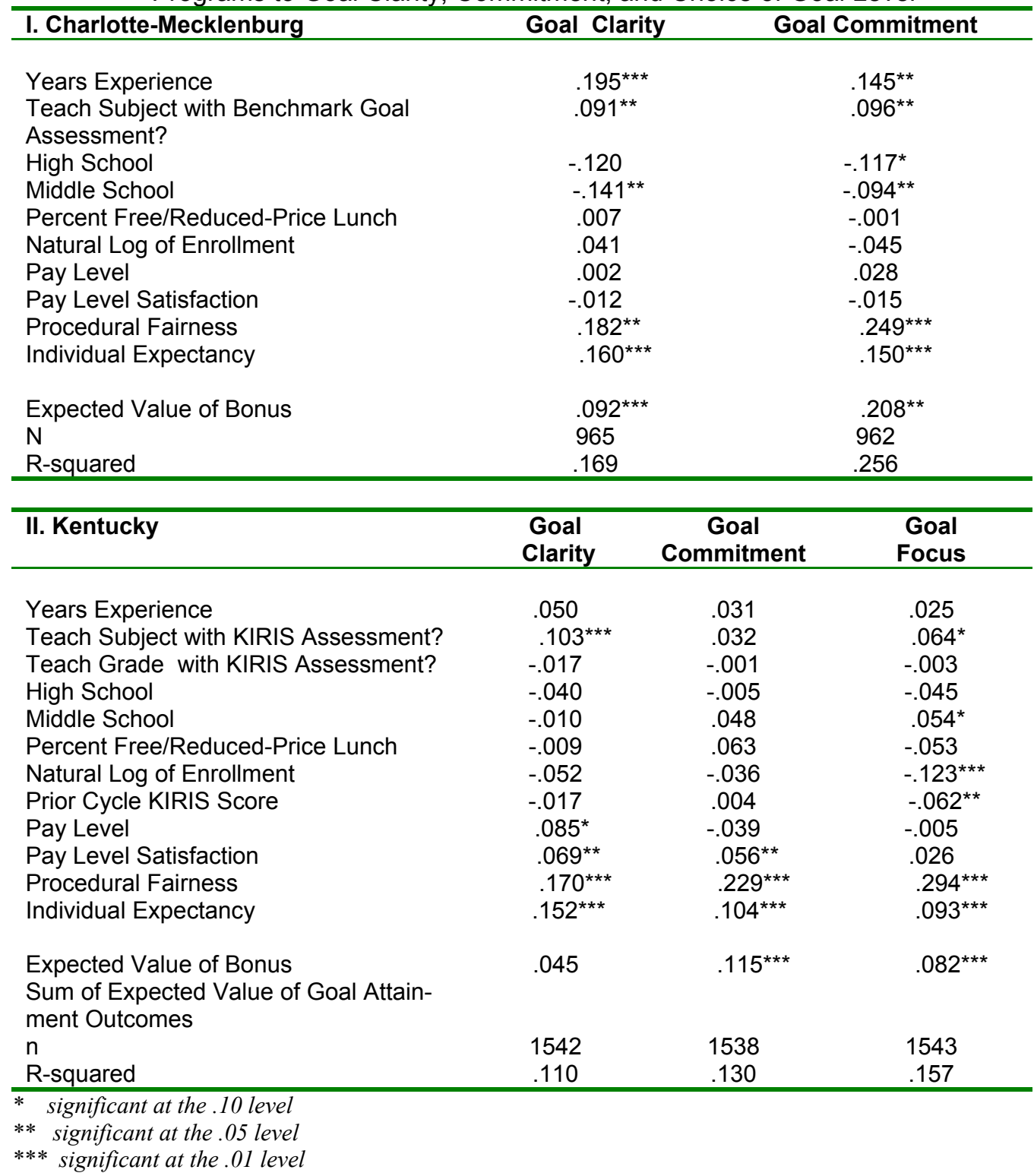

\section{Comment on Table A3}

The control variables of teaching experience (whether teaching a subject or grade in which an accountability assessment is given), school level, school percent on free/reduced-price lunch, school size, perceptions of program fairness were included because they represent factors that are likely to affect commitment or clarity. Pay level, pay level satisfaction, and individual expectancy are included because they are likely to affect the motivational value of the bonus. For the Kentucky analysis, an additional control variable the value of the prior cycle's accountability index was added since it might be harder to improve at higher absolute levels of achievement, and this could in turn have a negative effect on goal commitment and focus. 
Table A4. Standard Deviations of Probability Ratings (Instrumentalities) of Outcomes Associated with School-Based Performance Award Programs

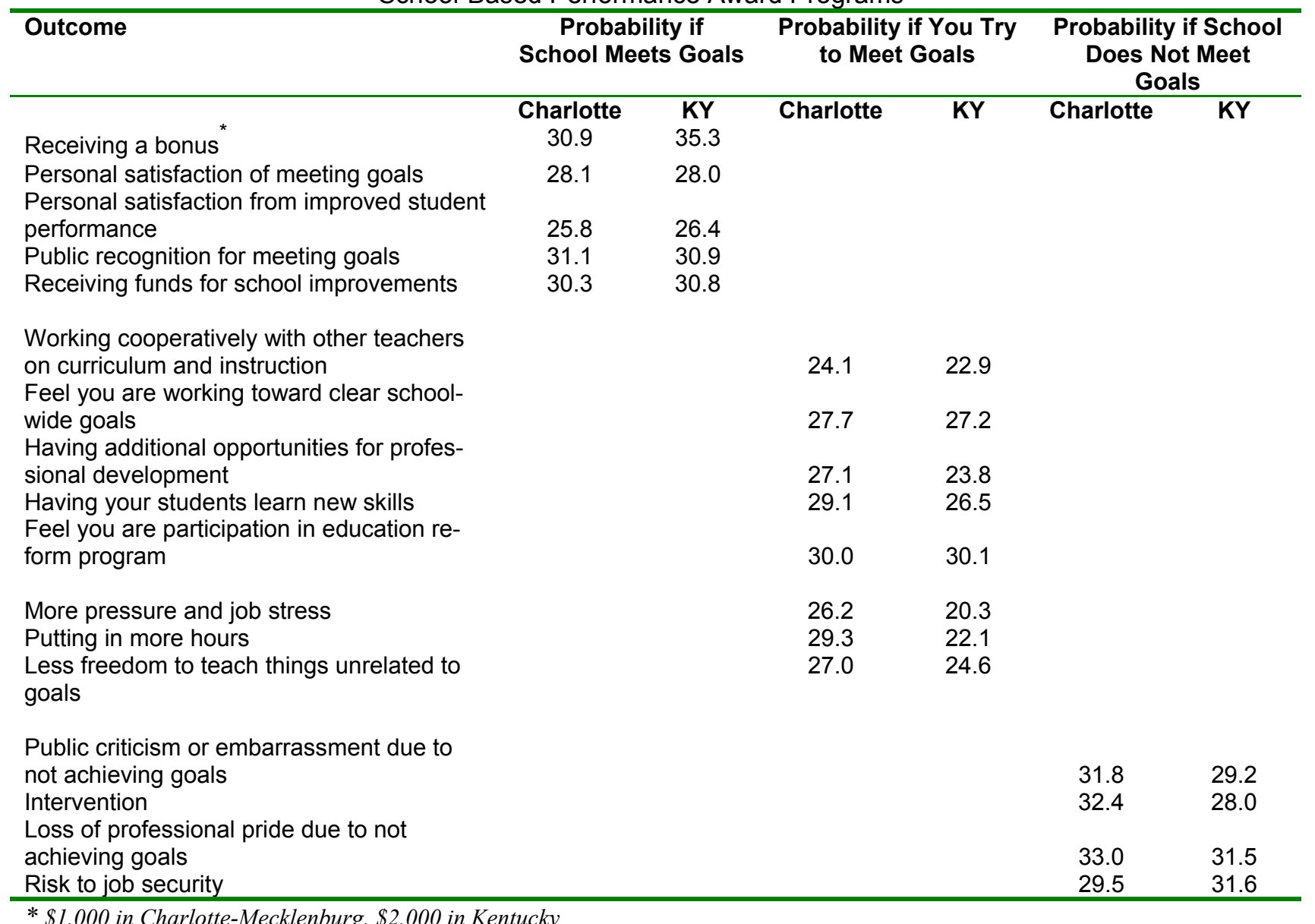


Table A5. Items Used in Scales for Analysis of Teacher Expectancy

\section{Dependent Variables:}

\section{Individual Teacher Expectancy}

Charlotte-Mecklenburg: If you were to make the highest level of effort you would be comfortable with (that you could sustain for the whole year), what is the probability or likelihood of your school meeting its Benchmark Goals? $(0 \%, 10 \%, 20 \%, \ldots 100 \%)$

Kentucky: What is the chance, probability, or likelihood that if you personally were to make the highest level of effort you could, your school would exceed its accountability goals by enough to be a "Reward" school? $(0 \%, 10 \%$, $20 \%, \ldots 100 \%)$

\section{Teacher Group Expectancy:}

Charlotte-Mecklenburg: If you and your colleagues were to work together as hard as you could, what is the probability or likelihood of your school meeting its Benchmark Goals? $(0 \%, 10 \%, 20 \%, \ldots 100 \%)$

Kentucky: What is the chance, probability, or likelihood that if you and your colleagues were to work together as hard as you could, your school would exceed its accountability goals by enough to be a "Reward" school? $(0 \%$, $10 \%, 20 \%, \ldots 100 \%)$

\section{Independent Variables:}

\section{School Characteristics:}

School Size: Student Headcount Enrollment

Free Lunch: Percent Free and Reduced-Price Lunch

Reward History: for Charlotte-Mecklenburg, 1995-96 performance on the Benchmark Goals (Reward=1, Nonreward=0); for Kentucky: Cycle 2 performance on the Kentucky School-Based Accountability Program (Reward=1, Nonreward $=0$ )

Enabling Conditions: Scales created from responses to the following five-point likert scale questions:

\section{Feedback}

Charlotte-Mecklenburg: Concerning the feedback you receive about the Benchmark Goals Program, to what extent:

- Do you receive the results of the tests or other assessments that are used to measure whether your school achieved its Benchmark Goals in the subjects you teach?

- Do you know how to interpret the results of the assessments related to the Benchmark Goals?

- Are the results of these assessments useful to you in figuring out how to help achieve your school's Benchmark Goals?

Kentucky: Concerning the feedback you receive about the accountability goals, to what extent:

- Do you receive KIRIS results relevant to the subjects you teach?

- Do you know how to interpret the results of the KIRIS assessments in relation to the accountability goals?

- Are the results of the KIRIS assessments useful to you in figuring out how to help achieve your school's accountability goals?

\section{Alignment}

Charlotte-Mecklenburg: At your school, to what extent:

- are teachers evaluated based on their efforts to achieve the school's Benchmark Goals?

- are new curriculum development efforts linked to the Benchmark Goals assessment?

- are teachers provided time to plan together about how to achieve the Benchmark Goals? 
- has your school mobilized its resources to meet its Benchmark Goals?

- do professional development activities in your school focus on helping you acquire knowledge and skills related to meeting the Benchmark Goals?

Kentucky: At your school, to what extent:

- Are teachers evaluated based on their efforts to achieve the school's accountability goals?

- Are new curriculum development efforts linked to KIRIS?

- Are teachers provided time to plan together about how to achieve the accountability goals?

- Has your school mobilized its resources to meet its accountability goals?

- Do professional development activities in your school focus on helping you acquire knowledge and skills related to meeting the accountability goals?

Community (a): At your school, to what extent do teachers in your school work together to improve teaching knowledge and skills?

Community (b) (for Kentucky only):

At your school, to what extent do teachers in your school work together to improve teaching knowledge and skills?

Do teachers seek the advice of other teachers when they have a teaching problem?

Do teachers discuss ideas about how to improve teaching and student learning among themselves?

Do teachers share a vision of student learning and what it takes to accomplish it?

Do teachers hold one another accountable to work hard to increase student learning?

Teacher Participation: At your school, to what extent:

- Do teachers make important decisions about curriculum and instruction?

- Do teachers make important decisions about the allocation of the school's budget?

- Do teachers make important decisions about the hiring of new teachers?

- Are teachers provided with the information they need to participate meaningfully in school-level management decisions?

\section{Principal Support}

Charlotte-Mecklenburg: To what extent is your school's principal:

- committed to achieving your school's Benchmark Goals?

- supportive of your efforts to achieve the school's Benchmark Goals?

- willing to work with teachers to help them understand how to achieve the Benchmark Goals?

Kentucky: To what extent is your school's principal:

- committed to achieving your school's accountability goals?

- supportive of your efforts to achieve the school's accountability goals?

- willing to work with teachers to help them understand how to achieve the accountability goals?

Goal Conflict (extent of agreement or disagreement with the following statements)

Charlotte-Mecklenburg:

- This year's Benchmark Goals conflict with other important goals of our school.

- Working toward our school's Benchmark Goals prevents me from working toward other important educational goals.

Kentucky:

- The accountability goals conflict with other important goals of our school.

- Working toward our school's accountability goals prevents me from working toward other important educational goals.

Teacher Attitudes: Scale created from responses to the following five-point likert scale questions: 
Fairness (extent of agreement or disagreement with the following statements)

Charlotte-Mecklenburg:

- The way our school's Benchmark Goals were established was fair.

- As a way to measure school performance, the Benchmark Goals are fair.

- Overall, the way the Benchmark Goals program is run is fair.

Kentucky:

- The way our school's accountability goals were established was fair.

- As a way to measure school performance, the accountability goals are fair.

- Overall, the way the accountability program is run is fair.

Goal Clarity (extent of agreement or disagreement with the following statements):

Charlotte-Mecklenburg:

- I have a clear understanding of what my school's Benchmark Goals are.

- I know how much each aspect of student achievement needs to improve in order to reach the Benchmark Goals for this year.

- I have a good understanding of how student achievement related to the Benchmark Goals is measured in the subject(s) I teach.

- I could explain my school's Benchmark Goals to others if asked.

Kentucky :

- I have a clear understanding of what my school's accountability goals are.

- I know how much each aspect of student achievement needs to improve in order to reach the accountability goals for this cycle.

- I have a good understanding of how student achievement is measured by KIRIS in the subject(s) I teach.

- I could explain my school's accountability goals to others if asked.

Teacher Characteristics

Experience: Total number of years of teaching experience.

Education: $1=$ Highest degree obtained is MA/MS, MA/MS plus credits, or EdD or PhD, else $=0$ 
Table A6. Means, Standard Deviations, and Intercorrelations of Variables Used to Predict Teacher Expectancy Levels Charlotte-Mecklenburg and Kentucky

\section{Charlotte-Mecklenburg ( $\mathrm{n}=900)$}

\begin{tabular}{|c|c|c|c|c|c|c|c|c|c|c|c|c|c|c|c|c|c|c|}
\hline Variable & Mean & Std & 1 & 2 & 3 & 4 & 5 & 6 & 7 & 8 & 9 & 10 & 11 & 12 & 13 & 14 & 15 & 16 \\
\hline 1. Individual Expectancy & 55.4 & 29.2 & & & & & & & & & & & & & & & & \\
\hline 2. Group Expectancy & 61.6 & 28.9 & .879 & & & & & & & & & & & & & & & \\
\hline 3. High School & 0.23 & 0.42 & -.112 & -.132 & & & & & & & & & & & & & & \\
\hline 4. Middle School & 0.23 & 0.42 & -.006 & -.066 & -.300 & & & & & & & & & & & & & \\
\hline 5. School Size & 6.72 & 0.47 & -.071 & -.101 & .747 & .015 & & & & & & & & & & & & \\
\hline 6. Free Lunch & 34.2 & 18.3 & .014 & .036 & -.480 & .008 & .035 & & & & & & & & & & & \\
\hline 7. Reward History & 0.56 & 0.64 & .113 & .153 & -.018 & -.316 & -.109 & -.035 & & & & & & & & & & \\
\hline 8. Feedback & 3.24 & 0.96 & .292 & .324 & -.025 & -.143 & -.065 & .035 & .147 & & & & & & & & & \\
\hline 9. Alignment & 3.14 & 0.86 & .233 & .266 & -.118 & -.106 & -.134 & .101 & .115 & .471 & & & & & & & & \\
\hline 10. Community a & 3.38 & 1.10 & .125 & .206 & -.007 & -.108 & -.116 & .033 & .152 & .328 & .607 & & & & & & & \\
\hline 11. Participation & 2.68 & 0.95 & .156 & .184 & .085 & -.016 & .039 & -.090 & -.015 & .306 & .489 & .439 & & & & & & \\
\hline 12. Principal Support & 4.14 & 0.95 & .204 & .276 & -.006 & -.010 & -.012 & -.028 & .149 & .431 & .626 & .469 & .489 & & & & & \\
\hline 13. Goal Conflict & 2.81 & 1.00 & -.224 & -.217 & .089 & -.053 & .065 & -.029 & -.063 & -.230 & -.274 & -.166 & -.265 & -.197 & & & & \\
\hline 14. Fairness & 2.60 & 0.92 & .358 & .339 & .119 & -.016 & .079 & -.075 & 108 & .206 & .228 & .181 & .257 & .200 & -.311 & & & \\
\hline 15. Clarity & 3.51 & 1.01 & .242 & .272 & -.016 & -.145 & -.024 & .014 & .156 & .508 & .411 & .294 & .292 & .453 & -.173 & .195 & & \\
\hline 16. Experience & 13.4 & 9.5 & -.035 & -.013 & .119 & -.036 & .152 & -.127 & .011 & .202 & .116 & .073 & .043 & .126 & -.029 & -.093 & .173 & \\
\hline 17. Education & 0.37 & 0.48 & -.043 & -.045 & .006 & -.023 & -.024 & -.021 & .033 & .085 & .033 & .059 & .042 & .068 & .028 & -.062 & .033 & .278 \\
\hline
\end{tabular}

\section{Kentucky $(n=1384)$}

\begin{tabular}{|c|c|c|c|c|c|c|c|c|c|c|c|c|c|c|c|c|c|c|c|}
\hline Variable & Mean & Std & 1 & 2 & 3 & 4 & 5 & 6 & 7 & 8 & 9 & 10 & 11 & 12 & 13 & 14 & 15 & 16 & 17 \\
\hline 1. Individual Expectancy & 38.4 & 26.6 & & & & & & & & & & & & & & & & & \\
\hline 2. Group Expectancy & 51.9 & 28.8 & 691 & & & & & & & & & & & & & & & & \\
\hline 3. High School & 0.34 & 0.48 & -.122 & -.025 & & & & & & & & & & & & & & & \\
\hline 4. Middle School & 0.22 & 0.41 & -.056 & -.100 & -.380 & & & & & & & & & & & & & & \\
\hline 5. School Size & 6.38 & 0.53 & -.108 & .006 & .544 & .032 & & & & & & & & & & & & & \\
\hline 6. Free Lunch & 43.2 & 21.6 & .016 & -.017 & -.440 & .066 & -.498 & & & & & & & & & & & & \\
\hline 7. Reward History & 0.38 & 0.49 & .238 & .235 & -.113 & -.220 & -.169 & .020 & & & & & & & & & & & \\
\hline 8. Feedback & 3.07 & 0.89 & .291 & .266 & -.158 & .039 & -.156 & .081 & .091 & & & & & & & & & & \\
\hline 9. Alignment & 3.33 & 0.75 & .208 & .184 & -.248 & .090 & -.151 & .079 & .041 & .381 & & & & & & & & & \\
\hline 10. Community a & 3.36 & 0.98 & .224 & .158 & -.233 & .043 & -.154 & .049 & .070 & .277 & .681 & & & & & & & & \\
\hline 11. Community b & 3.34 & 0.81 & .221 & .118 & -.224 & .019 & -.193 & .075 & .087 & .300 & .647 & .794 & & & & & & & \\
\hline 12. Participation & 3.09 & 0.95 & .210 & .183 & -.108 & -.077 & -.131 & .081 & .106 & .294 & .558 & .463 & .450 & & & & & & \\
\hline 13. Principal Support & 4.06 & 0.90 & 177 & .197 & -.093 & .016 & -.097 & .008 & .055 & .254 & .563 & .436 & .385 & .487 & & & & & \\
\hline 14. Goal Conflict & 3.21 & 1.05 & -.274 & -.372 & .063 & .051 & .070 & .000 & -.128 & -.235 & -.193 & -.130 & -.113 & -.275 & -.217 & & & & \\
\hline 15. Fairness & 2.35 & 0.87 & .355 & .462 & -.003 & -.096 & .021 & -.020 & .202 & .249 & .137 & .101 & .062 & .174 & .134 & -.454 & & & \\
\hline 16. Clarity & 3.52 & 0.85 & .192 & .206 & -.072 & -.002 & -.077 & .018 & .078 & .576 & .358 & .303 & .306 & .309 & .296 & -.266 & .242 & & \\
\hline 17. Experience & 14.6 & 8.56 & -.026 & -.041 & .035 & -.074 & .036 & -.074 & -.000 & .082 & .080 & .093 & .023 & .062 & .055 & .073 & -.103 & .106 & \\
\hline 18. Education & 0.82 & 0.38 & -.065 & -.073 & -.044 & -.009 & .006 & .032 & -.009 & .067 & .017 & .058 & .004 & .028 & -.025 & .081 & -.126 & .064 & .475 \\
\hline
\end{tabular}


Table A7. Items Combined to Produce Scales Used in the Analysis of the Motivational Reactions of a Subsample of Kentucky Teachers to Features of the School-Based Performance Award Program and Internal Consistency Reliabilities

\begin{tabular}{|c|c|}
\hline Scale and Items & $\begin{array}{c}\text { Coefficient } \\
\text { Alpha }\end{array}$ \\
\hline $\begin{array}{l}\text { Fair Bonus } \\
\text { It is fair for teachers who increase student achievement to receive a bonus. } \\
\text { The size of the bonus I could receive is fair. }\end{array}$ & .71 \\
\hline $\begin{array}{l}\text { Likely Bonus Value } \\
\quad \text { Rated desirability of winning a } \$ 2,000 \text { bonus muliplied by likelihood of winning the bonus }\end{array}$ & NA \\
\hline $\begin{array}{l}\text { Unfair Winners } \\
\text { Some schools that do not deserve it are winning bonuses. } \\
\text { Some individuals that do not deserve it are winning bonuses }\end{array}$ & .82 \\
\hline $\begin{array}{l}\text { Fair Chance } \\
\text { Our school has as much chance of being a reward school as any other. } \\
\text { Our school has less chance of achieving is accountability goals because of our student } \\
\text { population. }\end{array}$ & .73 \\
\hline $\begin{array}{l}\text { Fair Process } \\
\text { As a way to measure school performance, the accountability goals are fair. } \\
\text { The standards (accountability goals) for my school to get a reward are fair. } \\
\text { The bonus part of the accountability system is administered fairly. } \\
\text { The appeal process a school can use to challenge its accountability results is fair. } \\
\text { The way our school's accountability goals were established is fair. }\end{array}$ & .81 \\
\hline $\begin{array}{l}\text { Teachers Divide } \\
\text { Only teachers should decide how to divide up the bonus money. } \\
\text { Only teachers should decide how to divide up the reward money between bonuses and school } \\
\text { improvements. }\end{array}$ & .97 \\
\hline $\begin{array}{l}\text { Principal Communication } \\
\text { Our principal works with us to achieve our accountability goals. } \\
\text { There has been adequate communication to teachers about the bonus process and program. }\end{array}$ & .55 \\
\hline $\begin{array}{l}\text { Pay Satisfaction } \\
\text { [How satisfied are you with] Your take home pay } \\
\text { [How satisfied are you with] Your current salary } \\
\text { [How satisfied are you with] Your overall pay level }\end{array}$ & .97 \\
\hline $\begin{array}{l}\text { Bonus Motivation } \\
\text { I would work just as hard to achieve our school's accountability goals even without the } \\
\text { possibility of getting a bonus. (reverse scored) } \\
\text { If the bonus were discontinued, my support for the accountability program would decrease. } \\
\text { Tripling the size of the bonus would greatly increase my motivation to meet our school's } \\
\text { accountability goals. }\end{array}$ & .62 \\
\hline $\begin{array}{l}\text { Bonus Continuation } \\
\text { The bonus part of the accountability program should be continued. }\end{array}$ & - \\
\hline $\begin{array}{l}\text { Withdrawal Intentions } \\
\text { [How likely are you to] Move to another teaching job in another school or district. } \\
\text { [How likely are you to] Move to a teaching job in a school that has been more successful in } \\
\text { meeting its goals. } \\
\text { [How likely are you to] Leave teaching for a different type of work. } \\
\text { [How likely are you to] Retire before you reach normal retirement age. }\end{array}$ & .80 \\
\hline
\end{tabular}


Table A8. Means, Standard Deviations, and Intercorrelations for Variables Used in the Analysis of the Motivational Reactions of a Subsample of Kentucky Teachers to Features of the School-Based Performance Award Program ( $n=747-751)$

\begin{tabular}{|c|c|c|c|c|c|c|c|c|c|c|c|c|c|c|c|c|c|c|c|c|}
\hline Variable & Mean & $\begin{array}{l}\text { Std. } \\
\text { Dev. }\end{array}$ & 1 & 2 & 3 & 4 & 5 & 6 & 7 & 8 & 9 & 10 & 11 & 12 & 13 & 14 & 15 & 16 & 17 & 18 \\
\hline 1. Years Experience & 15.01 & 8.80 & - & & & & & & & & & & & & & & & & & \\
\hline 2. Job Satisfaction & 3.27 & 1.09 & -.04 & - & & & & & & & & & & & & & & & & \\
\hline 3. Teach KIRIS Subject & 0.85 & 0.36 & -.04 & -.06 & - & & & & & & & & & & & & & & & \\
\hline 4. Teach KIRIS Grade & 0.73 & 0.45 & -.05 & -.05 & .22 & - & & & & & & & & & & & & & & \\
\hline 5. High School & 0.34 & 0.47 & .05 & .02 & -.01 & .17 & - & & & & & & & & & & & & & \\
\hline 6. Middle School & 0.30 & 0.46 & -.12 & -.00 & .08 & .07 & -.47 & - & & & & & & & & & & & & \\
\hline 7. MA or Above & 0.81 & 0.39 & .50 & -09 & -.03 & -.06 & -.03 & -.02 & - & & & & & & & & & & & \\
\hline 8. Cycle 2 Bonus & 0.45 & 0.50 & -.03 & .12 & -.02 & -.01 & .09 & -.19 & -.06 & - & & & & & & & & & & \\
\hline 9. Pay Satisfaction & 2.47 & 1.06 & -.09 & .32 & -.02 & -.04 & .01 & .05 & -.02 & .05 & - & & & & & & & & & \\
\hline 10. Fair Bonus & 2.96 & 0.94 & -.08 & .22 & .02 & .05 & .09 & -.03 & -.12 & .16 & .18 & - & & & & & & & & \\
\hline 11. Expected Bonus Value & 2.41 & 1.62 & .01 & .20 & -.05 & -.07 & -.07 & -.01 & -.00 & .29 & .04 & .29 & - & & & & & & & \\
\hline 12. Unfair Winners & 3.60 & 0.93 & .01 & -.19 & .04 & .10 & .07 & .03 & .02 & -.20 & -.16 & -.28 & -.18 & - & & & & & & \\
\hline 13. Fair Chance & 3.00 & 1.06 & .01 & .23 & -.01 & .01 & .01 & .01 & -.06 & .29 & .20 & .27 & .33 & -.28 & - & & & & & \\
\hline 14. Fair Process & 2.62 & 0.74 & -.04 & .38 & -.06 & -.03 & .03 & -.02 & -.07 & .28 & .25 & .55 & .34 & -.44 & .47 & - & & & & \\
\hline 15. Teachers Divide & 3.25 & 1.16 & .10 & -.02 & -.02 & .02 & .06 & -.04 & .06 & .18 & -.11 & .11 & .12 & -.01 & .08 & .06 & - & & & \\
\hline 16. Principal Communication & 3.57 & 0.89 & .10 & .32 & -.04 & .02 & -.01 & -.01 & .05 & .16 & .17 & .22 & .23 & -.24 & .25 & .34 & .04 & - & & \\
\hline 17. Bonus Motivation & 2.30 & 0.81 & -.14 & -.04 & -.01 & .02 & .13 & -.05 & -.03 & .17 & -.14 & .30 & .15 & -.05 & .09 & .18 & .20 & -.08 & - & \\
\hline 18. Bonus Continuation & 2.03 & 0.84 & -.12 & .18 & .01 & .04 & .06 & .02 & -.13 & .23 & .03 & .57 & .28 & -.26 & .28 & .47 & .17 & .14 & .44 & - \\
\hline 19. Withdrawal Intentions & 3.09 & 0.84 & .02 & -.41 & .05 & .08 & .01 & .04 & .06 & -.12 & -.18 & -.23 & -.15 & .31 & -.29 & -.42 & -.01 & -.22 & .03 & -.18 \\
\hline
\end{tabular}


Table A9. Means, Standard Deviations, and Intercorrelations for Variables Used in the Analysis of Charlotte-Mecklenburg Teacher Withdrawl $\left(\mathrm{n}=1150^{\mathrm{a}}\right)$

\begin{tabular}{|c|c|c|c|c|c|c|c|c|c|c|c|c|c|c|c|c|c|c|}
\hline Variable & Mean & SD & 1 & 2 & 3 & 4 & 5 & 6 & 7 & 8 & 9 & 10 & 11 & 12 & 13 & 14 & 15 & 16 \\
\hline 1. Years in Job & 5.04 & 5.52 & -- & & & & & & & & & & & & & & & \\
\hline 2. $M A / M S$ & 0.38 & .49 & .07 & -- & & & & & & & & & & & & & & \\
\hline 3. Age & 39.77 & 10.45 & .42 & .27 & -- & & & & & & & & & & & & & \\
\hline 4. Teach Math/Science & 0.09 & .28 & .04 & -.01 & -.01 & -- & & & & & & & & & & & & \\
\hline 5. High School & 0.09 & .28 & .13 & .04 & .10 & .19 & -- & & & & & & & & & & & \\
\hline 6. Middle School & 0.19 & .39 & .03 & -.02 & -.01 & .26 & -.15 & -- & & & & & & & & & & \\
\hline 7. Gender & 0.88 & .32 & -.07 & -.08 & -.02 & -.12 & -.19 & -.25 & -- & & & & & & & & & \\
\hline 8. Minority & 0.16 & .37 & .13 & .02 & .05 & .01 & .04 & .06 & -.05 & -- & & & & & & & & \\
\hline $\begin{array}{l}\text { 9. \% Free/Reduced-Price } \\
\text { Lunch }\end{array}$ & 38.00 & 17.97 & -.08 & -.04 & -.11 & -.13 & -.35 & -.09 & .15 & .02 & -- & & & & & & & \\
\hline 10. Pay Level (1000's) & 29.66 & 7.06 & .50 & .39 & .69 & .00 & .16 & .01 & -.09 & .12 & -.14 & -- & & & & & & \\
\hline 11. Pay Lvl Satisfaction & 1.61 & .74 & .01 & .04 & .11 & -.03 & .06 & -.03 & .02 & -.03 & .01 & .07 & -- & & & & & \\
\hline 12. Bonus School & 0.51 & .50 & -.04 & .00 & .01 & -.06 & .04 & -.30 & .10 & -.05 & .03 & -.04 & .05 & -- & & & & \\
\hline 13. Fair to Receive Bonus & 3.11 & .82 & -.08 & -.09 & -.15 & .04 & .02 & -.02 & .07 & .03 & .01 & -.14 & .19 & .02 & -- & & & \\
\hline 14. Intent to Leave & 2.61 & .74 & -.12 & .05 & -.06 & .00 & .00 & .01 & -.04 & -.15 & .10 & -.08 & -.01 & -.05 & -.10 & -- & & \\
\hline 15. Leave District & 0.08 & .26 & -.08 & -.05 & -.12 & -.02 & -.04 & .01 & .00 & -.03 & .05 & -.12 & .05 & .01 & .02 & .12 & -- & \\
\hline 16. Transfer Schools & 0.11 & .32 & -.07 & .01 & -.01 & .09 & .03 & .06 & -.02 & -.01 & .06 & -.05 & .01 & -.09 & -.02 & .11 & -.10 & -- \\
\hline 17. Total Turnover & 0.19 & .39 & -.11 & -.03 & -.09 & .06 & .01 & .06 & -.02 & -.03 & .08 & -.12 & .04 & -.06 & -.01 & .17 & .59 & .74 \\
\hline
\end{tabular}

Note: $r=.04, p<.10 ; r=.06, p<.05 ; r=.07, p<.01$

(a) For the turnover analyses, missing values of the independent variables were replaced by mean values. 
Table A10. Items Combined to Produce Fairness of School-Based Performance Award Programs Scales and the Internal Consistency Reliability of the Scales

\begin{tabular}{lcc}
\hline Scale and Items & $\begin{array}{c}\text { Charlotte } \\
\text { Coefficient } \\
\text { Alpha }\end{array}$ & $\begin{array}{c}\text { Kentucky } \\
\text { Coefficient } \\
\text { Alpha }\end{array}$ \\
\hline $\begin{array}{c}\text { School has a fair chance to win award (2 item scale) } \\
\text { Our school has as much chance of being a reward school as any other. }\end{array}$ & .78 \\
Our school has less chance of achieving its accountability goals than others \\
Because of our student population. (scale reversed) \\
Program is procedurally fair \\
As a way to measure school performance, the accountability goals are fair. \\
The way our school's accountability goals were established is fair. \\
Overall, the way the accountability program is run is fair. \\
\hline
\end{tabular}

\section{Technical Issues in School-Level Analysis of School Performance}

As mentioned in the body of the paper, analyses of the effect of teacher motivational responses were done at the school level. This involved aggregating individual teacher responses by calculating the mean for each school of the scale or variable of interest. Unfortunately, there were a number of schools in which only a few teachers responded. A decision was made to drop schools from any school-level analyses if there were not at least four respondents per school. This meant dropping two schools from the Charlotte-Mecklenburg analysis and 50 schools from the Kentucky analysis. Additional schools also were dropped for both sites because information about some other variable needed for a specific analysis was not available for that school. This meant that for Charlotte, the sample size for school-level analyses was 114, and for Kentucky, 204. For the Charlotte schools, the average number of respondents per school for these schools was 9.6, while for the Kentucky schools, it was 7.8.

Whenever individual-level data are aggregated to form a score purporting to represent a higherlevel entity such as a school, the question of the degree of agreement in the responses of the individuals arises. Here we are concerned with the within-school averages of teachers' ratings of their motivational responses, which we are using to represent the average level of these constructs within each school. Within-school variability in individual teachers' responses leads to sampling error in each school-level average. One way to assess within-school variability is to calculate the intraclass correlation coefficient (ICC) within-school and use this coefficient to estimate the reliability of the school average using the Spearman-Brown formula (Nunnally, 1978). Table 11 shows the ICCs and reliability estimates for the motivational variables. 
Table A11. Intraclass Correlations, Reliabilities, and Average Within-School Standard Errors for SchoolLevel Expectancy Theory Variables

\begin{tabular}{|c|c|c|c|c|c|c|}
\hline Variable & $\begin{array}{l}\text { Charlotte } \\
\text { ICC }\end{array}$ & $\begin{array}{c}\text { Charlotte } \\
\text { Reliability } \\
\text { of Within- } \\
\text { School } \\
\text { Avg. }\end{array}$ & $\begin{array}{c}\text { Charlotte } \\
\text { Average } \\
\text { Within- } \\
\text { School } \\
\text { Stand. } \\
\text { Err. }\end{array}$ & $\begin{array}{l}\text { Kentucky } \\
\text { ICC }\end{array}$ & $\begin{array}{c}\text { Kentucky } \\
\text { Reliability } \\
\text { of Within- } \\
\text { School } \\
\text { Avg. }\end{array}$ & $\begin{array}{c}\text { Kentucky } \\
\text { Average } \\
\text { Within- } \\
\text { School } \\
\text { Stand. } \\
\text { Err. }\end{array}$ \\
\hline $\begin{array}{l}\text { Individual Expectancy - Reward } \\
\text { Individual Expectancy-Avoid Sanc- } \\
\text { tions }\end{array}$ & $\begin{array}{c}.093 \\
-\end{array}$ & $\begin{array}{c}479 \\
-\end{array}$ & 9.62 & $\begin{array}{l}.115 \\
.051\end{array}$ & $\begin{array}{l}.496 \\
.289\end{array}$ & $\begin{array}{l}9.08 \\
9.60\end{array}$ \\
\hline Expected Value - Bonus & .072 & .421 & .24 & .130 & .533 & .27 \\
\hline $\begin{array}{l}\text { Expected Value - Goal Attainment } \\
\text { Outcomes }\end{array}$ & .087 & .468 & .71 & .089 & .423 & .77 \\
\hline $\begin{array}{l}\text { Expected Value - Learning Out- } \\
\text { comes }\end{array}$ & .075 & .429 & .79 & .090 & .426 & .86 \\
\hline Expected Value - Sanctions & .004 & .038 & .78 & .041 & .245 & .82 \\
\hline Expected Value - Stress Outcomes & .058 & .363 & .57 & .029 & .183 & .67 \\
\hline
\end{tabular}

The ICCs in the table can be interpreted as the percent of variation in teachers' response levels that is accounted for by working in the same school. The reliability coefficient can be interpreted as the expected correlation between average scorers across different samples of the same size within the average school in the sample. While the ICCs show that there is significant betweenschool variation in the motivational reactions (all of the underlying ANOVA's show a betweenschool effect significant at the .05 level or beyond, except for the expected value of sanctions for Charlotte-Mecklenburg) the proportion of variation attributable to schools is relatively low. While we did not expect to see a large school effect for the expected value variables (in part, because there is no a priori reason to think that teachers differ greatly in what they value across schools), the small school effect on expectancy was not expected, since the motivational model and prior results at the individual level suggest that what happens at the school level (e.g., principal leadership and feedback) helps determine expectancy perceptions.

However, it should be recognized that ICCs are not the ideal basis for reliability assessment here, because they tend to be low when between-group variation is low, even if there is relatively good agreement within groups (schools) (Jones et al, 1983). Therefore, another measure of withinschool variation, the within-school standard error of each of these measures was also calculated, and their averages are shown in Table A11. In general, the average standard errors of the aggregated measures cover about 10-15 percent of the observed range of school averages. A confidence interval of plus and minus two standard errors around the mean would on the average cover 40-60 percent of the observed ranges. This means that the school-level averages are likely to be subject to a substantial degree of sampling error, which would likely attenuate the observed relationships among the school-level averages of the motivational constructs. 
Table A12. Means, Standard Deviations, and Intercorrelations of School-Level Variables

\section{Charlotte-Mecklenburg}

\begin{tabular}{|c|c|c|c|c|c|c|c|c|c|c|}
\hline & Mean & Std. Dev. & 1 & 2 & 3 & 4 & 5 & 6 & 7 & 8 \\
\hline 1. Goal Points & 50.21 & 15.73 & & & & & & & & \\
\hline 2. Log Enrollment & 6.51 & 0.44 & -0.280 & & & & & & & \\
\hline 3. Percent Free/Reduced Lunch & 38.25 & 0.18 & -0.382 & -0.518 & & & & & & \\
\hline 4. Expectancy & 56.58 & 12.88 & 0.280 & -0.171 & 0.049 & & & & & \\
\hline 5. Bonus & 1.17 & 0.31 & 0.175 & -0.012 & -0.028 & 0.453 & & & & \\
\hline 6. Goal Attainment Outcomes & 3.85 & 0.96 & 0.047 & -0.078 & 0.136 & 0.515 & 0.788 & & & \\
\hline 7. Learning Outcomes & 5.22 & 1.00 & -0.716 & -0.248 & 0.285 & 0.500 & 0.411 & 0.645 & & \\
\hline 8. Sanctions & -1.30 & 0.83 & 0.146 & 0.230 & -0.213 & -0.097 & -0.145 & -0.174 & -0.221 & \\
\hline 9. Stress Outcomes & -2.52 & 0.74 & -0.093 & -0.017 & -0.037 & 0.088 & -0.014 & -0.013 & 0.018 & 0.093 \\
\hline
\end{tabular}

\section{Kentucky}

\begin{tabular}{|c|c|c|c|c|c|c|c|c|c|c|c|c|}
\hline & Mean & Std. Dev. & 1 & 2 & 3 & 4 & 5 & 6 & 7 & 8 & 9 & 10 \\
\hline 1. KIRIS Index Change & 4.09 & 4.70 & & & & & & & & & & \\
\hline 2. Log Enrollment & 6.21 & 0.49 & 0.063 & & & & & & & & & \\
\hline 3. Percent Free/Reduced Lunch & 46.93 & 20.80 & -0.144 & -0.393 & & & & & & & & \\
\hline 4. Cycle 2 KIRIS Index & 44.80 & 6.56 & -0.369 & -0.021 & -0.472 & & & & & & & \\
\hline 5. Expectancy - Reward Status & 39.00 & 14.35 & -0.057 & -0.076 & -0.110 & 0.500 & & & & & & \\
\hline 6. Expectancy - Avoiding Decline & 44.60 & 12.40 & 0.003 & -0.104 & -0.042 & 0.355 & 0.855 & & & & & \\
\hline 7. Bonus & 0.64 & 0.04 & -0.024 & -0.016 & 0.021 & 0.303 & 0.413 & 0.435 & & & & \\
\hline 8. Goal Attainment Outcomes & 2.97 & 1.09 & -0.158 & -0.080 & 0.029 & 0.280 & 0.481 & 0.512 & 0.853 & & & \\
\hline 9. Learning Outcomes & 4.36 & 1.24 & -0.112 & -0.199 & 0.011 & 0.316 & 0.451 & 0.446 & 0.548 & 0.721 & & \\
\hline 10. Sanctions & -3.57 & 1.02 & -0.113 & -0.007 & -0.116 & 0.223 & 0.277 & 0.206 & 0.075 & 0.112 & 0.236 & \\
\hline 11. Stress Outcomes & -3.26 & 0.83 & -0.165 & -0.073 & -0.037 & 0.259 & 0.309 & 0.291 & 0.322 & 0.401 & 0.393 & 0.472 \\
\hline
\end{tabular}




\section{Table A13. Items and Factor Loadings from Factor Analysis of Kentucky and Maryland Principal Survey Responses}

\section{Financial Incentives (Factor 1)}

Qvii6* Tripling the size of the reward available would greatly increase the motivation of teachers to meet our school's goals.

Qvii4* The possibility of a bonus helps me motivate teachers to work toward the accountability goals.

Qvii** Tripling the size of the reward available would greatly increase the motivation of teachers to meet our school's goals.

Qvii5* The bonus provides a shared goal that encourages school staff to work together.

Qvii7* The possibility of the bonus motivates me to work toward achieving the accountability goals.

Qvii10* The bonus part of the accountability program should be continued.

Qvii3* Is it fair for teachers who increase student achievement to receive a bonus?

Qviii5* To what extent have you as a principal referred to the possibility of getting a bonus in discussing the school's accountability goals with the teachers?

\section{Improvement of Teaching (Factor 2)}

To what extent:

Qii5 have teachers worked together to plan and implement changes in what is taught or how teaching is done?

Qii3 have teachers changed the way they teach (e.g., used different teaching methods)?

Qiil have teachers spent more hours on teaching and teaching-related tasks?

Qii4 have teachers engaged in professional development activities (e.g., in-service or other training) aimed at increasing their ability to help students achieve higher [accountability program] scores?

Qii2 have teachers changed the content of what they teach?

Qii9* does the typical teacher in this school continually strive to keep up with the latest developments in curriculum and instructional practice?

Qii6 have teachers focused their teaching more on those aspects of student learning related to the [accountability program] assessments?

Qiii20 are teachers provided time to plan together about how to improve students scores on the [accountability program] tests?

\section{District Support (Factor 3)}

To what extent:

Qv2 do district staff support your efforts to achieve your school's accountability goals?

Qv3 has your district provided you with technical assistance toward achieving your school's accountability goals?

Qv5 has your district provided you with the resources you need to achieve your school's accountability goals?

Qv1* are district administrative staff committed to the accountability program?

Qv6 has your district provided you the discretion to do what needs to be done to achieve your school's accountability goals?

\section{Principal Understanding/Commitment (Factor 4)}

Qi2 I know how much each factor of the accountability index needs to improve to reach this cycle's accountability goals.

Qi4 I could explain my school's accountability goals to others if asked.

Qi1 I have a clear understanding of what my school's accountability goals are.

Qi3 I have a good understanding of how student achievement is measured by the ...tests used in the accountability program.

Qi9 I am strongly committed to pursuing my school's accountability goals.

\section{Resource Allocation (Factor 5)}

To what extent:

Qiii11 have budgeted funds been reallocated to acquire instructional materials that would contribute to better [accountability program] scores?

Qiii14 has your school invested in new technology (e.g., computers, Internet) to achieve the accountability goals? 
Qiii12 have tutoring or similar programs been established in subjects covered by the [accountability program's] tests?

Qiii10 has staff been reallocated to assign the better teachers to the [accountability program's] assessment grades?

Qiii9 are incentives or rewards provided for students to do well on the tests?

Qiii7 are new curriculum development efforts linked to the [accountability program's] assessments?

\section{Principal Skill (Factor 6)}

To what extent:

Qii11 do you yourself have the knowledge and skills to help teachers improve their teaching?

Qii12 do you have the skills needed to mobilize your school to achieve its accountability goals?

Qiiil have you as a principal helped teachers figure out what they need to do to help achieve the accountability goals?

Qii10 do you know how to use the results of the [accountability program's] assessments to figure out what needs to be done to meet your school's accountability goals?

Qiii36 has your school mobilized all its resources to meet its accountability goals?

\section{Teacher Teamwork and Learning (Factor 7)}

To what extent:

Qiii18 are teachers provided time to plan together about how to achieve the accountability goals?

Qiii21 are teachers given opportunities to learn about best practices of other schools that can be used to raise [accountability program] scores?

Qiii19 are professional development programs focused on helping teachers acquire knowledge and skills needed to improve students scores on the [accountability program's] tests?

Qiii17 are teachers in related subjects or functions encouraged to work together in teams?

Qiiil5 has more emphasis been put on using assessment results to guide teaching efforts?

* Questions not included in Charlotte-Mecklenburg Principals' Survey.

Table A14. Coefficient Alpha Reliabilities for Factor-Based Scales

\begin{tabular}{ll}
\hline Scale & Alpha \\
\hline & \\
Financial Incentives & .90 \\
Improvement of Teaching & .81 \\
Principal Understanding & .86 \\
District Support & .89 \\
Resource Allocation & .76 \\
Principal Skill & .67 \\
Teamwork and Learning & .77 \\
\hline
\end{tabular}


Table A15. Rotated Factor Loadings Obtained from Factor Analysis of Items on the Kentucky and Maryland Principals' Survey

\begin{tabular}{|c|c|c|c|c|c|c|c|c|}
\hline \multirow[b]{2}{*}{ Item } & \multicolumn{8}{|c|}{ Factor } \\
\hline & & $\begin{array}{l}1 \\
\text { Finan } \\
\text { Inc }\end{array}$ & $\begin{array}{l}2 \\
\text { Imp } \\
\text { Tea }\end{array}$ & $\begin{array}{l}3 \\
\text { Prin } \\
\text { Und }\end{array}$ & $\begin{array}{l}4 \\
\text { Dis } \\
\text { Supp }\end{array}$ & $\begin{array}{l}5 \\
\text { Res }\end{array}$ & $\begin{array}{l}6 \\
\text { Prin } \\
\text { Skill }\end{array}$ & $\begin{array}{l}7 \\
\text { Team }\end{array}$ \\
\hline Qvii6 & Tripling reward motivates teachers & .85 & .02 & .00 & .04 & -.03 & .06 & -.01 \\
\hline Qvii4 & Possibility bonus helps me motivate & .83 & .01 & .07 & .02 & .02 & .05 & .00 \\
\hline Qvii8 & Tripling reward motivates me & .82 & .05 & -.08 & -.01 & .03 & -.01 & .01 \\
\hline Qvii5 & Bonus provides shared goal & .81 & .01 & .11 & .05 & .06 & .02 & .03 \\
\hline Qvii7 & Bonus motivates me more & .77 & .03 & -.11 & -.06 & .05 & .03 & -.06 \\
\hline Qvii10 & Bonus award should continue & .76 & -.05 & .06 & .04 & -.12 & .09 & .03 \\
\hline Qvii3 & Fair for teachers to get reward & .71 & -.04 & .08 & .05 & -.19 & .05 & .09 \\
\hline Qiii5 & Principal referred to bonus & .60 & .02 & -.03 & .01 & .05 & .05 & .08 \\
\hline Qii5 & Teachers worked change teach. & .03 & .75 & .04 & .08 & .05 & .20 & .24 \\
\hline Qii3 & Teachers changed way teach & .07 & .71 & .06 & .06 & -.07 & -.02 & .11 \\
\hline Qii1 & Teachers spent hours teaching & .00 & .64 & .04 & -.01 & .14 & .10 & .05 \\
\hline Qii4 & Teachers prof. dev. activities & -.04 & .63 & .08 & .18 & .22 & -.01 & .06 \\
\hline Qii2 & Teachers changed content & -.09 & .56 & .07 & -.08 & .28 & .02 & -.04 \\
\hline Qii9 & Have knowledge help teachers & .16 & .53 & -.01 & .11 & .04 & .26 & .25 \\
\hline Qii6 & Teachers focused stud. learning & -.11 & .52 & .24 & .11 & .16 & .07 & .19 \\
\hline Qiii20 & Teachers provided time plan & .05 & .49 & .05 & .25 & .04 & .16 & .47 \\
\hline Qi2 & Know improve to meet goals & 00 & .14 & .82 & .09 & .03 & .12 & .00 \\
\hline Qi4 & Could explain goals to others & -.09 & .08 & .81 & .07 & .13 & .14 & .01 \\
\hline Qi1 & Clear understanding goals & .03 & -.02 & .80 & .19 & .02 & .05 & .05 \\
\hline Qi3 & Understanding stud. ach. meas. & .04 & .00 & .77 & .16 & .04 & .19 & .04 \\
\hline Qi9 & Committed to pursuing goals & .01 & .22 & .50 & .14 & -.05 & .01 & .02 \\
\hline Qv2 & District staff support efforts & .02 & .08 & .12 & .84 & -.04 & .11 & .12 \\
\hline Qv3 & District provided tech. assistance & .02 & .04 & .21 & .79 & .16 & .09 & .12 \\
\hline Qv5 & District provided resources & .01 & .04 & .16 & .75 & .21 & .02 & .17 \\
\hline Qv1 & District admin. staff committed & .09 & .12 & .11 & .73 & -.13 & .16 & .01 \\
\hline Qv6 & District provided you discretion & .02 & .16 & .16 & .67 & .03 & .06 & .08 \\
\hline Qiii11 & Budgeted funds reallocated & .00 & .15 & .01 & -.01 & .73 & .08 & .16 \\
\hline Qiii14 & School invested new technology & -.01 & .03 & .05 & .12 & .72 & .06 & .23 \\
\hline Qiii12 & Tutoring/programs established & -.03 & .19 & .00 & .08 & .67 & .10 & .00 \\
\hline Qiii10 & Staff realloc. assign teachers & .00 & .21 & .13 & -.02 & .62 & .03 & -.16 \\
\hline Qiii9 & Incentives/rewards for students & .20 & .00 & .13 & .10 & .42 & .03 & .00 \\
\hline Qiii7 & New curr. development efforts & -.13 & .21 & .07 & .15 & .34 & .05 & .27 \\
\hline Qii11 & Knowledge help teachers & .05 & .07 & .14 & .09 & .12 & .79 & .08 \\
\hline Qii12 & Skills mobilize school & .14 & .07 & .18 & .14 & .08 & .74 & .15 \\
\hline Qiii1 & Helped teachers figure out & .09 & .22 & .22 & .08 & .00 & .59 & .22 \\
\hline Qii10 & Know use assessments & .07 & .17 & .45 & .12 & .04 & .57 & -.01 \\
\hline Qiii2 & Worked individually teachers & .09 & .30 & .19 & .10 & .05 & .48 & .20 \\
\hline Qiii36 & School mobilized resources & .09 & .29 & .20 & .23 & .12 & .31 & .20 \\
\hline Qiii18 & Teachers provided time plan & .04 & .10 & -.04 & .07 & .01 & .11 & .73 \\
\hline Qiii21 & Teachers opport. best practices & .12 & .20 & .10 & .15 & .21 & .10 & .67 \\
\hline Qiii19 & Prof. dev. programs help teachers & -.01 & .24 & .11 & .14 & .30 & .11 & .56 \\
\hline Qiii17 & Teachers encouraged team & .08 & .37 & -.08 & .10 & .00 & .16 & .51 \\
\hline Qiii15 & Using results guide teaching & -.03 & .31 & .12 & .18 & .28 & .02 & .34 \\
\hline
\end{tabular}

* Varimax rotation 